University of Redlands

\title{
GIS-Driven Translations of Film Narratives: A Space-Time Cube of Christopher Nolan's Dunkirk
}

A Major Individual Project submitted in partial satisfaction of the requirements

for the degree of Master of Science in Geographic Information Systems

\author{
by \\ Grace "Miles" Ng \\ Mark Kumler, Ph.D., Committee Chair \\ Fang Ren, Ph.D.
}

December 2019 
GIS-Driven Translations of Film Narratives: A Space-Time Cube of Christopher Nolan's Dunkirk

Copyright (C) 2019

by

Grace "Miles" Ng 
The report of Grace "Miles" Ng is approved.
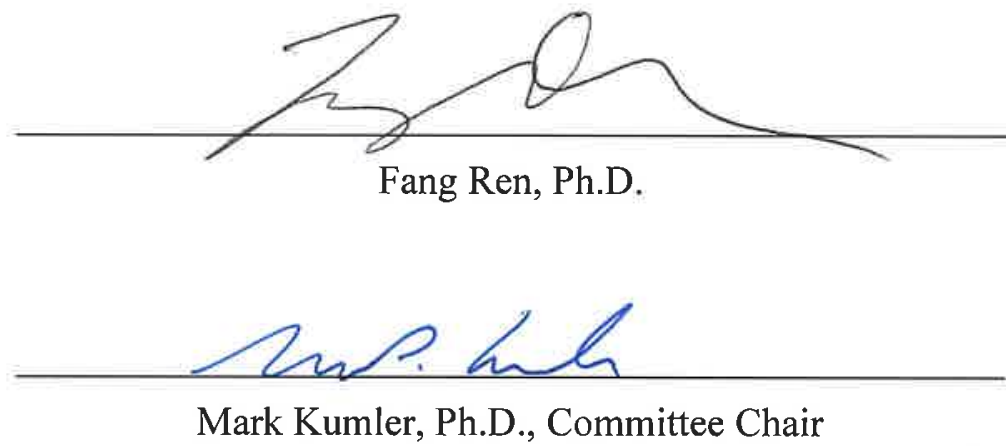

December 2019 



\section{Acknowledgements}

For Jessica.

To Nathan Shephard, with gratitude.

And for family, instructors, friends,

Creators, storytellers, and dreamers of the day. 



\begin{abstract}
GIS-Driven Translations of Film Narratives: A Space-Time Cube of Christopher Nolan's Dunkirk

by

Grace "Miles" Ng

Space-time cubes are a form of 3D cartography ideal for the synthesis of temporal and spatial data, and have thus been used to construct qualitative narratives that map the pathways of stories and life histories over time. This project extends this methodology into the realm of filmmaking by translating Christopher Nolan's 2017 film Dunkirk into a space-time cube. In doing so, this project in turn offers a synthesis of GIS and digital humanities. Through deliberate cutting across multiple characters' perspectives, Dunkirk tells a tripartite narrative that is emotionally gripping yet logistically confusing. This project transforms Dunkirk's non-linear narrative into a space-time cube for the purpose of chronological elucidation in a GIS environment. Multiple sets of temporal and spatial data were derived through the study of Dunkirk's fictional plot and research of true historical events. The data were then mapped in a space-time cube in linear chronological order. The results of this project analyze the proficiency of GIS in translating stories from the medium of film into 3D cartographic space, as well as the wider application of spacetime cubes in film narrative storyboarding.
\end{abstract}





\section{Table of Contents}

Chapter 1 - Introduction ............................................................................................. 1

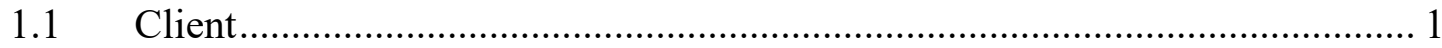

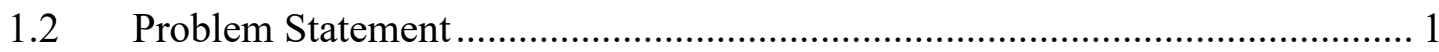

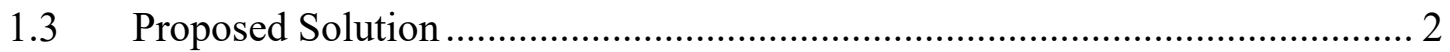

1.3.1 Goals and Objectives ........................................................................... 3

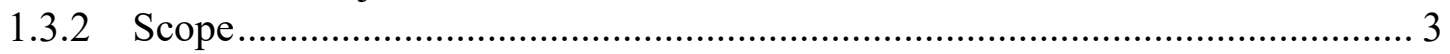

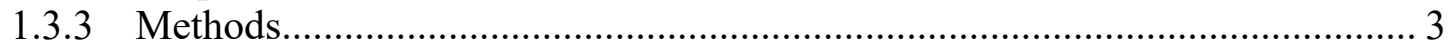

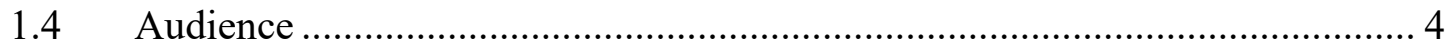

1.5 Overview of the Rest of this Report ............................................................. 4

Chapter 2 - Background and Literature Review ............................................................ 5

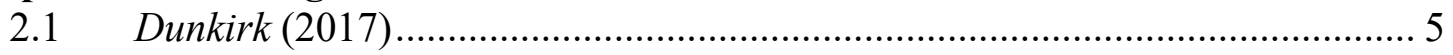

2.1.1 Additional Ventures in Movie Mapping ............................................................ 6

$2.2 \quad$ Space-Time Cubes .................................................................................... 7

2.2.1 Napoleon, the 1966 FIFA World Cup, and Quantitative Space-Time Cubes... 8

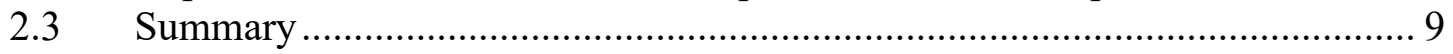

Chapter 3 - Systems Analysis and Design.................................................................... 11

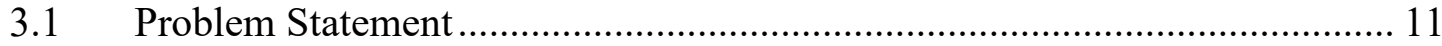

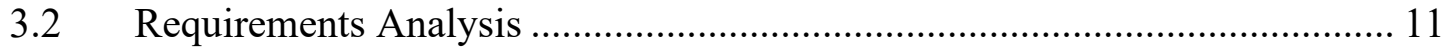

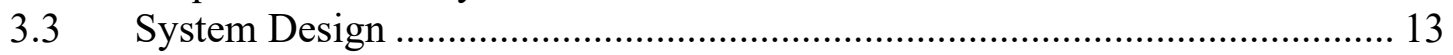

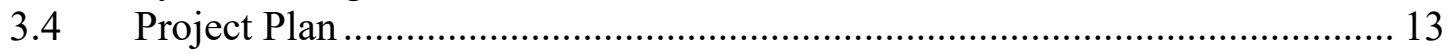

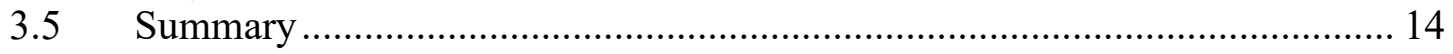

Chapter 4 - Database Design............................................................................................ 15

4.1 Conceptual Data Model .................................................................. 15

4.2 Logical Data Model ............................................................................ 16

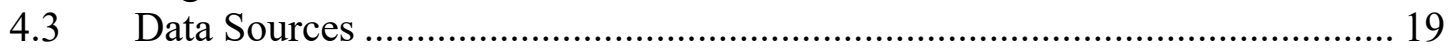

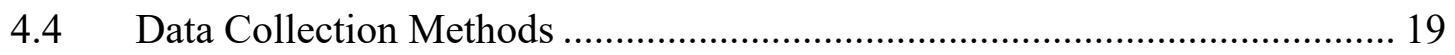

4.5 Data Scrubbing and Loading …………………..................................... 20

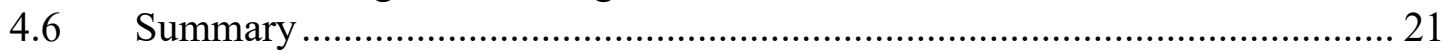

Chapter 5 - Implementation............................................................................................. 23

$5.1 \quad$ Characters Traveling in Groups ……………………………………….... 23

5.2 Time Compaction and Resampling.............................................................. 26

5.2.1 Adjusting Time with Square Root, Cube Root, and Logarithm Equations .... 27

5.2.2 Time Sections and Linear Resampling ...................................................... 28

5.2.3 The Time Section Coastlines and Coastline Wall........................................... 31

5.3 Publishing the Space-Time Cube as a Web Scene in ArcGIS Online ............ 32

5.3.1 Reprojecting the Space-Time Cube …………………................................ 32

5.3.2 Displaying the Space-Time Cube in Real-World Units................................... 33

5.3.3 Converting 3D Line Feature Classes to Multipatches .................................... 33

5.3.4 Generating Pop-up Windows with Photo Attachments ................................... 34

5.3.5 Creating Bookmarks for Conversion to Slides …………………………....... 35

5.3.6 The Publishing Process and Adjusting to the Scene Viewer Interface ........... 35 
Chapter 6 - Results and Analysis................................................................................. 37

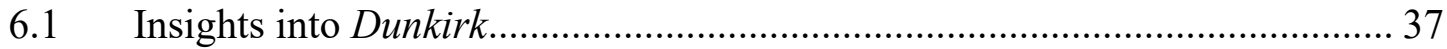

6.1.1 Plot Holes in Timelines: Fictional vs Real .................................................. 37

6.1.2 Plot Holes for Artistic Cinematography: The Voyage of the Moonstone ....... 38

6.1.3 Plot Holes for Artistic Cinematography: Farrier's Landing ………………..... 39

6.2 Limitations in Translation......................................................................... 41

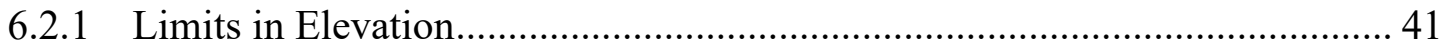

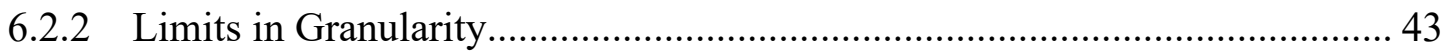

6.2.3 Remaining Vertical Compaction.................................................................. 43

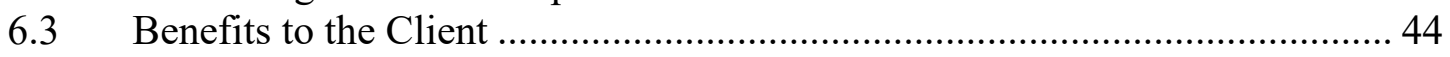

Chapter 7 - Conclusions and Future Work ..................................................................... 45

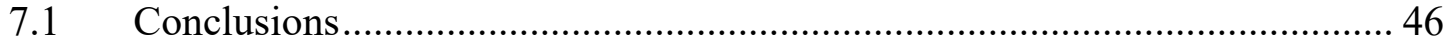

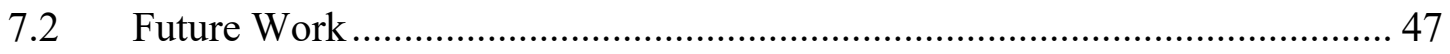

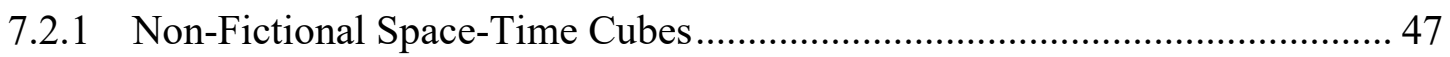

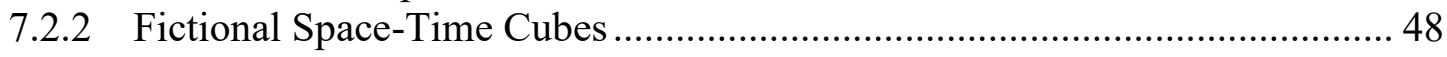

7.2.3 Beyond Space-Time Cubes: The Potential of 3D GIS..................................... 49

Works Cited ..........................................................................................................................51

Appendix A. Location and Time Certainty ................................................................... 53

Appendix B. Group Codes ............................................................................................59 


\section{Table of Figures}

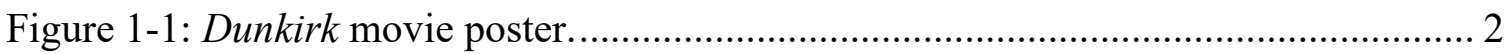

Figure 2-1: Andrew DeGraff's map of Jaws. ............................................................... 7

Figure 2-2: England's first goal in the 1966 FIFA World Cup Finals............................... 9

Figure 4-1: Conceptual model of project data sources and data derivatives. ................... 16

Figure 4-2: Example of symbolized attributes............................................................... 18

Figure 5-1: Shivering Soldier meets Tommy and Alex off the coast of Dunkirk............. 24

Figure 5-2: Shivering Soldier is rescued by Mr. Dawson, Peter, and George................... 24

Figure 5-3: Example of the GROUP CODE attribute. ................................................... 26

Figure 5-4: Certain points appear vertically compacted.................................................. 27

Figure 5-5: Comparison of RELATIVE SECONDS versus square root equation........... 28

Figure 5-6: RELATIVE SECONDS resampled into five time sections of equal size...... 31

Figure 5-7: Cartographic representation of the time sections as coastlines...................... 32

Figure 5-8: Data using a consistent display size versus using real-world units................. 33

Figure 5-9: The Layer 3D to Feature Class geoprocessing tool. ....................................... 34

Figure 5-10: The Dunkirk web scene QR code............................................................. 36

Figure 6-1: Mr. Dawson watches an enemy fighter plane approach the Moonstone........ 39

Figure 6-2: The Moonstone returning to Weymouth.................................................... 39

Figure 6-3: Farrier arrives at Dunkirk beach. . ............................................................ 40

Figure 6-4: Farrier watches his Spitfire burn as enemy soldiers appear........................... 40

Figure 6-5: Gibson and Tommy in the substructure of the mole.................................... 42

Figure 6-6: Colonel Winnant and Commander Bolton on the deck of the mole.............. 42

Figure 7-1: Machine learning with the South Africa national union rugby team............. 48

Figure 7-2: New filmmaking functionalities in ArcGIS Pro. ........................................ 50

A-1: George in Weymouth, England. ………………….......................................... 54

A-2: Farrier's map at five minutes to Dunkirk. …………………………..................... 54

A-3: Highlanders make their way towards a beached trawler......................................... 55

A-4: Collins trapped in his sinking Spitfire............................................................... 56

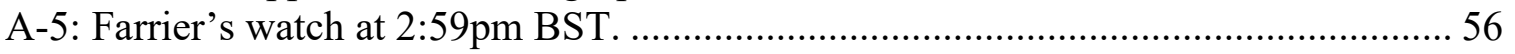

A-6: Soldiers returning to Dunkirk at daybreak. ………………………..................... 57

A-7: The Moonstone passes an Allied destroyer. ………….......................................... 58

A-8: Peter back in Weymouth, England. .................................................................. 58 



\section{List of Tables}

Table 1. Summary of Selected Dunkirk Characters .................................................. 6

Table 2. Summary of Functional Requirements …………………………………..... 12

Table 3. Database Attributes Collected During Initial Data Collection ...................... 17

Table 4. The GROUP CODE Database Attribute................................................... 25

Table 5. The Five Time Sections in the Chronological Narrative ............................... 28

Table 6. TIME SECTION ID and ADJUSTED RELATIVE SECONDS ................... 30

Table 7. Data time sections and the linear equation applied to each ........................... 30

Table 8. Timelines Presented in Dunkirk vs. the Space-Time Cube............................ 38

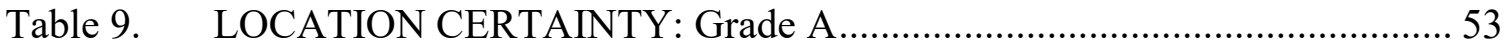

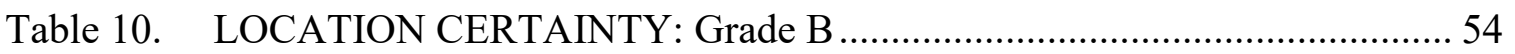

Table 11. LOCATION CERTAINTY: Grade C ...................................................... 55

Table 12. LOCATION CERTAINTY: Grade D...................................................... 55

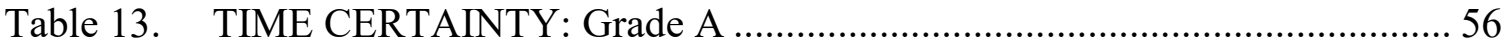

Table 14. TIME CERTAINTY: Grade B............................................................. 57

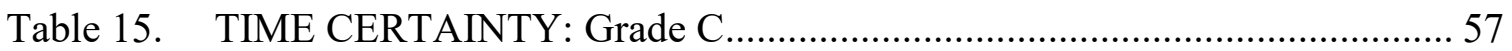

Table 16. TIME CERTAINTY: Grade D ……………………………………........ 58

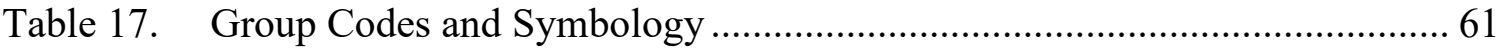





\section{List of Acronyms and Definitions}

ABM Agent-based model - a computer model that simulates the paths and interactions of discrete individuals - or agents - in order to understand an agent's effect on a larger general system

BEF British Expeditionary Force - the British Army stationed in Western Europe during World War II from 1939 to 1940

BST British Summer Time - the time zone observed in Britain from the last Sunday in March to the last Sunday in October. Is one hour later than CEST

CEST Central European Summer Time - the time zone observed in France from the last Sunday in March to the last Sunday in October. Is one hour earlier than BST

COTS Commercial-off-the-shelf - pre-packaged products ready for deployment out of the box, to be adapted to specific needs after purchase. As opposed to custom-made, one-off products tailored for a particular usage

Esri Environmental Systems Research Institute - international developer and supplier of GIS software, web services, and geodatabase systems

GIS Geographic information system - computer systems designated for the creation, storage, presentation, and analysis of spatial data

RAF Royal Air Force - the air force branch of the United Kingdom's military

TTC Time to complete - the amount of time required to complete a task 



\section{Chapter 1 - Introduction}

The space-time cube is a 3D mapping technique first proposed by Swedish geographer Torsten Hägerstrand in 1970. As a cultural geographer, Hägerstrand introduced the idea of integrating time and space together for the analysis of life histories of people and their interactions (Hägerstrand, 1970). In a space-time cube, 2-dimensional location data form the base of the cube while a third axis representing time data forms the cube's height. When mapping a life history, a space-time cube simultaneously visualizes spatial and temporal data on the horizontal and vertical axes, respectively. Space-time cubes offer certain advantages over 2D maps in displaying information about timing, duration, and sequence of activities in a single presentation (Kwan, 2004, p. 272). In doing so, spacetime cubes provide a unique avenue of cartographic communication and visualization.

The purpose of this project is twofold. First, this project proposes the application of space-time cubes to the realm of filmmaking as a storyboarding tool to help creators visualize and design the flow of space-time in film narratives. Secondly, this project offers proof of concept by untangling the intricate narratives of Christopher Nolan's 2017 film Dunkirk through visualization in a space-time cube. In doing so, this project serves as an exploration in storyboarding and in translating stories from the medium of film to 3-dimensional geographic information systems (GIS).

\subsection{Client}

The client for this project is Nathan Shephard, a 3D GIS software engineer at Environmental Systems Research Institute (Esri). Mr. Shephard is responsible for software product design and direction for 3D GIS, including project management primarily for ArcGIS Pro (Shephard, n.d.). His team works to deliver software components such as interactive analysis tools to improve the strength and utility of ArcGIS Pro as a whole (N. Shephard, personal communication, March 19, 2019). Mr. Shephard is interested in expanding the capacity of 3D GIS in ArcGIS Pro as a storyboarding tool in industries such as film and video games. This project serves as a proof of concept demonstrating the proficiency of ArcGIS Pro to visualize a fictional narrative in an interactive 3D GIS interface.

\subsection{Problem Statement}

It is not uncommon to observe narrative, spatial, and temporal continuity errors in films. In an extreme example of all three errors, a film protagonist is traveling in a red car from New York to Jersey. He is shown entering a New York City highway tunnel while the sun is up. In the next cut, he is shown exiting that same tunnel in the middle of Kansas on the same day, riding a blue jet ski. Without a narrative explanation for these non sequiturs, the audience can tell that the film is in error. Errors like these may indicate poor filmmaking, can break audience immersion, and lessen the quality of a film overall.

It is essential to note that in the context of this project, Dunkirk itself is not considered a "problem" in need of "correcting." The film is a fictional retelling of Operation Dynamo, the World War II evacuation of the British Expeditionary Force 
(BEF) and its French allies from the beaches of Dunkirk, France to the relative safety of England. From May 26 to June 4, 1940, over 300,000 Allied soldiers were rescued across the English Channel through a joint effort between Allied Navy forces and a flotilla of British civilian ships (Newsom, 2017). Dunkirk's non-chronological narrative is an awesome, if confusing, spectacle. Director Christopher Nolan interweaves three distinct timelines of Operation Dynamo - all occurring at different locations, perspectives, and levels of mobility - and presents these perspectives out of chronological order. In doing so, the film presents a complex triptych of the Dunkirk evacuation: Allied soldiers trapped on the Dunkirk beach desperately awaiting rescue, a yacht carrying a small group of civilians across the English Channel as part of the rescue effort, and two Royal Air Force (RAF) pilots soaring above the English Channel to defend the Allied forces for as long as their fuel supply lasts (Nolan \& Thomas, 2017).

Nolan purposely avoided exact historical recreation while making Dunkirk, choosing instead to deliver an impressionistic experience that manipulates the film's timelines to heighten narrative urgency (Morgenstern, 2017). It should be made clear that while the narrative of Dunkirk is non-chronological overall, there are no flashbacks or time travel in the film. The timelines in Dunkirk progress forward in a linear fashion, each one beginning and concluding separately. However, due to precise camera cuts from one timeline to the next, the three are designed to appear concurrent. While Nolan's technique proves emotionally evocative, it is also logistically confusing. As film critic David Edelstein wrote in his review of Dunkirk, "[w]ith all the cutting among timelines, we have a lot of narrative holes to fill, connections to make and characters to keep straight" (Edelstein, 2017). A Dunkirk movie poster is provided in Figure 1-1.

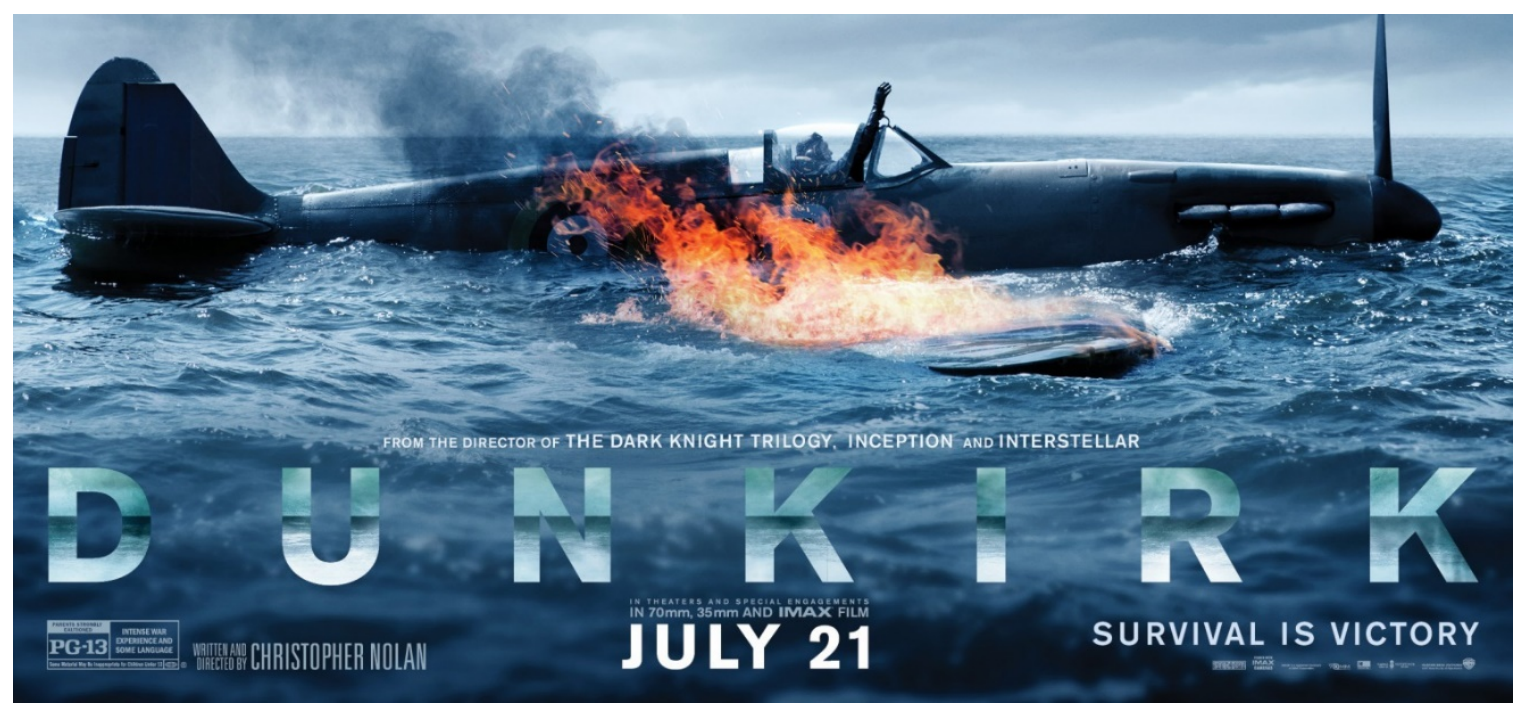

Figure 1-1: Dunkirk movie poster. (Warner Bros. Entertainment Inc., 2016).

\subsection{Proposed Solution}

To address narrative, spatial, and temporal continuity errors in films, this project explores the potential of space-time cubes for mapping film narratives as a storyboarding technique. By designing a film narrative in an interactive 3D GIS environment that inherently displays geography and time, filmmakers may be able to better visualize the 
pathways of characters and the order of plot events. This in turn could result in improved preservation of narrative, spatial, and temporal continuity, and thus better movies overall. As a proof of concept, this project re-visualized Dunkirk's complex narrative into a 3D GIS to achieve linear clarity. Dunkirk understands that Operation Dynamo was a military event defined by its geographic context and utilizes that context as an integral storytelling element. At the same time, space-time cubes provide a synthesis of two necessary components of narrative-based storytelling: a story's setting and its progression - or in GIS terminology, its spatial-temporal data. Tomoki Nakaya writes that transforming spatial-temporal data is central to understanding relationships and structures in geographic dynamics (Nakaya, 2013). This project sought to understand the spatialtemporal dynamics of Dunkirk's narrative by transforming the film into a space-time cube. In doing so, this project also explores the potential of space-time cubes as storyboarding tool for writers and creators in the realm of filmmaking.

\subsubsection{Goals and Objectives}

The objective of this project was to explore the capacity of space-time cubes as a storyboarding tool by translating fictional life histories from the medium of film to 3D GIS. The Dunkirk space-time cube serves as a proof of concept by mapping the spatialtemporal pathways of eleven selected characters to determine the linear passing of real time in Dunkirk - as opposed to the original non-chronological depiction in the film. These pathways were then used to generate a scaled model of the film in the form of a space-time cube. The cube was also designed to provide visual clarity to Dunkirk's complex tripartite narrative by chronologically reframing the spatial-temporal aspect of the plot in an interactive $3 \mathrm{D}$ environment.

\subsubsection{Scope}

This project's primary information product was a space-time cube of the 2017 film Dunkirk. The space-time cube restructured the nonlinear plot of the film into chronological order and conveyed the plot as 3-dimensional events and pathways of eleven selected characters. The end result provided real-world temporal values that illustrated the true passing of time over the course of the plot and compared them to the more artistic presentation of time in the film. Two versions of the space-time cube were produced, one in ArcGIS Pro version 2.4 as a Local Scene and the other on ArcGIS Online as a web scene accessed in the Scene Viewer application. The Local Scene provides an animation of the cube, explaining its design and the use of the Z-axis to map the chronological passing of real time over geographic space. In addition, the web scene guides users through the main plot events of the film by providing slides - also known as bookmarks — of these events for users to explore.

\subsubsection{Methods}

The Dunkirk film served as the primary source of data for this project. Scene by scene, spatial, temporal, and narrative data were derived for eleven selected characters. Of particular value in determining this information was the filmmakers' decision to shoot certain scenes on location in France and England, as well as contextual clues provided in 
the film's dialogue. Location and time data were collected for each character to provide 3D geographic visualization of the film's plot. When real-world space-time data could not be determined from viewing the film, research regarding the making of the movie and the history of Operation Dynamo was used to fill in the gaps.

Using this method, a table of attribute data was created for each selected character. These tables were then converted into Z-enabled point layers representing the narrative events of the film's plot as perceived chronologically by each character. The points were used to generate a space-time cube in a Local Scene using ArcGIS Pro version 2.4. Eleven sets of Z-enabled two-point line layers were then manually drawn using the point layers to represent each character's narrative pathway from one plot event to the next. Relevant attribute data from the point layers were copied into the line attribute tables.

Once the initial sets of 3D character points and lines were mapped, an adjusted Zvalue was added to artificially inflate the vertical distance between datasets and control the compaction of visual data (N. Shephard, personal communication, June 17, 2019). To accomplish this, the original Z-values used to vertically map the point layers were separated into five sections based on natural breaks in the film's plot. A unique linear function was then applied to each time section to resample the Z-values, increasing their relative vertical distance from one another. The $3 \mathrm{D}$ line layers were then redrawn using the adjusted points, resulting in improved visual clarity in the space-time cube overall. Additional line layers were developed to illustrate the boundaries of the five time sections and the spread of the characters' narrative events and pathways in between.

Final software deliverables were generated using commercial off-the-shelf (COTS) functionality provided in ArcGIS Pro version 2.4 and ArcGIS Online, such as creating animations and publishing the space-time cube to a 3D web scene.

\subsection{Audience}

As a contribution to GIS, film, and digital humanities, this project addresses members in all three communities. Specifically, this project is aimed towards GIS users specializing in 3D application for the purpose of storytelling. However, creative leads in filmmaking and scholars of the digital humanities may also take interest in this project's intersection of GIS and the visual arts. Familiarity with GIS will be beneficial to the audience, but is not required.

\subsection{Overview of the Rest of this Report}

Chapter One of this report provides an introduction of the project, while Chapter Two describes the background research and literature review conducted in the project's early stages. Chapter Three details the project's systems analysis and design, and Chapter Four outlines database design of the Dunkirk space-time cube. The project implementation process is discussed in Chapter Five; project results and analysis are described in Chapter Six. Chapter Seven concludes this report and identifies possibilities for future developments that build upon this project's work. 


\section{Chapter 2 - Background and Literature Review}

Topics researched for this project generally fell into two main areas of study. The first area focused on understanding the background of the Dunkirk film, including creative decisions in the making of the movie. This was essential towards understanding where scenes were physically shot, as well as garnering in-depth information on the film's characters. As an offshoot of this topic, research into other movie mapping projects was also conducted to glean what was cartographically feasible. The second area of study was comprised of previous works involving the use of space-time cubes to map narratives both qualitative and quantitative. Understanding how space-time cubes have been used in the past was necessary to determine if they were an appropriate tool for the sake of this project, and how this project could offer an advancement on what research had already been conducted.

\subsection{Dunkirk (2017)}

Film director Christopher Nolan is renowned in the realm of cinema for his clever, mindbending movies, some of which take place in impossible settings: dreams within dreams from his 2010's Inception, or in a 5th dimension inside a black hole from his 2014's Interstellar. Dunkirk is unique amongst Nolan's films in that it is based on Operation Dynamo, the real-life World War II evacuation of the British Expeditionary Forces (BEF) from Dunkirk, France. However, Nolan chose not to adhere strictly to historical fact when writing Dunkirk, instead delivering a fictional portrayal of events that cuts back and forth between different timelines in different settings. There are no flashbacks or time travel in Dunkirk; as the film progresses, its timelines converge at emotionally crucial moments, yet the plot itself remains non-chronological overall. According to Nolan, "[w]hat I wanted to do was use the physics, use the geography of evacuation, the main events, the movements, and try and put those together as the backbone and the basis of the storytelling" (Mottram, 2017, p. 16).

Nolan chose to film many Dunkirk scenes on location in both France and England, stating that the real-world geography of the Dunkirk evacuation was a character in itself (Mottram, 2017, p. 19). To convey what he termed the "varied, complex, and fascinating" events of Operation Dynamo, Nolan decided to film an ensemble of narratives spread across three distinct settings, each with their own timelines (Mottram, 2017, p. 7). These settings are introduced early in the film in the following order:

1. "THE MOLE - one week" refers to the BEF trapped on the beaches at Dunkirk, France. The "mole" is the eastern breakwater installed at Dunkirk harbor, from which the BEF are attempting to evacuate.

2. "THE SEA - one day" refers to a group of British civilians departing from Weymouth, England to sail across the English Channel as part of the Dunkirk evacuation effort.

3. "THE AIR - one hour" refers to a duo of Royal Air Force (RAF) pilots soaring above the English Channel to defend the Dunkirk evacuation on a limited fuel supply (Nolan \& Thomas, 2017).

Representing these three settings are an ensemble of eleven characters scattered across space and time. In order to translate the plot of Dunkirk into a 3-dimensional 
geographic information system (GIS), this project mapped the individual narrative events and pathways of each character in chronological order. Table 1 provides a summary of each character, grouped into the setting he originally appears in.

Table 1. Summary of Selected Dunkirk Characters

\begin{tabular}{|c|c|}
\hline \multicolumn{2}{|r|}{ Characters from "THE MOLE - one week" } \\
\hline Name & Description \\
\hline Tommy & $\begin{array}{l}\text { The film's first protagonist, a young BEF soldier desperately } \\
\text { trying to return to England. }\end{array}$ \\
\hline Gibson & $\begin{array}{l}\text { A silent young Allied soldier who joins Tommy near the } \\
\text { onset of the film. }\end{array}$ \\
\hline Alex & $\begin{array}{l}\text { A second young BEF soldier who joins Tommy after } \\
\text { Tommy rescues him early in the film. }\end{array}$ \\
\hline Commander Bolton & $\begin{array}{l}\text { A Navy commander of the BEF overseeing the Dunkirk } \\
\text { evacuation. }\end{array}$ \\
\hline Colonel Winnant & $\begin{array}{l}\text { An Army colonel of the BEF also overseeing the Dunkirk } \\
\text { evacuation. }\end{array}$ \\
\hline \multicolumn{2}{|r|}{ Characters from "THE SEA - one day" } \\
\hline Shivering Soldier & $\begin{array}{l}\text { An unnamed BEF soldier stranded in the English Channel } \\
\text { and suffering from shellshock, he is rescued by the } \\
\text { Moonstone on its way to Dunkirk. }\end{array}$ \\
\hline Mr. Dawson & $\begin{array}{l}\text { A middle-aged British civilian sailing his yacht, the } \\
\text { Moonstone, to aid in the BEF evacuation. }\end{array}$ \\
\hline Peter & $\begin{array}{l}\text { Mr. Dawson's 19-year-old son, he joins his father on their } \\
\text { voyage. Had an older brother who died serving in the RAF } \\
\text { earlier in the war. }\end{array}$ \\
\hline George & $\begin{array}{l}\text { 17-year-old friend of the Dawsons, who joins them on their } \\
\text { voyage. }\end{array}$ \\
\hline \multicolumn{2}{|r|}{ Characters from "THE AIR - one hour" } \\
\hline $\begin{array}{l}\text { Farrier, call sign } \\
\text { Fortis } 1\end{array}$ & $\begin{array}{l}\text { An RAF pilot and member of Fortis Group patrolling the } \\
\text { English Channel to defend the BEF evacuation for as long as } \\
\text { his fuel lasts. }\end{array}$ \\
\hline $\begin{array}{l}\text { Collins, call sign } \\
\text { Fortis } 2\end{array}$ & $\begin{array}{l}\text { Farrier's wingman, gets shot down over the English Channel } \\
\text { and rescued by the Moonstone on its way to Dunkirk. }\end{array}$ \\
\hline
\end{tabular}

(Nolan \& Thomas, 2017).

\subsubsection{Additional Ventures in Movie Mapping}

Research into other movie mapping projects uncovered the art of Andrew DeGraff, particularly his Cinemaps: An Atlas of 35 Great Movies (Cinemaps) (DeGraff \& Jameson, 2017). Cinemaps is a compilation of hand-painted maps depicting characters' patterns of movement from 35 Hollywood films. Through these maps, DeGraff reimagines film narratives onto colorful 2D environments that track characters' adventures through space, literally, in the case of his Star Wars maps, and time, again literally, in the case of his Back to the Future maps. Though not to scale, DeGraff's maps 
demonstrate a careful study of complex and often physics-breaking film narratives while extending cartographic techniques to their reinterpretation. Figure 2-1 is an example of DeGraff's map of the film Jaws.

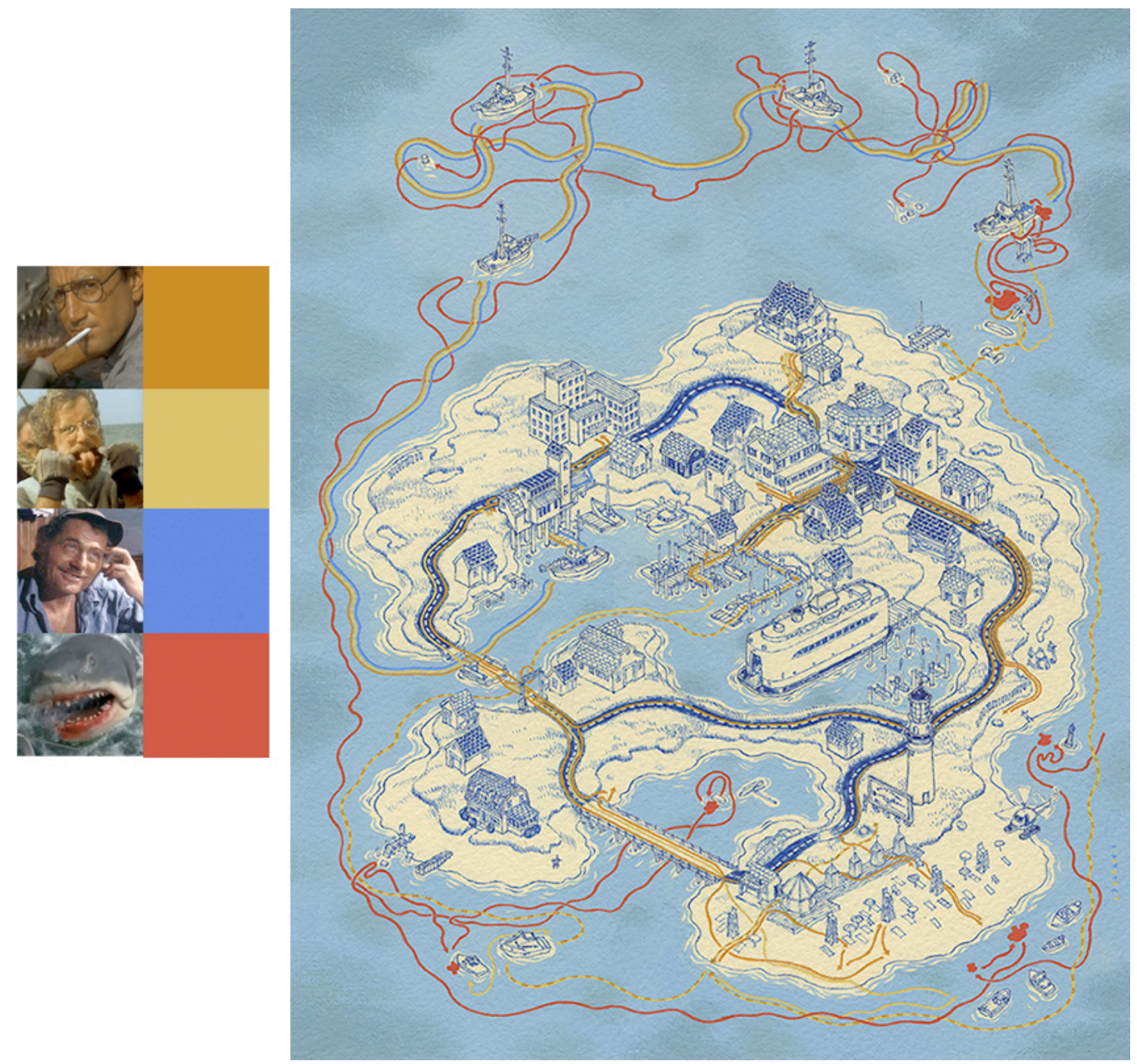

Figure 2-1: Andrew DeGraff's map of Jaws. (DeGraff, 2017).

\subsection{Space-Time Cubes}

There exists some discrepancy among GIS academia regarding the nomenclature of the space-time cube versus a space-time aquarium. The assertion is that the terms "cube" and "aquarium" describe two types of 3D space-time maps. The term "space-time cube" is preferred by some to define a 3D map that organizes space-time data points into bins so that statistical analysis may be performed. Kang, Cho and Son (2018) used this technique to analyze spatial-temporal characteristics of traffic accidents involving the elderly population in Seoul. A "space-time aquarium" is preferred by others to define a 3D map that conveys the space-time pathways of individuals for sociological studies. Kwan and 
Ren (2008) use the term "space-time aquarium" to describe their research into race, employment, and travel patterns of African- and Asian-Americans in Portland, Oregon.

While the scope of this project is more in line with the definition of a "space-time aquarium," it chooses to employ the term "space-time cube." Menno-Jan Kraak writes that "[ $\mathrm{t}]$ he Space-Time-Cube is most suitable for the display and analysis of paths of (multiple) individuals, groups or other objects moving through space" (Kraak, 2003). In addition, this project's client, Nathan Shephard, maintains that "the content displayed within [a space-time cube] does not have to contain regularly-gridded cubes (or voxels) of information - it can be points, lines, areas, or volumes" (N. Shephard, personal communication, November 1, 2019). Therefore, the decision was made to use the term "space-time cube" in favor of "space-time aquarium."

Previous work has demonstrated that space-time cubes are effective in mapping qualitative data. A study by Kwan and Ding (2008) examined the post-9/11 experiences of Muslim women in Columbus, Ohio. The authors studied the spatial-temporal patterns of the women, whose fear of religious intolerance affected their physical movements over time. Kwan and Ding synthesized various media, including diary surveys, recorded interviews, and photos into a 3D GIS environment using an approach they termed the "geo-narrative." According to Kwan and Ding (2008), the geo-narrative was "developed to facilitate the creation and interpretation of contextualized cartographic or visual narratives. It is intended to be helpful in the analysis of various types of narrative materials, such as oral histories, life histories, and biographies" (p. 446).

This project combines the notion of the geo-narrative (Kwan \& Ding, 2008) with the space-time data form known as agent-based models (ABMs). According to Michael Goodchild (2013), ABMs "attempt to simulate real geographic processes through the actions and decisions of discrete agents. Each agent is typically represented as a discrete object and acts by moving and changing state according to specified rules of behavior" (p. 1075). ABMs are typically portrayed using vector data in the form of paths, stations, and prisms, with paths showing movement behavior of agents through space and time (Kraak \& Kveladze, 2017).

\subsubsection{Napoleon, the 1966 FIFA World Cup, and Quantitative Space-Time Cubes}

Space-time cubes have also proven useful in visualizing quantitative information in a 3D GIS. Cubes created by Environmental Systems Research Institute (Esri) senior cartographic engineer Kenneth Field and this project's client, Esri 3D GIS software engineer Nathan Shephard, demonstrate the capacity of 3D GIS to visualize real-life events at a variety of granularities, ranging from hundreds of miles to the dimensions of a soccer field. Akin to this project's goal of translating spatial, temporal, and narrative data, Field and Shephard's Napoleon's March on Moscow 1812-1813 in 3D is a space-time cube translation of Charles Minard's 1869 map, itself a graphic depiction of Napoleon's Russian campaign (Field \& Shephard, 2013). In their space-time cube, Field and Shephard successfully recreate the complexity of Minard's multivariate map-involving the shrinking size of Napoleon's army, its geographic location, and the regional temperature on various dates over time - with the added benefit of the third dimension of time to illustrate periods when Napoleon's army was not only in transit, but stationary as well. 
However, the space-time cube by Field and Shephard (2013) focuses on the movement of a large, single entity, as opposed to the movements of individuals and small groups that are present in Dunkirk. Instead, Kenneth Field's cube of the 1966 FIFA World Cup Finals examines the movements of individual soccer match events bounded by the dimensions of Wembley Stadium (Field, 2016). In this cube, events from the match were translated into 3D point and line data representing players and the path of the ball, respectively. Match events were then mapped vertically, using the match play time as the third dimension. Special attention was given to the goals scored in the match, which were assigned a unique slide in the cube for viewers to zoom to immediately.

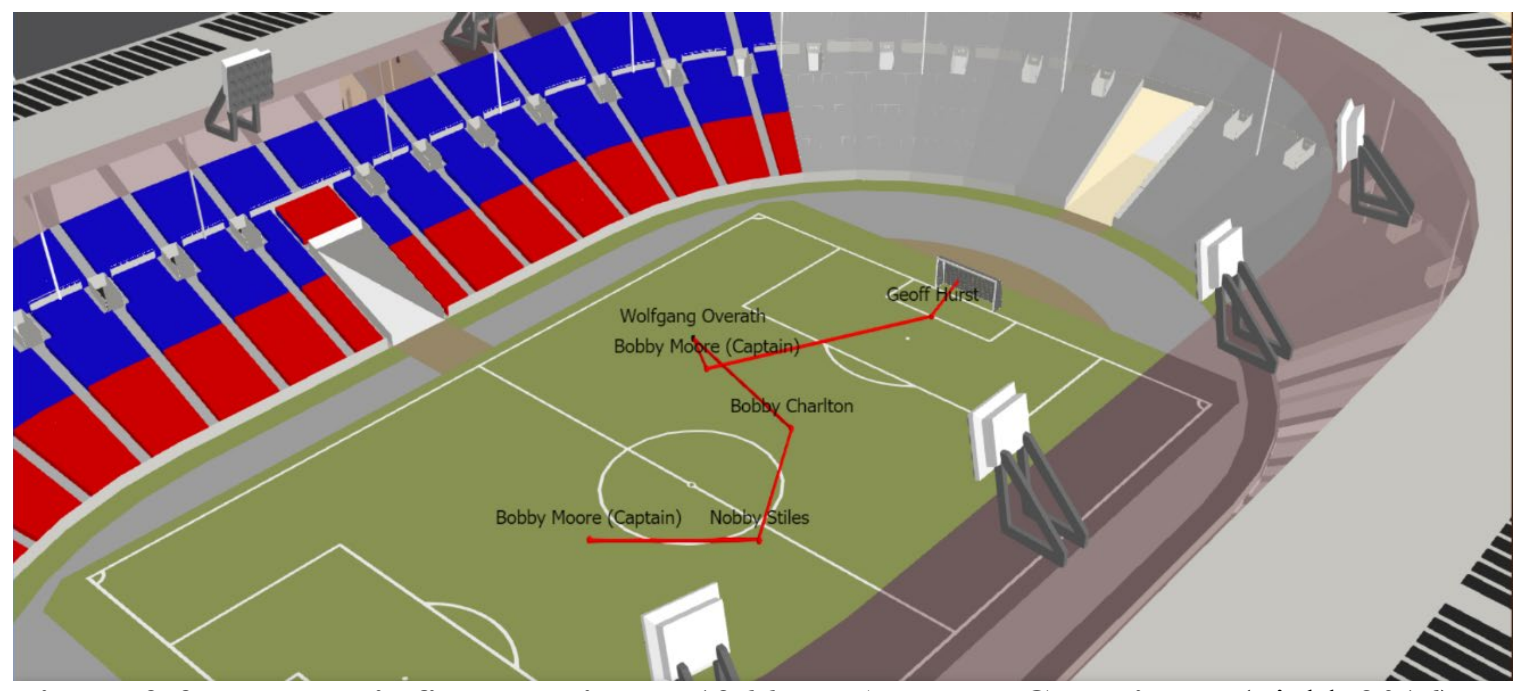

Figure 2-2: England's first goal in the 1966 FIFA World Cup Finals. (Field, 2016).

\subsection{Summary}

This project's examination of literature focused on two main areas of study: the Dunkirk film and previous space-time cube projects. The purpose of researching the film was to gain an understanding of plot design, filming locations, and characters of importance; comprehending the background of Dunkirk was essential for its translation. Research into additional projects in movie mapping demonstrated what was cartographically feasible, albeit in a $2 \mathrm{D}$ environment lacking scale. This project differs in that it does consider the geographic scale of Dunkirk and constructs a 3D space-time cube to match that scale.

Analysis of previous efforts using space-time cubes revealed that they had been successful in visualizing qualitative and quantitative narratives at a variety of scales through the synthesis and translation of media. Awareness of the pre-existing body of knowledge illuminated how this project could contribute and expand upon the works of others. Similar to Kwan and Ding (2008), this project examines the spatial-temporal movements of characters driven by fear and synthesizes their narratives to build a geonarrative in a 3D GIS. In building upon the concept of ABMs, the characters of Dunkirk serve as the agents in this project's model of the film. While the agents' paths have been predetermined by the script, they are also presented in disordered time and can be challenging to follow. This project meets that challenge by mapping each agent in chronological real time. Lastly, this project synthesizes techniques used by Field and 
Shephard (2013) and Field (2016) by utilizing 3D spatial-temporal data to illustrate when Dunkirk characters are in motion or standing still. It places emphasis on individual persons and crucial moments in the narrative. All in all, combined research led to the conclusion that Dunkirk was an appropriate story to translate, and that a space-time cube was an appropriate medium for its translation. 


\section{Chapter 3 - Systems Analysis and Design}

Design of this project's systems relied upon the judicious translation of the film Dunkirk into 3-dimensional geographic information systems (GIS) data in ways that preserved the film's plot as much as possible. This required parsing scenes from the film and converting them into spatial-temporal data that the GIS could interpret. Like in all forms of translation, certain details from the original film were lost when adapted into the GIS, due to limitations in the software. However, this project's system design was oriented to capitalize on the strengths of GIS, including visualizing the film in new and illuminating ways.

\subsection{Problem Statement}

In movies, it is not uncommon to observe spatial and temporal mistakes in the plot. Sans a narrative explanation for these mistakes, the audience can tell that a film is in error, which lessens its overall quality. By storyboarding a film narrative in an interactive 3D GIS that inherently displays location and time, filmmakers may be able to better visualize the pathways of characters and the order of plot events. This in turn could result in improved preservation of narrative continuity and better movies overall. The purpose of this project is to explore the potential of space-time cubes in providing that 3D GIS environment.

As a proof of concept, this project translated Christopher Nolan's 2017 film Dunkirk into a space-time cube. Dunkirk was chosen due to its effective use of cutting across space and time between various characters to deliver multiple narratives at once. Understanding where each character is in relation to the others, both spatially and temporally, is integral to film's plot. However, events in the film are deliberately shown out of chronological order to give the audience a sense of "paradoxical geometry" (Berman, 2017, p. 54). While Dunkirk's non-linear narrative can be emotionally evocative, it is also logistically confusing. This project remedies this confusion by translating the film's narrative into a space-time cube, where it can be visualized in chronological order.

\subsection{Requirements Analysis}

To determine necessary project requirements, it was essential to comprehend the data requirements of other time-enabled maps and space-time cubes. Space-time cubes require three sets of data, each representing a dimension of the cube. Spatial data represent the $\mathrm{X}$ and $\mathrm{Y}$ dimensions - forming the base of the cube - and temporal data form the height, or $\mathrm{Z}$ dimension, of the cube. To create a space-time cube that accurately and recognizably depicted the narrative of Dunkirk, further project requirements were gathered from studying the film and its officially licensed book The Making of Dunkirk (Mottram, 2017). Functional requirements for the space-time cube are listed in Table 2. 
Table 2. Summary of Functional Requirements

\begin{tabular}{|c|c|c|}
\hline Requirement & Rationale & Fit Criteria \\
\hline $\begin{array}{l}\text { 1. The space-time cube } \\
\text { shall map the Dunkirk } \\
\text { narrative in } \\
\text { chronological order, as } \\
\text { it would have occurred } \\
\text { in reality. }\end{array}$ & $\begin{array}{l}\text { While the non-chronological } \\
\text { design of Dunkirk was a } \\
\text { stylistic choice made by the } \\
\text { film's creators, it has the } \\
\text { potential to confuse } \\
\text { audiences. By portraying the } \\
\text { narrative in chronological } \\
\text { order, the space-time cube } \\
\text { seeks to minimize audience } \\
\text { confusion. }\end{array}$ & $\begin{array}{l}\text { The space-time cube will } \\
\text { include real-life dates, } \\
\text { clock times, and relative } \\
\text { seconds for each data } \\
\text { entry as it occurs after the } \\
\text { first chronological } \\
\text { moment of the film. }\end{array}$ \\
\hline $\begin{array}{l}\text { 2. The space-time cube } \\
\text { shall account for the } \\
\text { non-chronological } \\
\text { narrative of Dunkirk, as } \\
\text { this is how the plot is } \\
\text { originally presented. }\end{array}$ & $\begin{array}{l}\text { To provide an accurate } \\
\text { translation of Dunkirk from } \\
\text { the medium of film to 3D } \\
\text { GIS, the space-time cube } \\
\text { will honor the original order } \\
\text { of plot events as portrayed } \\
\text { in the film. }\end{array}$ & $\begin{array}{l}\text { Beginning and ending } \\
\text { runtimes from the film } \\
\text { will be collected for each } \\
\text { data entry. This provides } \\
\text { temporal data that } \\
\text { matches precisely what is } \\
\text { shown in-film, even } \\
\text { though narrative events } \\
\text { are non-chronological. }\end{array}$ \\
\hline $\begin{array}{l}\text { 3. Dunkirk tells a tripartite } \\
\text { narrative from the } \\
\text { perspectives of multiple } \\
\text { characters. This } \\
\text { narrative shall be } \\
\text { translated into a space- } \\
\text { time cube. }\end{array}$ & $\begin{array}{l}\text { By ignoring any one of the } \\
\text { narratives from Dunkirk's } \\
\text { three settings, the space- } \\
\text { time cube will fail to } \\
\text { provide an accurate } \\
\text { translation of the film. Also, } \\
\text { because all three narratives } \\
\text { are interwoven, failure to } \\
\text { include one will make it } \\
\text { impossible to map the } \\
\text { others. }\end{array}$ & $\begin{array}{l}\text { Spatial, temporal, and } \\
\text { narrative data will be } \\
\text { collected from eleven film } \\
\text { characters representing all } \\
\text { three film settings. }\end{array}$ \\
\hline $\begin{array}{l}\text { 4. The space-time cube } \\
\text { shall portray characters' } \\
\text { methods of travel, as } \\
\text { this plays an important } \\
\text { part in the film's } \\
\text { narrative. }\end{array}$ & $\begin{array}{l}\text { In Dunkirk, characters' } \\
\text { methods of travel are } \\
\text { integral to their narratives, } \\
\text { controlling how and when } \\
\text { they engage each other, and } \\
\text { convey plot progression. }\end{array}$ & $\begin{array}{l}\text { For each data entry, } \\
\text { method of travel, as well } \\
\text { as approximate velocity } \\
\text { and direction, is collected. }\end{array}$ \\
\hline
\end{tabular}




\begin{tabular}{|l|l|l|}
\hline \multicolumn{1}{|c|}{ Requirement } & \multicolumn{1}{c|}{ Rationale } & \multicolumn{1}{c|}{ Fit Criteria } \\
\hline $\begin{array}{l}\text { 5. The space-time cube } \\
\text { shall visually resemble } \\
\text { the film upon which it } \\
\text { is based. }\end{array}$ & $\begin{array}{l}\text { The space-time cube must } \\
\text { provide a recognizable } \\
\text { visual translation of Dunkirk } \\
\text { into a 3D GIS to relate the } \\
\text { two forms of media. }\end{array}$ & $\begin{array}{l}\text { Stills from the film will be } \\
\text { included in the space-time } \\
\text { cube to connect the data } \\
\text { to their corresponding } \\
\text { moment in the film. }\end{array}$ \\
\hline
\end{tabular}

\subsection{System Design}

This project's first final information product was a space-time cube that untangles the nonlinear timelines of Dunkirk. Created and accessed in ArcGIS Pro version 2.4, the cube was generated with commercial-off-the-shelf (COTS) functionality to construct 3D feature classes (point and line datasets) using spatial-temporal data derived from the film. In addition to the feature classes, cartographic elements such as symbology, pop-up windows, photo attachments, and bookmarks were built into the cube using COTS functionality. Lastly, the space-time cube was animated to demonstrate how the third dimension of time offers superior visualization of characters' pathways in relation to each other, as opposed to traditional 2D maps. Animation was created using the ArcGIS Pro Animation toolset, which was also provided with COTS functionality.

The second final information product was an interactive web scene of the spacetime cube published from ArcGIS Pro to the ArcGIS Online Scene Viewer application. The online nature of the web scene is ideal for disseminating the information in the cube to a larger audience without the need for prior installation of ArcGIS Pro. In addition, the web scene provided slides and pop-up windows to enrich audience interaction with the online cube. Adjustments to the web scene were made using Scene Viewer COTS functionality; no custom scripts or programming were utilized in either the space-time cube in ArcGIS Pro or the web scene in ArcGIS Online.

\subsection{Project Plan}

Upon starting this project, the project plan was conglomerated into four major stages, each with an estimated time to complete (TTC). These four stages were as follows:

1. Planning: gathering research on the Dunkirk film and space-time cubes. Resources allocated to this stage included:

a) Researching the making of Dunkirk, historical information regarding Operation Dynamo, and peer-reviewed articles on space-time cubes

b) Acquiring a copy of the film

c) Estimated TTC: November 2018 to February 2019

2. Design: translating the narrative of Dunkirk into spatial-temporal data in a database. Resources allocated to this stage included:

a) Building the database to store and arrange data derived from the film

b) Extrapolating real-world spatial-temporal data when fictional in-film data were insufficient for mapping

c) Estimated TTC: February 2019 to May 2019 
3. Development: mapping the spatial-temporal data into a space-time cube in ArcGIS Pro and establishing cartographic elements in the cube. Resources allocated to this stage included:

a) Importing the Dunkirk database into ArcGIS Pro to generate the spacetime cube

b) Establishing cartographic elements of the cube

c) Estimated TTC: May 2019 to August 2019

4. Deployment: publishing the cube to ArcGIS Online as a web scene and animating the cube in ArcGIS Pro. Resources allocated to this stage included:

a) Publishing an interactive web scene of the space-time cube on ArcGIS Online

b) Animating the cube in ArcGIS Pro

c) Estimated TTC: August 2019 to November 2019

Regarding the project plan estimated at the start of the project versus the reality of implementation, only the first major stage-Planning - was completed in accordance with the initial TTC. This was due to the fact that resources required for this stage were simple to acquire. Stages 2 and 3-Design and Development - both required an additional month beyond the estimated TTC to finish. The actual time required for Design ranged from February to June 2019, and the time required for Development ranged from June to September 2019. These two stages proved to be a series of iterative processes, where inadequate resources in Development often required improvements in Design. Because stages 2 and 3 required additional time to finish, this subtracted available time away from completing stage 4-Deployment. This stage, too, was an iterative process, as changes made to the space-time cube in ArcGIS Pro required multiple republishing to the web scene on ArcGIS Online. Nathan Shephard, this project's client, was an active contributor to the project throughout its lifespan, offering advice at every stage. While additional time was usually required to implement his input, the improvements they made to the project were considered worth the risk of possible scope creep.

\subsection{Summary}

This project's systems were designed to demonstrate the ability of space-time cubes to translate fictional narratives from the medium of film to 3D GIS, and thus work as a storyboarding tool. This project translated the 2017 film Dunkirk into two major components, a space-time cube built and accessed in ArcGIS Pro and a web scene published in ArcGIS Online. Both of these components were created using COTS functionalities provided in ArcGIS Pro and ArcGIS Online. The data requirements for this project synthesized the required $\mathrm{X}, \mathrm{Y}$, and $\mathrm{Z}$ dimensions for a space-time cube with the requirement to convey an accurate and recognizable translation of the film's narrative, albeit in chronological order. At the start of the project, the project plan was organized into four stages, each with an estimated TTC. However, given the reality of implementation, only one of those stages finished within the estimated TTC. Lastly, input from this project's client often required additional time to implement yet resulted in marked improvements in the project's overall output. 


\section{Chapter 4 - Database Design}

The design of this project's database was based upon information gathered from background and literature review (see Chapter Two) as well as functional requirements determined for the system's design (see Chapter Three). This project's space-time cube and subsequent web scene were built upon a database that included the requisite spatialtemporal data to form the three dimensions of the cube, as derived from the Dunkirk film. Aside from spatial-temporal data, additional attributes of information were extracted primarily from the film to generate a more detailed translation of the plot as it is conveyed by the eleven selected characters. Other attributes were formulated for the purposes of cartographic visualization. Once finished, the database was imported into ArcGIS Pro to create the 3-dimentional feature classes of the space-time cube.

\subsection{Conceptual Data Model}

The conceptual data model of this project was comprised of three main entities. The first entity included the sources of this project's data input and the raw data derived from them. Foremost of the data sources was the Dunkirk film, from which the majority of the primary data was derived. The second source of data was the officially licensed The Making of Dunkirk book, which included behind-the-scenes filmmaking decisions made by the creators of Dunkirk. Information from The Making of Dunkirk was used to supplement and bolster the data derived from the film. Lastly, the third source of data was historical research of the real-life Operation Dynamo, which helped to solidify certain fictional elements from the film into mappable reality.

The second main entity of the conceptual data model was the database where information from the data sources was stored and organized for each of the eleven selected film characters. Because the original plot of Dunkirk is portrayed nonchronologically, the order of the film scenes was rearranged in the database and assigned numeric time values to order them chronologically. Additional data attributes essential for the development of the space-time cube and web scene were developed using the raw input in the database. These included data for spatial-temporal mapping, cartographic visualization, and a certainty metric to address the inherent imprecision in translating fictional narratives. The database was then imported into a geographic information system (GIS) to develop the space-time cube, where cartographic elements such as symbology, bookmarks, and pop-up windows were added. Figure 4-1 illustrates this project's conceptual data model. 


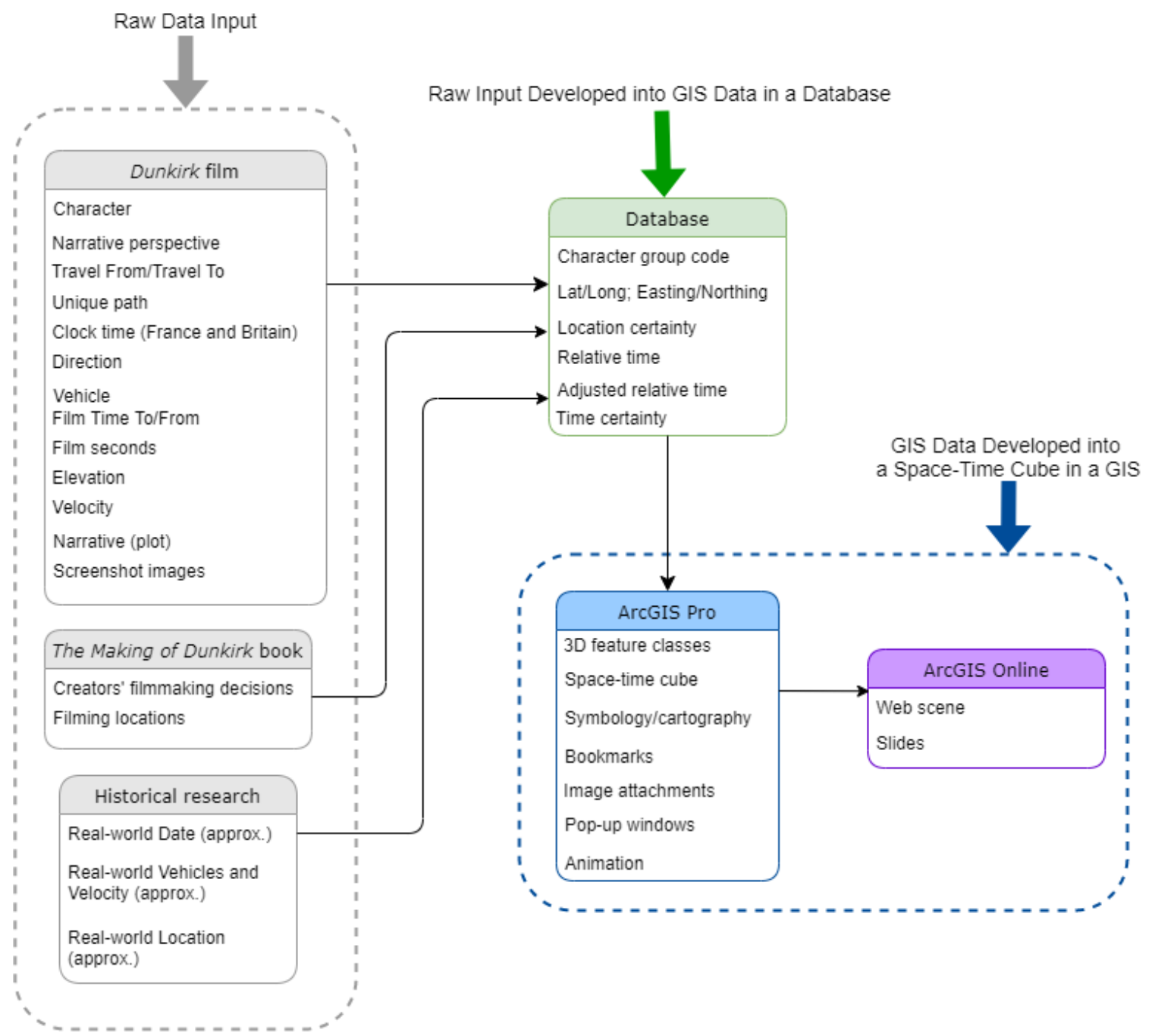

Figure 4-1: Conceptual model of project data sources and data derivatives.

\subsection{Logical Data Model}

Scene by scene, the narrative of Dunkirk was translated into spatial-temporal data specific to the perspectives of eleven selected characters and mapped into a space-time cube in ArcGIS Pro. Events from the plot were visualized as 3D points, specific to each character. This allowed individual characters to be mapped independently using eleven 3D point feature classes. Spatial and temporal data stored in the database were used to plot each 3D point on a horizontal (XY) plane for space and a vertical (Z) plane for time. The progression of time was plotted upwards using successively greater time values, meaning that points at the bottom of the vertical plane represented events at the chronological beginning of the story, whereas points at the top represented events at the chronological end. Table 3 lists the data attributes developed for each of the eleven 3D point feature classes during this stage of the project. Additional data attributes developed at later stages of the project are presented in Chapter Five. 
Table 3. Database Attributes Collected During Initial Data Collection

\begin{tabular}{|c|c|}
\hline Attribute & Description \\
\hline CHARACTER & $\begin{array}{l}\text { Indicates which of the eleven characters is the focus of } \\
\text { each data entry. }\end{array}$ \\
\hline PERSPECTIVE & $\begin{array}{l}\text { Which of the film's three narrative perspectives is the } \\
\text { focus of each data entry (THE MOLE - one week, THE } \\
\text { SEA - one day, or THE AIR - one hour). }\end{array}$ \\
\hline TRAVEL FROM & $\begin{array}{l}\text { The event or location each CHARACTER is traveling } \\
\text { from. }\end{array}$ \\
\hline TRAVEL TO & The event or location each CHARACTER is traveling to. \\
\hline UNIQUE PATH & $\begin{array}{l}\text { The name of each CHARACTER's movement track } \\
\text { segment, usually a short summation of TRAVEL FROM } \\
\text { and TRAVEL TO. }\end{array}$ \\
\hline CLOCK TIME FRANCE & $\begin{array}{l}\text { Estimated real-world date and time for each data entry in } \\
\text { Central European Summer Time (CEST). }\end{array}$ \\
\hline CLOCK TIME BRITAIN & $\begin{array}{l}\text { Estimated real-world date and time for each data entry in } \\
\text { British Summer Time (BST). }\end{array}$ \\
\hline DIRECTION & $\begin{array}{l}\text { The direction each CHARACTER is facing during his } \\
\text { travels using a } 0 \text { - } 359 \text {-degree scale, with } 0 \text { indicating } \\
\text { north (geographic rotation style). }\end{array}$ \\
\hline VEHICLE & Indicates each CHARACTER's method of travel. \\
\hline FILM TIME FROM & $\begin{array}{l}\text { The film runtime at the start of each data entry, in } \\
\text { hh:mm:ss format. }\end{array}$ \\
\hline FILM TIME TO & $\begin{array}{l}\text { The film runtime at the end of each data entry, in } \\
\text { hh:mm:ss format. }\end{array}$ \\
\hline FILM SECONDS & $\begin{array}{l}\text { How many seconds have passed since the film began } \\
\text { playing for each data entry. }\end{array}$ \\
\hline RELATIVE TIME FROM & $\begin{array}{l}\text { How much time has passed since the film's first } \\
\text { chronological moment at the beginning of each data entry, } \\
\text { in hh:mm:ss format. }\end{array}$ \\
\hline RELATIVE TIME TO & $\begin{array}{l}\text { How much time has passed since the film's first } \\
\text { chronological moment at the end of each data entry, in } \\
\text { hh:mm:ss format. }\end{array}$ \\
\hline RELATIVE SECONDS & $\begin{array}{l}\text { How many seconds have passed since the film's first } \\
\text { chronological moment at the end of each data entry, in } \\
\text { seconds. }\end{array}$ \\
\hline TIME CERTAINTY & $\begin{array}{l}\text { A metric ranging from A (very certain) to D (very } \\
\text { uncertain) to measure the level of certainty in determining } \\
\text { real-world relative time values from fictional film data. }\end{array}$ \\
\hline LONGITUDE & $\begin{array}{l}\text { Horizontal location of each data entry in a geographic } \\
\text { coordinate system. }\end{array}$ \\
\hline LATITUDE & $\begin{array}{l}\text { Vertical location of each data entry in a geographic } \\
\text { coordinate system. }\end{array}$ \\
\hline EASTING & $\begin{array}{l}\text { Horizontal location of each data entry in UTM zone } 31 \\
\text { north projected coordinate system. This is the } \mathbf{X} \text {-value. }\end{array}$ \\
\hline
\end{tabular}




\begin{tabular}{|l|l|}
\hline \multicolumn{1}{|c|}{ Attribute } & \multicolumn{1}{c|}{ Description } \\
\hline NORTHING & $\begin{array}{l}\text { Vertical location of each data entry in UTM zone 31 north } \\
\text { projected coordinate system. This is the Y-value. }\end{array}$ \\
\hline $\begin{array}{l}\text { LOCATION } \\
\text { CERTAINTY }\end{array}$ & $\begin{array}{l}\text { A metric ranging from A (very certain) to D (very } \\
\text { uncertain) to measure the level of certainty in determining } \\
\text { real-world location values from fictional film data. }\end{array}$ \\
\hline ELEVATION FT & $\begin{array}{l}\text { Each CHARACTER's approximate elevation above } \\
\text { sea/ground level in each data entry. }\end{array}$ \\
\hline VELOCITY MPH & $\begin{array}{l}\text { The estimated velocity each CHARACTER is traveling at } \\
\text { based on their narrative, spatial, and temporal } \\
\text { information. }\end{array}$ \\
\hline NARRATIVE & $\begin{array}{l}\text { A description of the film's plot as it occurs in each data } \\
\text { entry. }\end{array}$ \\
\hline
\end{tabular}

After the eleven 3D point feature classes were developed, a series of 3D two-point line feature classes was created to string the points together. Each line feature class represents the pathway a character took to get from one narrative event to the next, in chronological order. In this way, the space-time cube displays not only the spatialtemporal location of each plot point, but the path that each character took to reach it. The 3D lines were made from 2-point lines drawn manually from point to point for each character, resulting in a total of eleven $3 \mathrm{D}$ line feature classes.

Aside from visualizing the spatial-temporal locations and pathways of the plot of Dunkirk as conveyed by each character, the 3D point and line feature classes were symbolized to represent a number of data attributes. The CHARACTER attribute was symbolized by color, PERSPECTIVE was symbolized by point shape, DIRECTION was symbolized by point rotation, and VELOCITY MPH was illustrated by the slope of each line segment. Figure 4-2 illustrates how these attributes were symbolized.

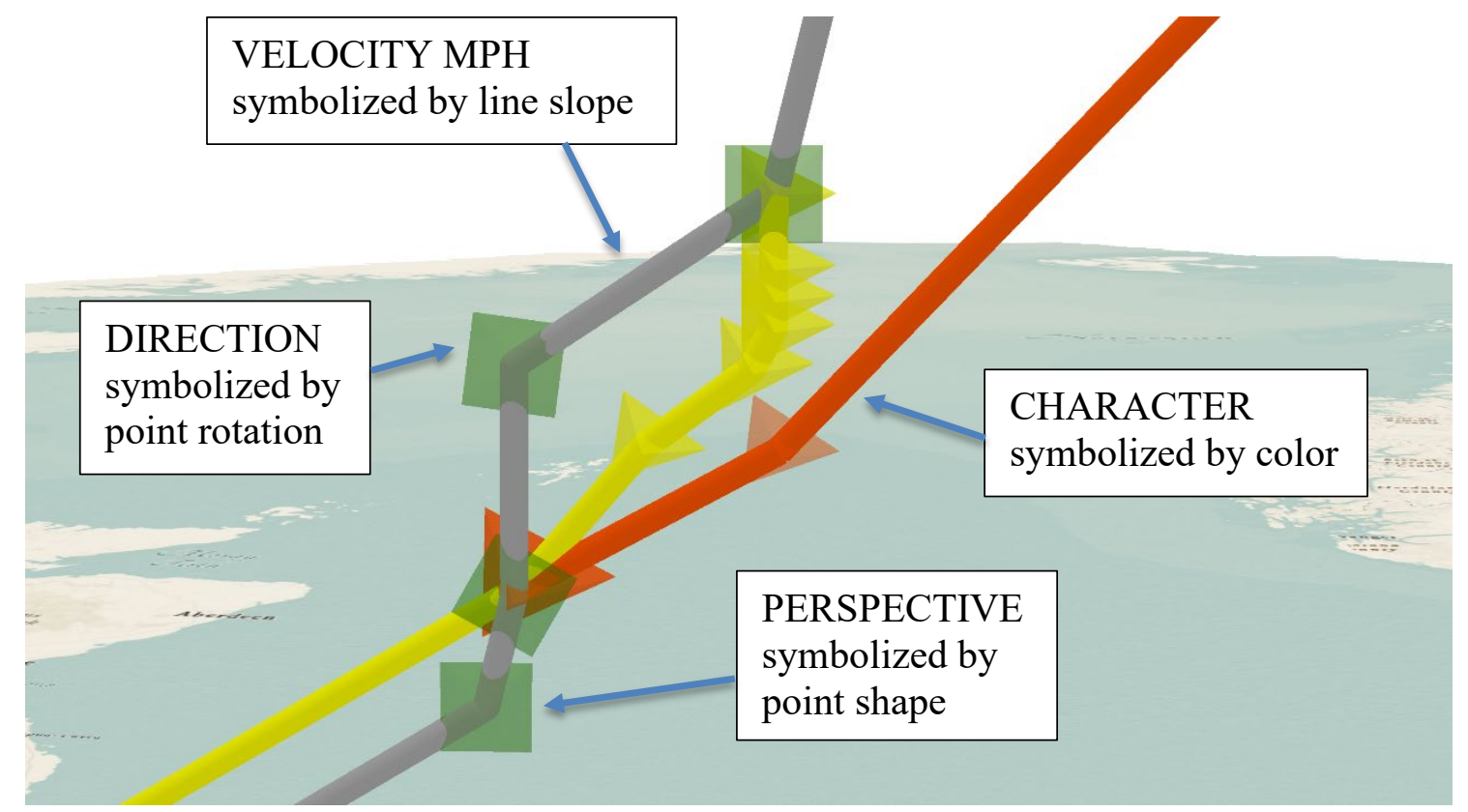

Figure 4-2: Example of symbolized attributes. 
In applying this project's conceptual data model to the logical data model, certain compromises had to be made. For instance, the space-time cube could not use the vertical (Z) plane to visualize the ELEVATION attribute because that plane was reserved for ADJUSTED RELATIVE SECONDS instead. As a result, ELEVATION was not symbolized in the cube, but was included as information in the pop-up windows.

\subsection{Data Sources}

One of the main objectives of this project was to translate the film Dunkirk into chronological order in a space-time cube. As a result, the film itself was the primary source of the cube's data. There is no extended edition or director's cut of Dunkirk; project data were derived from the theatrical version of the film. It is important to note that the film's runtime values - stored in the database as the attributes FILM TIME FROM, FILM TIME TO, and FILM SECONDS - were taken from the DVD version of the film, which differ from the runtimes in the digital and Blu-Ray versions of the film.

The secondary data source for this project was The Making of Dunkirk, the officially-licensed book describing the behind-the-scenes development of the film (Mottram, 2017). The Making of Dunkirk was used mainly to determine location, character, and vehicle information in the database.

Lastly, historical research of Operation Dynamo was used to fill in any remaining gaps of information due to the fictional nature of Dunkirk's narrative. This included information such as the locations of Royal Air Force (RAF) airfields active during World War II and the Allied defense perimeters held at Dunkirk, France during the evacuation of the British Expeditionary Forces (BEF). Because the purpose of this project was to translate the fictional plot of Dunkirk, any historical information found to be in direct conflict with the film was disregarded.

\subsection{Data Collection Methods}

Data was collected scene by scene from the Dunkirk film and organized into various attributes in the database. The amount of information collected in each database entry was largely determined by camera cuts jumping from characters in one setting to characters in another. For example, a single data entry would include information from a 1-minute scene focusing on Mr. Dawson at sea. At the end of that scene, the camera cuts to a new scene focusing on Collins in the air, and a new data entry is made. At other times, the amount of information collected in each database entry was determined by major changes in direction made by characters on the move. These data entries pertained to longer scenes containing extended action sequences. For example, a 4-minute scene of Tommy running from enemies could be split into multiple data entries to capture his path in greater detail.

Much of the data collected from the film were directly transferred into the database based on explicit visual context, such as the attributes of CHARACTER. Other data attributes - such as VELOCITY - had to be logically extrapolated using a combination of logical reasoning, historical research, and the equation: distance of travel (D) equals rate of travel (R) multiplied by travel time (T), as shown in Equation 4-1. 


$$
D=R * T
$$

To account for the inherent imprecision in translating fictional data into real-world space-time, two certainty metrics were included in each data entry as the attributes LOCATION CERTAINTY and TIME CERTAINTY. The metric ranged from grade A (very certain) to D (very uncertain). Scenes filmed on-location and whose time of day was readily discernable rated higher in the certainty metric, while scenes filmed offlocation and whose time of day was unclear rated lower. A full breakdown of the LOCATION CERTAINTY and TIME CERTAINTY is provided in Appendix A.

Upon the conclusion of the data collection phase, the entirety of the Dunkirk film had been rearranged into chronological order and stored in a database. For every scene, spatial-temporal information had been determined for each of the eleven characters, and the database was ready for implementation into a GIS. From there, 3D point and line feature classes were built to translate the plot of Dunkirk into a space-time cube.

\subsection{Data Scrubbing and Loading}

As mentioned in the Problem Statement in Chapter One, this project is not a depiction of the real-life Operation Dynamo, but a reframing of the fictional Dunkirk film. This project is not a critique of Dunkirk and makes no attempt to "correct" or "improve" it. Therefore, any historical errors present in the film are also present in this project.

That being said, much of Dunkirk's spatial-temporal data required special preparation before being loaded into the database and subsequent GIS. Translation of the film necessitated the input of real-world location (XY) data in the forms of the LONGITUDE, LATITUDE, EASTING, and NORTHING attributes. Much of this data had to be extrapolated based on contextual information shown in-film. Though many scenes were shot on-location in France and England - making them easy to replicate in the GIS - other scenes were shot in the Netherlands and California (Mottram, 2017). Since these locations were nowhere near the settings of the film plot, substitute locations were chosen so that the plot could be mapped logically in the GIS. For example, in a scene from Dunkirk, an Allied destroyer is torpedoed by an enemy submarine. Narratively, the destroyer was anchored off the coast of Dunkirk. However, that scene was physically filmed at Falls Lake in Universal Studios, North Hollywood (Mottram, 2017, p. 102). Because the plot of Dunkirk does not take place in North Hollywood, contextual information from the film was used to approximate a logical location for the destroyer in the GIS. In addition, Equation 4-1 was frequently used to determine a realworld location for database entries whose scenes could not be explicitly located in-film.

Another challenging data attribute to load was RELATIVE SECONDS, which served as the space-time cube's original temporal data mapped to the vertical (Z) plane. In its original medium, the plot of Dunkirk is non-chronological, yet plot events are portrayed as occurring simultaneously. Dunkirk director Christopher Nolan referred to this as "a present-tense narrative" (Mottram, 2017, p. 17). While this method of storytelling is effective in-film, it makes it difficult to understand exactly when events are happening relative to each other in real-time. In order to load this data, it was essential to identify the first chronological moment of the plot. This was the scene containing the earliest moment of the story, from which everything else - no matter the order of presentation in-film - happened afterward. Once the first chronological moment was 
identified, every successive data entry was given a value indicating how many real-world seconds had passed since the first moment to that data entry. Unfortunately, this assessment had few contextual clues to rely on for accuracy, save for a couple pieces of dialogue, a watch that was consulted twice, the tides at Dunkirk, and dates in newspapers. The natural sunlight present in daytime scenes provided limited evidence to discern the clock time, and the equation $D=R * T$ was utilized often to approximate RELATIVE SECONDS.

\subsection{Summary}

The bulk of conveying the narrative of Dunkirk into a 3D GIS relied on how information presented in the project's data sources was translated into spatial-temporal attributes in a database. The Dunkirk film was the primary source of information, while secondary sources helped to determine real-world space-time data from the film's fictional plot. Many database attributes were derived directly from information shown explicitly infilm, while others had to be determined based on contextual details. The requisite realworld spatial-temporal attributes were often challenging to determine, due to the fictional nature of the plot and the realities of filmmaking. Logical decision-making was employed to derive $\mathrm{X}, \mathrm{Y}$, and $\mathrm{Z}$ values for data entries whose in-film spatial-temporal information was unclear.

Once the initial rounds of data collection were complete, the plot of Dunkirk had been rearranged into chronological order in a database. The database was then imported into ArcGIS Pro to create the space-time cube. The spatial-temporal data stored in the database was used to create eleven 3D point feature classes, one for each character. Each point represented a plot event from the film, mapped in both the real-world horizontal $(\mathrm{XY})$ and vertical $(\mathrm{Z})$ axes. The passing of time was visualized as moving upwards from the base of the space-time cube; the first chronological plot event was mapped at the base whereas the last plot event marked the cube's ceiling. Eleven 3D two-point line feature classes were then drawn to connect the points and illustrate the narrative pathways of each character as he traveled from one event to the next, in chronological order. Additional database attributes were used to visually enhance the level of detail captured from the film, such as characters' direction of travel and formation of traveling groups. 



\section{Chapter 5 - Implementation}

Following the initial database design, import of the database into ArcGIS Pro, and creation of the 3-dimensional feature classes detailed in Chapter Four, additional configuration of the database and space-time cube was necessary to optimize the display of data. The first version of the Dunkirk space-time cube drew from the RELATIVE SECONDS attribute to plot the 3D points on the cube's vertical (Z) axis. For each data entry, the RELATIVE SECONDS attribute represented the number of real-world seconds that had passed chronologically from the beginning of the plot of Dunkirk. For instance, if a scene was determined to have taken place 10 hours from the start of the story, it would have the numeric value of 36,000 . Using this attribute, 3D point feature classes were mapped throughout the space-time cube, with the earliest moment of the film's story placed at the bottom of the cube and the last moment placed at the top. A total of eleven 3D point feature classes were created, one for each film character. Eleven 3D twopoint line feature classes were then drawn to connect the points together. Each line feature class represented the physical pathway a character had to traverse in order to get from one point to the next.

\subsection{Characters Traveling in Groups}

One of the first challenges that the Dunkirk space-time cube had to address was how to visualize the paths of multiple characters traveling together. Throughout the film, certain characters band together and break apart over the course of their journeys, resulting in different combinations of characters traveling together or separately. In the database, both individuals and groups were treated as a single entity, meaning that all members of a group were assigned the same spatial and temporal values, even though no two group members actually existed in the exact same spatial location. As a result, while each character was assigned his own point and line feature class, when all characters were drawn in the space-time cube at the same time, many points and lines overlapped one another, indicating when characters were traveling together.

An essential element to the plot of Dunkirk is not only where each character is located, but whom he is traveling with. Therefore, the joining and separating of characters was a crucial factor in determining the chronological order of the film. For example, even though the non-chronological order of the film suggests otherwise, we can establish that Shivering Soldier met Tommy, Gibson, and Alex off the coast of Dunkirk hours before he was rescued by Mr. Dawson, Peter, and George in the middle of the English Channel (Figure 5-1 and Figure 5-2) (Nolan \& Thomas, 2017). A combination of logical reasoning, clues in the characters' dialogue, and the coming and going of characters into different groups helped translate the film's plot into chronological order in the database. As a result, in order to reduce data redundancy and acknowledge the formation and dissolution of character groups, a code was developed to indicate whether a character was traveling alone or with others. If he was with others, the code also indicated who the members of the group were. A total of 22 codes were created and added to the database as a new attribute called GROUP CODE, described in Table 4. 


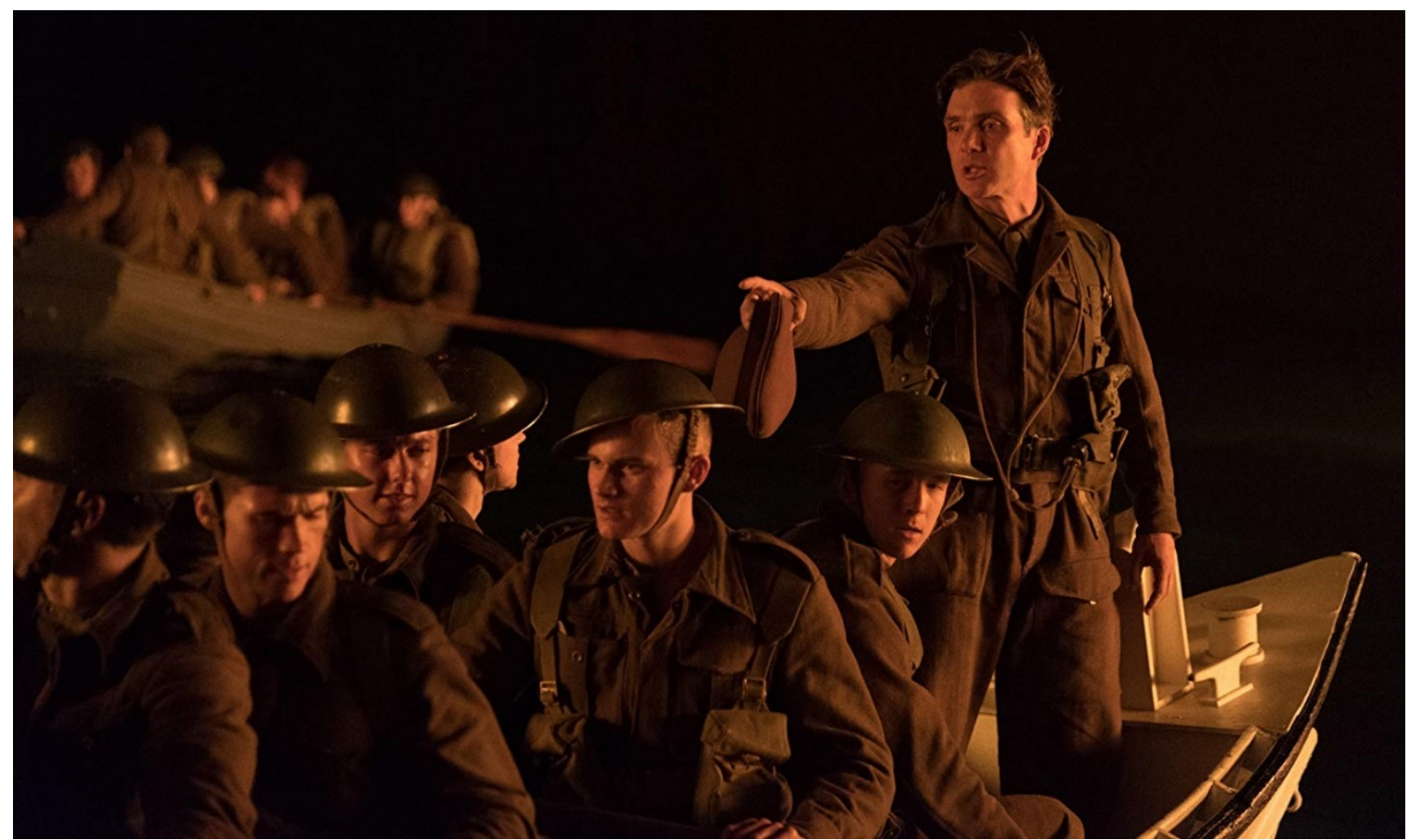

Figure 5-1: Shivering Soldier meets Tommy and Alex off the coast of Dunkirk.

(Gordon, 2016).

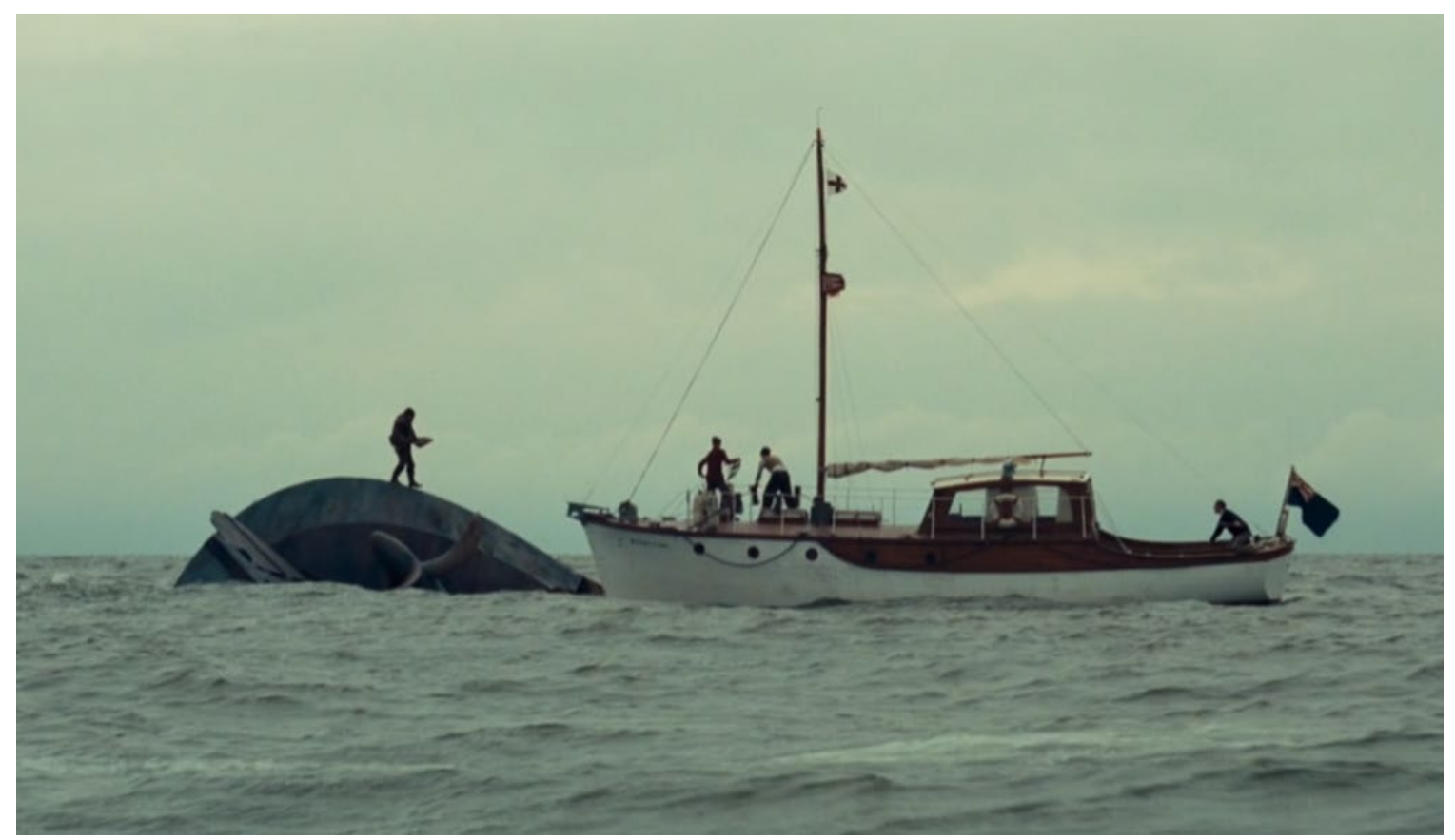

Figure 5-2: Shivering Soldier is rescued by Mr. Dawson, Peter, and George. (Nolan \& Thomas, 2017). Screenshot by author. 
Table 4. The GROUP CODE Database Attribute

\begin{tabular}{|l|l|}
\hline \multicolumn{1}{|c|}{ Attribute } & \multicolumn{1}{c|}{ Description } \\
\hline GROUP CODE & $\begin{array}{l}\text { A code indicating that CHARACTERS are either } \\
\text { traveling independently or have grouped together and are } \\
\text { traveling as a single entity. For each group, the code also } \\
\text { indicates which individuals are included. }\end{array}$ \\
\hline
\end{tabular}

The codes in GROUP CODE were designated based on distinct elements of each character's setting of origin, combined with character initials, a numeric identifier, or call sign. The soldiers originating from "THE MOLE - one week" were given the code letter "D" for Dunkirk, followed by character initials. The civilians from "THE SEA - one day" were given the code name "Moon" for Moonstone, the name of the yacht captained by Mr. Dawson. In addition to character initials, numeric values were assigned to unique groupings of characters that board the Moonstone over the course of the film. Lastly, the pilots from "THE AIR - one hour" were given the code letter " $F$ " for Fortis, the name of their Royal Air Force (RAF) squadron. When flying together in formation, the pilots were coded as "FG" for Fortis Group, the full name of their squadron. However, when separated, the pilots were coded by a number matching their call sign (Nolan \& Thomas, 2017).

Given the importance of GROUP CODE, the eleven 3D point and line feature classes were re-symbolized to visualize this new attribute. Drawing inspiration from the works of Andrew DeGraff (DeGraff \& Jameson, 2017) and Field and Shephard's Napoleon's March on Moscow 1812-1813 in 3D (2013), GROUP CODE was symbolized by differing sizes of point and line features. As groups grew or shrank, the size of the points and lines changed accordingly. GROUP CODE was also symbolized by two-tone striped line features that mainly visualized groups of two characters. Any group larger than two characters was typically symbolized with larger points and lines. Figure 5-3 is an example of how these attributes were symbolized. A full breakdown of this project's group codes and corresponding symbology is provided in Appendix B. 


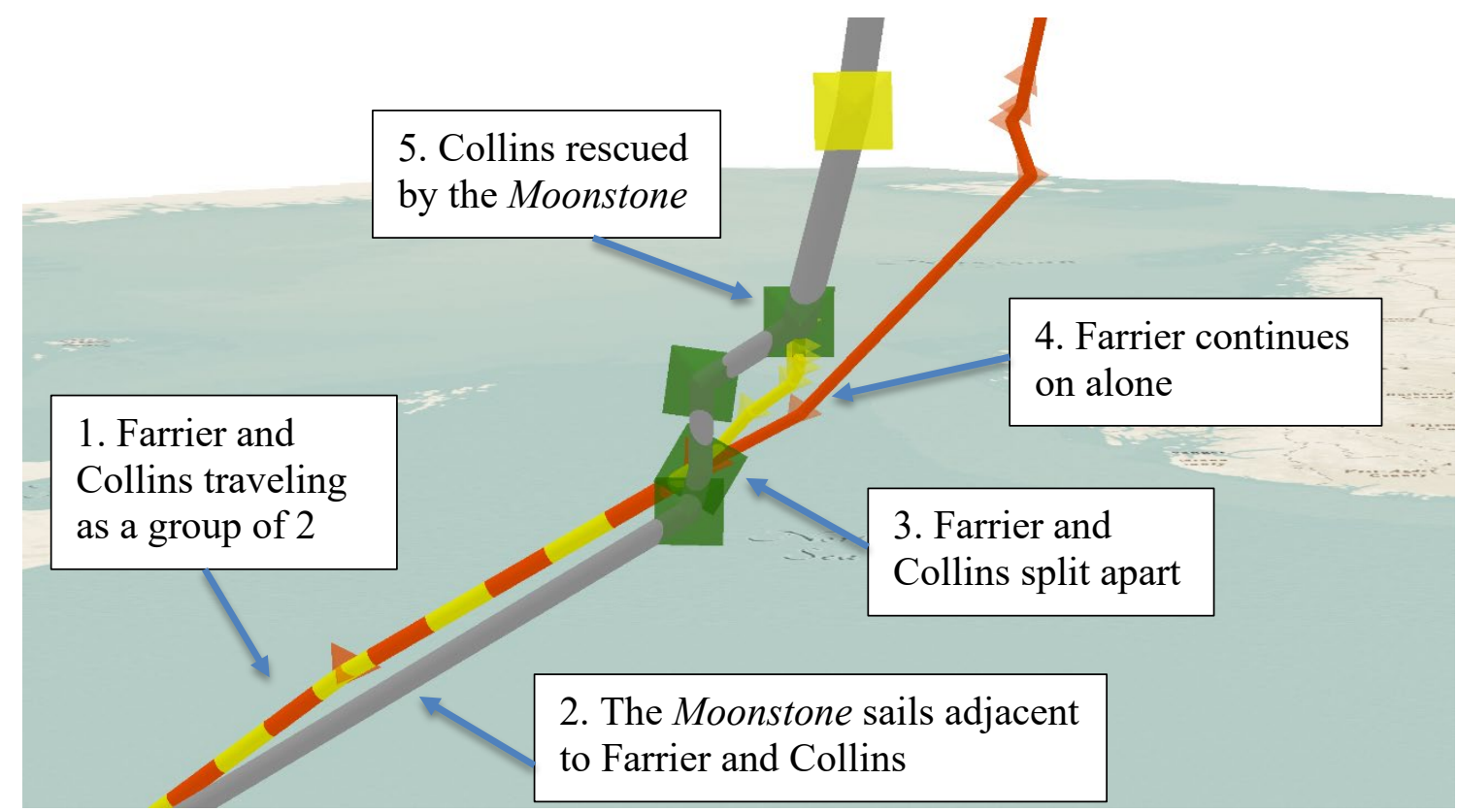

Figure 5-3: Example of the GROUP CODE attribute.

\subsection{Time Compaction and Resampling}

Initially, the Dunkirk space-time cube used the RELATIVE SECONDS attribute to map data along the Z-axis. However, a problem quickly arose from this method. In Chapter Two, it was explained that the film's plot takes place across three main settings: "THE MOLE - one week," "THE SEA - one day," and "THE AIR - one hour." Although each setting's time designation was proven to be exaggerated, certain characters, such as Alex, exist in the story for as long as three real-world days, while others, such as Farrier, enter and exit the story in as little as six hours. To expand the presence of characters like Farrier, the film included them in numerous scenes scattered throughout its runtime. However, when these scenes were placed in chronological order in the database, it became apparent that for many, very little real-world time was passing between them. In other words, there was little difference between the RELATIVE SECONDS for each of these particular data entries. As a result, when these data entries were plotted in the space-time cube as points, there was little vertical space separating them. Because of this, the space between certain points appeared compacted, making each point difficult to differentiate. Figure 5-4 illustrates this issue. 


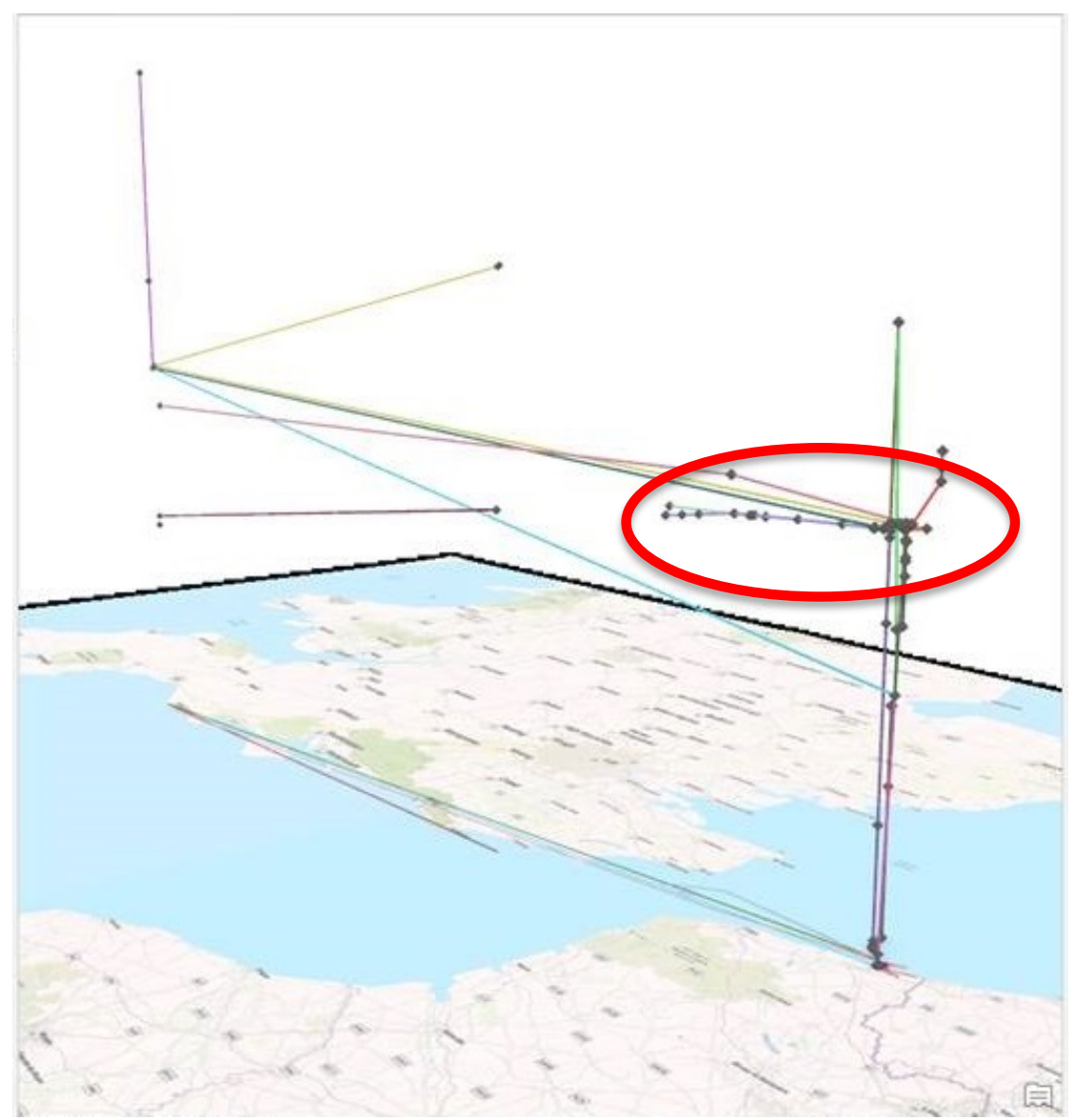

Figure 5-4: Certain points appear vertically compacted.

(N. Shephard, personal communication, June 17, 2019).

\subsubsection{Adjusting Time with Square Root, Cube Root, and Logarithm Equations}

To address the issue of compacted space between points, the time values in the RELATIVE SECONDS attribute needed to be adjusted. Three different equations - a square root, a cube root, and a logarithm - were applied to the RELATIVE SECONDS attribute to generate three sets of new values; the points were then vertically mapped using these three sets. Figure 5-5 is a comparison of the original points mapped using RELATIVE SECONDS (on the left) versus mapped using values adjusted by a square root equation (on the right). Corresponding points are marked with blue lines. 


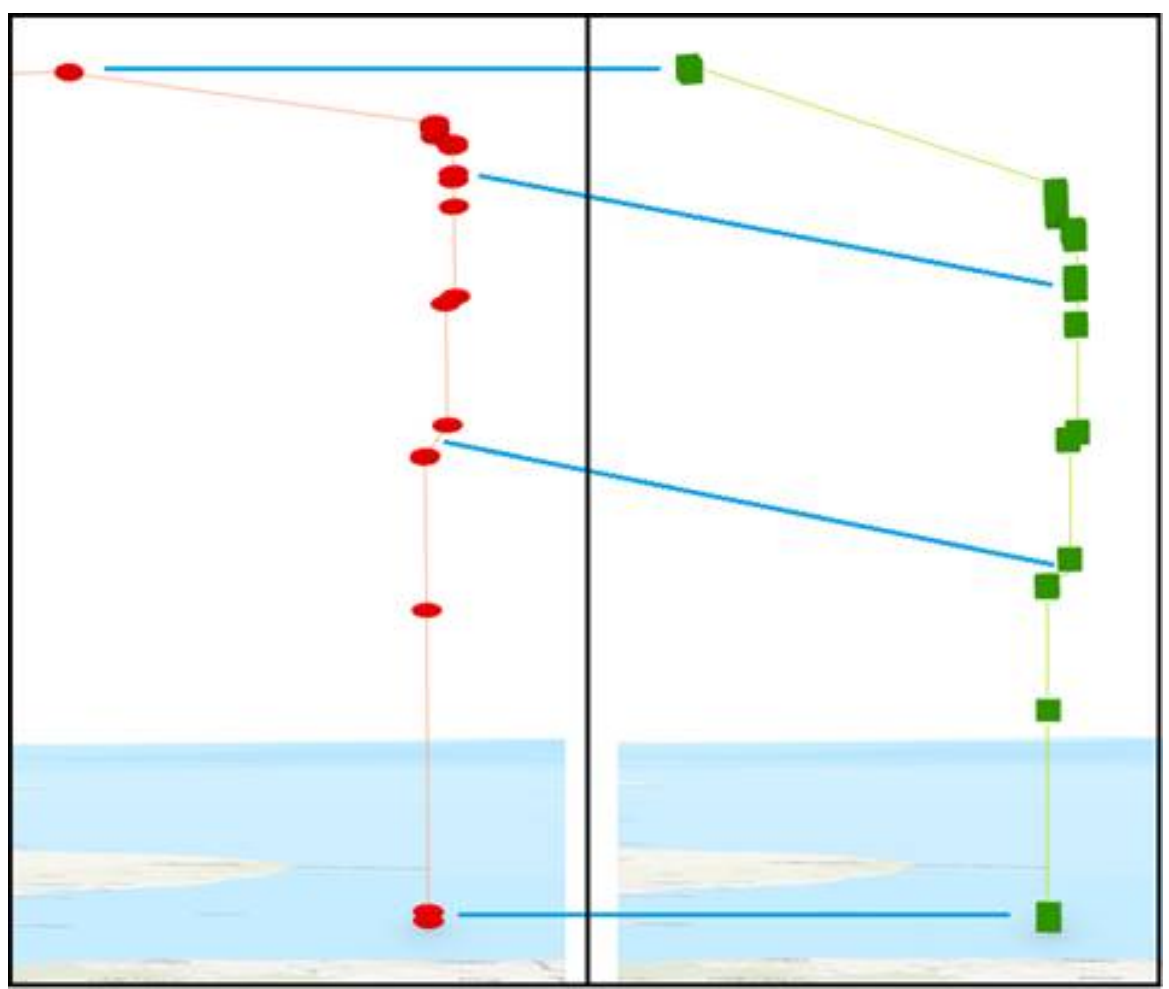

Figure 5-5: Comparison of RELATIVE SECONDS versus square root equation. (N. Shephard, personal communication, June 30, 2019).

\subsubsection{Time Sections and Linear Resampling}

Unfortunately, after visually comparing the points mapped using Equations 5-1, 5-2, and 5-3 versus the original RELATIVE SECONDS, it was deemed that none of the equations sufficiently addressed the issue of compacted vertical space between points. A fourth approach was instead used to solve this issue, in which all the data entries in the project database were classified into five time sections, effectively parting the story into five pieces. Each time section was bounded by a natural break in the chronological narrative, usually a scene of falling action after a climax. This resulted in a varying amount of data entries and real-world time contained in each section, not unlike writing chapters of unequal lengths in a book. Table 5 describes where these time sections in the narrative were determined.

Table 5. The Five Time Sections in the Chronological Narrative

\begin{tabular}{|l|l|l|l|}
\hline \multicolumn{4}{|c|}{ Time section 1 } \\
\hline NARRATIVE from & NARRATIVE to & $\begin{array}{l}\text { RELATIVE } \\
\text { SECONDS from }\end{array}$ & $\begin{array}{l}\text { RELATIVE } \\
\text { SECONDS to }\end{array}$ \\
\hline $\begin{array}{l}\text { introducing Tommy } \\
\text { in Malo-les-Bains, } \\
\text { Dunkirk }\end{array}$ & $\begin{array}{l}\text { returning to } \\
\text { Dunkirk beach after } \\
\text { the Maillé-Brézé is } \\
\text { torpedoed }\end{array}$ & 0 seconds & $\begin{array}{l}70,140 \text { seconds } \\
(19.5 \text { real-world } \\
\text { hours since start of } \\
\text { story) }\end{array}$ \\
\hline
\end{tabular}




\begin{tabular}{|c|c|c|c|}
\hline \multicolumn{4}{|c|}{ Time section 2} \\
\hline NARRATIVE from & NARRATIVE to & $\begin{array}{l}\text { RELATIVE } \\
\text { SECONDS from }\end{array}$ & $\begin{array}{l}\text { RELATIVE } \\
\text { SECONDS to }\end{array}$ \\
\hline $\begin{array}{l}\text { introducing the } \\
\text { crew of the } \\
\text { Moonstone in } \\
\text { Weymouth, } \\
\text { England }\end{array}$ & $\begin{array}{l}\text { Peter locks } \\
\text { Shivering Soldier } \\
\text { below deck }\end{array}$ & 75,647 seconds & $\begin{array}{l}106,913 \text { seconds } \\
\text { ( } 29.7 \text { real-world } \\
\text { hours since start of } \\
\text { story) }\end{array}$ \\
\hline \multicolumn{4}{|c|}{ Time section 3} \\
\hline NARRATIVE from & NARRATIVE to & $\begin{array}{l}\text { RELATIVE } \\
\text { SECONDS from }\end{array}$ & $\begin{array}{l}\text { RELATIVE } \\
\text { SECONDS to }\end{array}$ \\
\hline $\begin{array}{l}\text { introducing Fortis } \\
\text { Group }\end{array}$ & $\begin{array}{l}\text { Gibson drowns } \\
\text { aboard the fishing } \\
\text { trawler }\end{array}$ & 107,211 seconds & $\begin{array}{l}109,868 \text { seconds } \\
(30.5 \text { real-world } \\
\text { hours since start of } \\
\text { story) }\end{array}$ \\
\hline \multicolumn{4}{|c|}{ Time section 4} \\
\hline NARRATIVE from & NARRATIVE to & $\begin{array}{l}\text { RELATIVE } \\
\text { SECONDS from }\end{array}$ & $\begin{array}{l}\text { RELATIVE } \\
\text { SECONDS to }\end{array}$ \\
\hline $\begin{array}{l}\text { Farrier's decision to } \\
\text { turn back and } \\
\text { defend the Sittard }\end{array}$ & $\begin{array}{l}\text { the Moonstone } \\
\text { escapes the burning } \\
\text { oil }\end{array}$ & 109,910 seconds & $\begin{array}{l}111,672 \text { seconds } \\
\text { ( } 31 \text { real-world } \\
\text { hours since start of } \\
\text { story) }\end{array}$ \\
\hline \multicolumn{4}{|c|}{ Time section 5} \\
\hline NARRATIVE from & NARRATIVE to & $\begin{array}{l}\text { RELATIVE } \\
\text { SECONDS from }\end{array}$ & $\begin{array}{l}\text { RELATIVE } \\
\text { SECONDS to }\end{array}$ \\
\hline $\begin{array}{l}\text { Farrier arrives in } \\
\text { Dunkirk out of fuel }\end{array}$ & $\begin{array}{l}\text { Mr. Dawson and } \\
\text { Peter read about } \\
\text { George in the } \\
\text { newspaper }\end{array}$ & 111,724 seconds & $\begin{array}{l}252,650 \text { seconds } \\
\text { ( } 70 \text { real-world } \\
\text { hours since start of } \\
\text { story) }\end{array}$ \\
\hline
\end{tabular}

(Nolan \& Thomas, 2017).

A unique linear equation was applied to each time section to resample the values in RELATIVE SECONDS into new time values, now in five evenly-sized time sections 60,000 seconds in length. The resizing worked to expand compacted time sections so that the data in those sections could be spread out more legibly across the $\mathrm{Z}$ axis. These resampled time values were placed in a new database attribute called ADJUSTED RELATIVE SECONDS; an additional attribute called TIME SECTION ID was created to identify which time section each data entry was classified into. Table 6 describes these two new attributes while Table 7 lists the equations applied to each time section. Figure 5-6 illustrates the breakdown of data entries into uneven time sections and how the time sections were resampled to be of equal size. 
Table 6. TIME SECTION ID and ADJUSTED RELATIVE SECONDS

\begin{tabular}{|l|l|}
\hline \multicolumn{1}{|c|}{ Attribute } & \multicolumn{1}{c|}{ Description } \\
\hline TIME SECTION ID & $\begin{array}{l}\text { Classifies values from RELATIVE SECONDS into five } \\
\text { sections, and determines which of five linear equations } \\
\text { are applied to each section to resample the data for } \\
\text { improved vertical display. }\end{array}$ \\
\hline $\begin{array}{l}\text { ADJUSTED RELATIVE } \\
\text { SECONDS }\end{array}$ & $\begin{array}{l}\text { An adjusted time value determined from applying one of } \\
\text { five linear equations to the RELATIVE SECONDS value } \\
\text { to resample the data for improved vertical display. This is } \\
\text { the current Z-value. }\end{array}$ \\
\hline
\end{tabular}

Table 7. Data time sections and the linear equation applied to each

\begin{tabular}{|c|l|}
\hline Time Section & \multicolumn{1}{c|}{ Equation } \\
\hline 1 & $([$ RELATIVE SECONDS] $/ 70,140) * 60,000$ \\
\hline 2 & $\begin{array}{l}((([\mathrm{RELATIVE} \mathrm{SECONDS]}-70,140) /(106,913-70,140)) * \\
60,000)+60,000\end{array}$ \\
\hline 3 & $\begin{array}{l}((([\mathrm{RELATIVE} \text { SECONDS] }-106,913) /(109,868-106,913)) * \\
60,000)+120,000\end{array}$ \\
\hline 4 & $\begin{array}{l}((([\mathrm{RELATIVE} \mathrm{SECONDS]}-109,868) /(111,672-109,868)) * \\
60,000)+180,000\end{array}$ \\
\hline 5 & $\begin{array}{l}((([\mathrm{RELATIVE} \text { SECONDS] }-111,672) /(252,650-111,672)) * \\
60,000)+240,000\end{array}$ \\
\hline
\end{tabular}




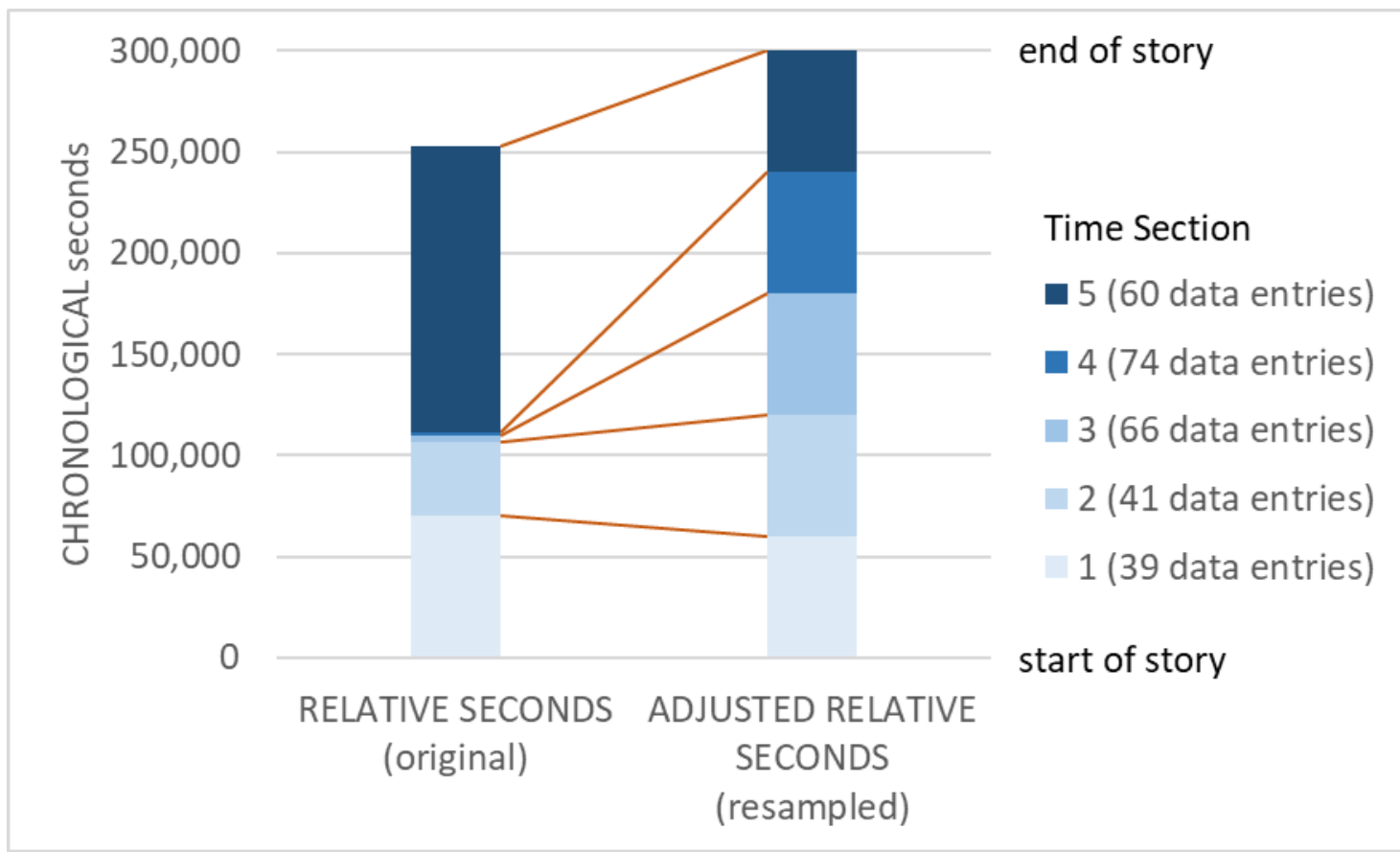

Figure 5-6: RELATIVE SECONDS resampled into five time sections of equal size.

After organizing the project database into five sections and resampling each section independently, the eleven 3D point and line feature classes were redrawn in the spacetime cube using the ADJUSTED RELATIVE SECONDS attribute as the new Z-value. As a result, the overall height of the cube was increased and vertical space between points was artificially expanded. The plot events of Dunkirk could now be clearly differentiated, making the chronological narrative of the film easy to follow throughout the cube.

It is important to understand that creating the time sections and resampling the data in the RELATIVE SECONDS attribute was purely for visual legibility of the data in the space-time cube, and did not alter the length of the story. For every pre-existing database entry, the resampling process simply generated an adjusted value for the data to be mapped on the $\mathrm{Z}$ axis. This served to increase the vertical space between compacted data, but did not create any additional data points or lines. Other date and time attributes such as CLOCK TIME FRANCE were unaffected by the resampling process, and remained unchanged.

\subsubsection{The Time Section Coastlines and Coastline Wall}

The five time sections of the project database were cartographically represented in the space-time cube by two new feature classes. The first feature class was comprised of a series of 3D lines that illustrated the boundaries of each time section, and were drawn to mimic the coastlines of southern England and northern France. This feature class provided a visual of where each time section started and ended, and simultaneously marked how much of the film's chronological plot was contained in each section. The second feature class was comprised of two 3D lines that were also shaped like the aforementioned coastlines, and were vertically extruded from the bottom to the top of the space-time cube. With layer transparency turned on, this feature class served as floor-to- 
ceiling "walls" of the cube and helped create the illusion of cube faces. Figure 5-7 provides a visual of the space-time cube, complete with the time section coastlines and coastline walls.

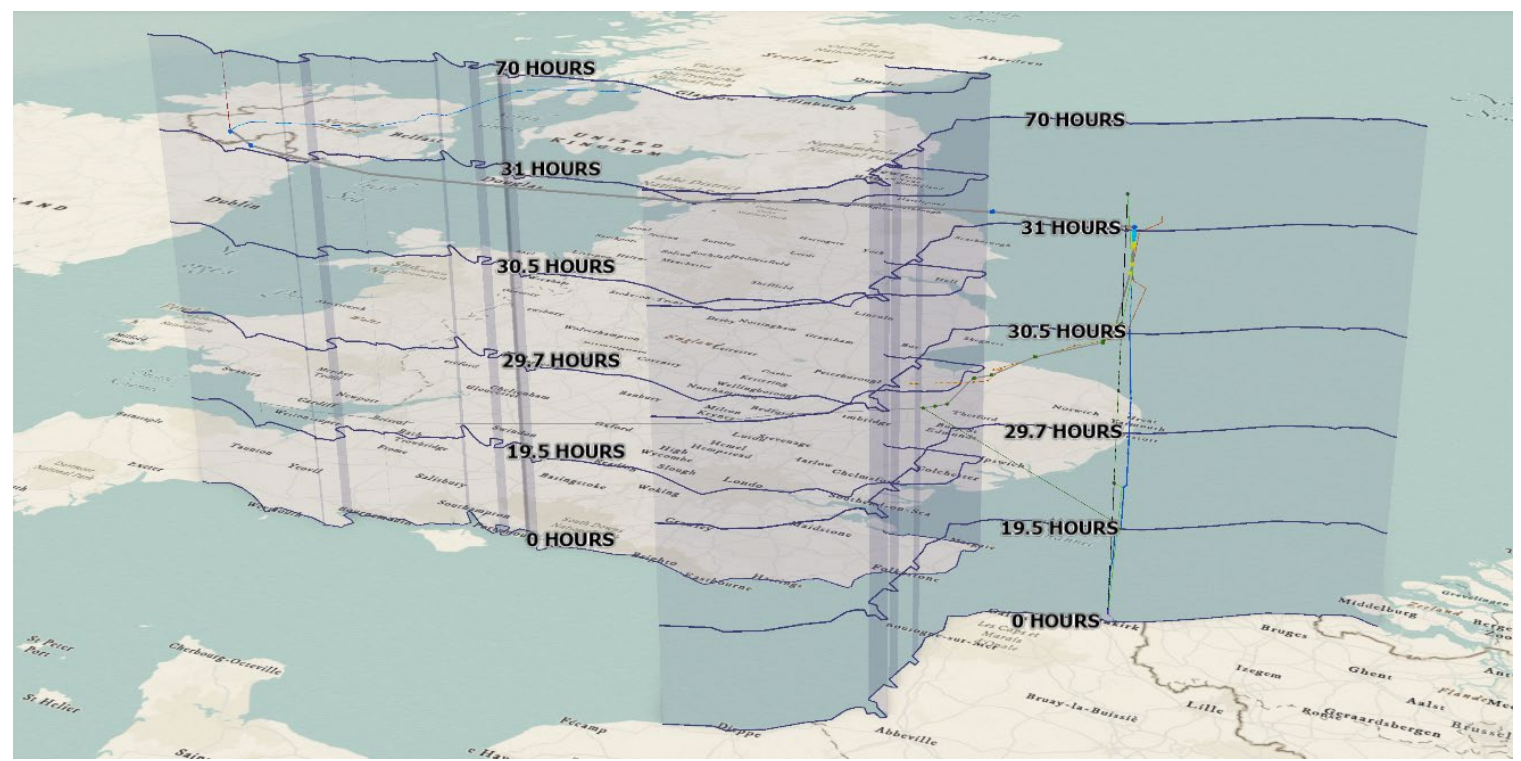

Figure 5-7: Cartographic representation of the time sections as coastlines.

\subsection{Publishing the Space-Time Cube as a Web Scene in ArcGIS Online}

As covered in Chapter Three, one of this project's final information products was a version of the Dunkirk space-time cube published from ArcGIS Pro to ArcGIS Online as an interactive 3D web scene in the Scene Viewer application. The advantage of an online web scene is the ability to share the results of the project with a wider audience without the need for prior purchase and installation of the ArcGIS Pro desktop software. However, before the cube could be published online, numerous adjustments and additional features were added in ArcGIS Pro using commercial-off-the-shelf (COTS) functionalities to make the cube compatible with the limitations and requirements of Scene Viewer. Once the Dunkirk cube was successfully published as a web scene, final adjustments were made for optimal display of the web scene in the Scene Viewer interface.

\subsubsection{Reprojecting the Space-Time Cube}

Various changes and additions were made to the space-time cube in ArcGIS Pro to prepare the cube for publishing to ArcGIS Online. The first change was to project the original spatial reference system of the cube (Universal Transverse Mercator zone 31 north) to the spatial reference system required by ArcGIS Online (WGS $1984 \mathrm{Web}$ Mercator Auxiliary Sphere) using the Project geoprocessing tool. Without first reprojecting the cube, data layers such as the $3 \mathrm{D}$ feature classes and the basemap could not be drawn in the web scene, rendering the entire endeavor pointless. 


\subsubsection{Displaying the Space-Time Cube in Real-World Units}

The second adjustment made to the space-time cube before publishing to ArcGIS Online was to change all data layers from a consistent display size to real-world units. When using a consistent display size, the 3D point and line feature classes always remained the same size onscreen, no matter how far zoomed in or out the cube was. However, web scenes in ArcGIS Online only support 3D feature classes that are drawn using real-world units. Therefore, it was necessary to change the properties of the feature classes in the cube to display in real-world units. With the real-world units display activated, the 3D points and lines now increased in size onscreen when the user zoomed in, and shrank when the user zoomed out (Figure 5-8). Because the cube was projected to the WGS 1984 Web Mercator Auxiliary Sphere spatial reference system, the real-world unit used for display was meters.

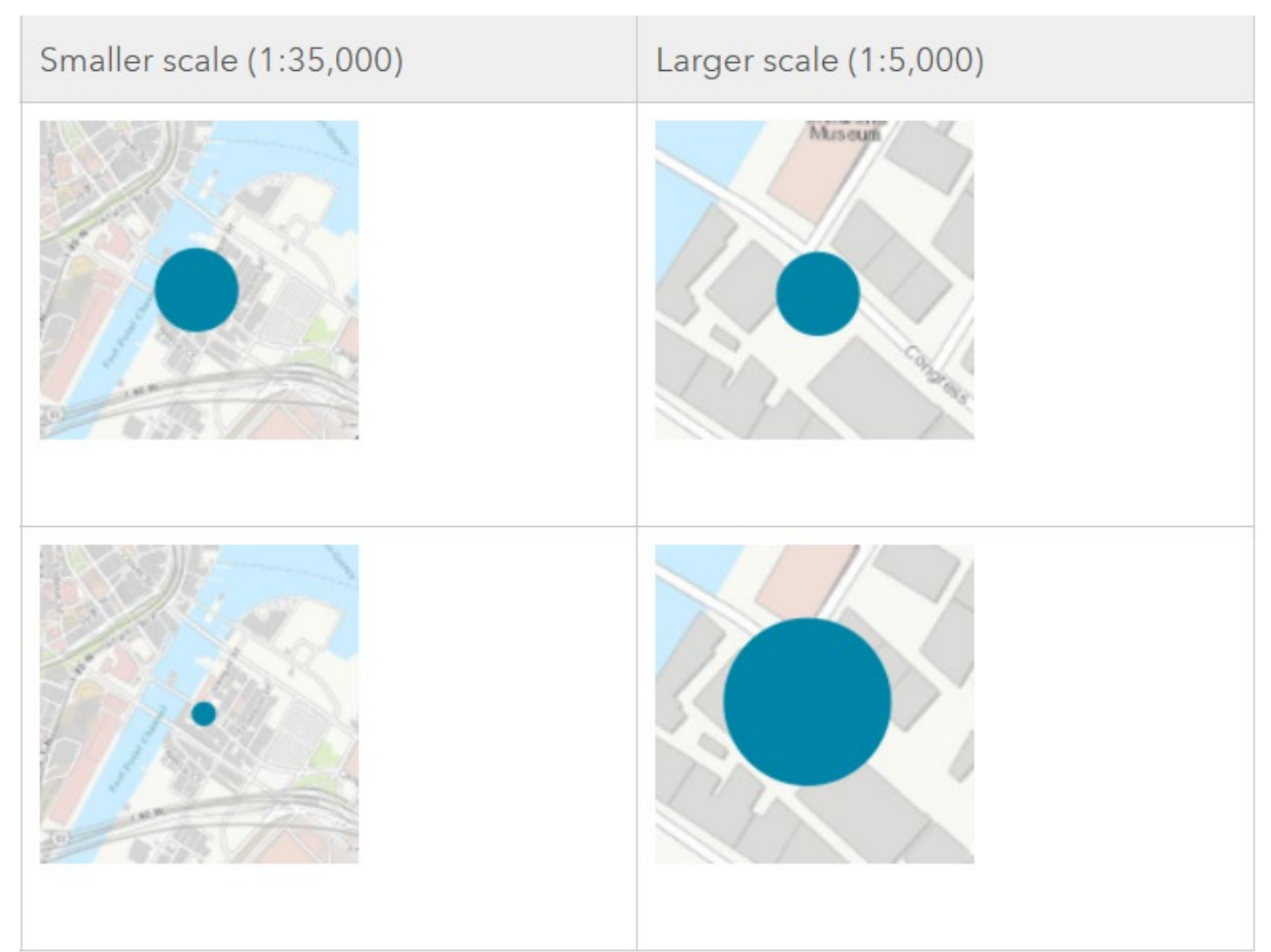

Figure 5-8: Data using a consistent display size versus using real-world units. Units and symbol size (n.d.).

\subsubsection{Converting 3D Line Feature Classes to Multipatches}

The next step in preparing the space-time cube for publishing to ArcGIS Online was to convert all 3D line feature classes into multipatches. A multipatch is "a GIS object that stores a collection of patches to represent the boundary of a 3D object as a single row in a database" (Multipatches, n.d.). The reason for this conversion is that ArcGIS Online does not support 3D line feature classes; multipatches were instead used as a substitution. This conversion was applied to the eleven line feature classes representing the Dunkirk 
characters' narrative pathways, as well as the two line feature classes representing the time section coastlines and coastline walls. The Layer 3D To Feature Class geoprocessing tool was used to perform the conversion, with the "Disable Color and Texture" option turned off. In this way, the multipatches inherited the established symbology from the line feature classes, as well as copies of their attribute tables. An example of the tool is shown in Figure 5-9.

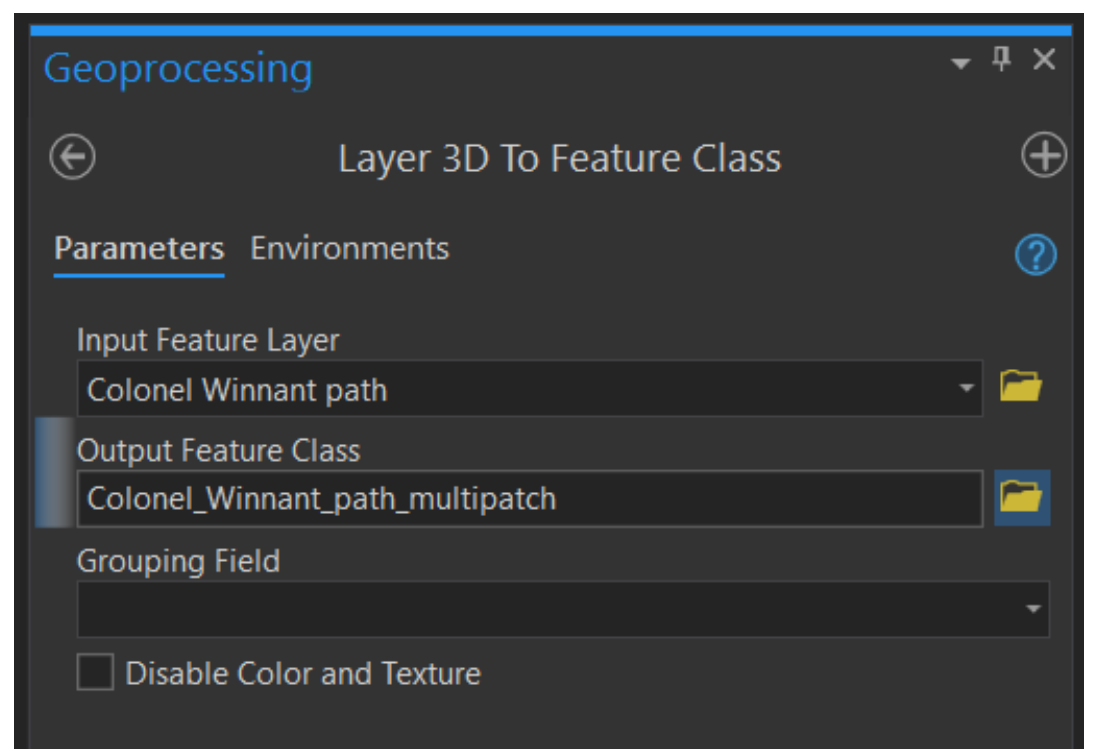

Figure 5-9: The Layer 3D to Feature Class geoprocessing tool.

\subsubsection{Generating Pop-up Windows with Photo Attachments}

Informational pop-up windows were then created for the majority of the layers in the space-time cube-including the eleven 3D point feature classes representing the chronological plot events of Dunkirk, the eleven multipatches representing characters' narrative pathways, and the multipatch representing the time section coastlines - prior to publishing. The pop-up windows were designed to enhance users' interactions with the cube by providing extra details from the project database at each point and multipatch segment.

An important element of the pop-up windows was the 919 photos added as attachments to the 3D point feature classes. The photos were generated by taking screenshots of the film, and served as a visual connection between points in the spacetime cube and associated scenes from the movie. Thus, the photo attachments were a vital part of translating the Dunkirk narrative from film into a 3D GIS. To add the photos to the cube, the Enable Attachments geoprocessing tool was applied to the point feature classes. For every feature class, the tool generated a file geodatabase table to contain the photo attachments and a file geodatabase relationship class to relate photos in the table to the proper attribute in the feature class. This allowed specific photos to be attributed to specific points. When capturing the screenshots, it was imperative to avoid including special characters such as apostrophes in the screenshot names, as doing so resulted in script errors in the GIS software. 


\subsubsection{Creating Bookmarks for Conversion to Slides}

The next step in preparing the space-time cube for publishing to ArcGIS Online was to add a collection of bookmarks. In ArcGIS Pro, a bookmark captures a chosen location and viewing angle in the map, allowing users to quickly return to that location. When multiple bookmarks are created, they can be used as a guide through the GIS, showing users areas of interest in the data. Twenty-three bookmarks were created throughout the Dunkirk cube to showcase how the 3D data represented the narrative of the film in chronological order. Upon publishing the cube to Scene Viewer, these bookmarks were converted into the ArcGIS Online equivalent-known as slides - so that the same benefit was made available to web users.

\subsubsection{The Publishing Process and Adjusting to the Scene Viewer Interface}

The Dunkirk space-time cube was published from ArcGIS Pro to ArcGIS Online using the Share as Web Scene function. This function allowed for the entire cube-complete with 3D layers, pop-up windows, and bookmarks - to be published as a single cohesive web scene, as opposed to publishing each layer independently.

Initial attempts to publish the cube using the default online caching option for all features resulted in failure due to problems submitting the tile caching job. This may have been due to the size of the eleven 3D point feature classes and their 919 photo attachments. In order to simplify the publishing process, visibility limitations were established for the point feature classes. This included capping the visibility range at 1,500,000 meters above the surface level of the cube, and setting the appropriate scale range in the metadata from 1:5,000,000 (State level) to 1:5,000 (Building level). Doing this made the vector tiles of the point layers easier to create and draw, as the server no longer drew them past scales smaller than 1,500,000 meters. While it was necessary to cache the point feature classes online in order to retain their photo attachments, the cube's thirteen multipatches did not have photo attachments and were configured to cache locally instead.

Upon successful publication of the Dunkirk space-time cube to ArcGIS Online as a

web scene, components of the web scene were fine-tuned for optimal display in the Scene Viewer interface. This included adjusting the bookmarks (referred to as slides in Scene Viewer) and correcting any clashing textures (also known as Z-fighting) in the mutipatches. Completion of the web scene was finalized by adding metadata such as credits, a thumbnail to the item description web page, and making the web scene accessible to the public. Below, readers may scan the QR code provided in Figure 5-10 with a smartphone and/or tablet to access the Dunkirk web scene online. 


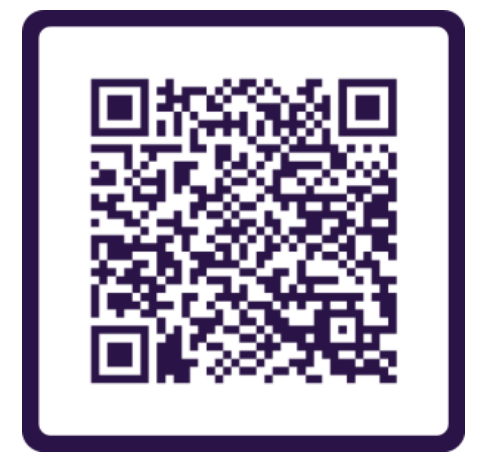

Figure 5-10: The Dunkirk web scene QR code. 


\section{Chapter 6 - Results and Analysis}

The finished space-time cube successfully visualized the spatial-temporal events and pathways of Dunkirk's eleven main characters. It untangled the complex tripartite narrative of the original film for display in chronological order in real-world time. Using the three axes of the space-time cube to measure space and time, the cube not only revealed exactly where each character went, but how long it took for him to traverse there. By bridging the gap between the fictional plot of the film and real space-time in the geographic information system (GIS), the Dunkirk cube served as a proof of concept for the use of space-time cubes as a viable storyboarding tool. In addition, the Dunkirk cube revealed a few interesting insights about the film that may not have been apparent from simply watching it as a moviegoer. However, this project also demonstrated certain limitations in the ability of space-time cubes to translate narratives from the medium of film to GIS.

\subsection{Insights into Dunkirk}

In Chapter One, it was established that this project does not consider the film Dunkirk as a "problem" in need of "correcting," and that it was not the purpose of this project to offer a critique of the film. However, in translating Dunkirk into a space-time cube, certain discrepancies in the narrative were discovered. Finding these discrepancies is inherent to the ability of GIS to visualize challenges and uncover solutions, and is not intended to diminish the quality of the film. On the contrary, these discrepancies reveal some insightful information about the creative process behind Dunkirk, such as deliberately introducing plot holes for the sake of artistic cinematography and emotional evocation.

\subsubsection{Plot Holes in Timelines: Fictional vs Real}

As introduced in Chapter Two, the narrative of Dunkirk is scattered across three different settings, each operating on its own timeline. These settings were introduced in the film as "THE MOLE - one week," "THE SEA - one day," and "THE AIR - one hour" (Nolan \& Thomas, 2017). Throughout the duration of the film, the camera cuts back and forth between settings and timelines so often, it can be difficult to ascertain how much time has truly passed over the course of the story. However, as each scene was translated into spatial-temporal data with real-world date and time values in the space-time cube, it became evident that the timelines presented by the film did not truly encapsulate the length of time that they professed to. In fact, the total length of the story-when accounting for overlapping timelines - is only four days, which is shorter than the "one week" timeline established by the film. In contrast, the other two timelines ("one day" and "one hour") were revealed to be longer in the cube than what was originally put forth by the film. Despite the disparity between fictional and real timelines, the makers of Dunkirk most likely chose to retain the "one week," "one day," "one hour" nomenclature due to its poetic structure. In addition, regardless of the inaccuracy, these timelines truthfully alert the audience that each narrative setting is operating on its own separate 
time scale. Table 8 compares the fictional timelines espoused by the film to the timelines determined in the space-time cube.

Table 8. Timelines Presented in Dunkirk vs. the Space-Time Cube

\begin{tabular}{|c|c|c|c|}
\hline Setting & $\begin{array}{c}\text { Timeline presented } \\
\text { in-film }\end{array}$ & $\begin{array}{c}\text { Timeline confirmed } \\
\text { in space-time cube }\end{array}$ & $\begin{array}{c}\text { Difference } \\
\text { between film and } \\
\text { space-time cube }\end{array}$ \\
\hline THE MOLE & 1 week & 3 days & -4 days \\
\hline THE SEA & 1 day & 3 days & +2 days \\
\hline THE AIR & 1 hour & 1.6 days & +1.56 days \\
\hline
\end{tabular}

\subsubsection{Plot Holes for Artistic Cinematography: The Voyage of the Moonstone}

Because Dunkirk did not explicitly show every second of each character's journey, character pathways in the space-time cube often had to be extrapolated using a combination of logical reasoning, historical research, and Equation $4.1\left(D=R^{*} T\right)$. Extrapolating real-world spatial-temporal data from the film's fictional narrative revealed several plot holes in the characters' travel paths, some of which were most likely retained in-film for artistic purposes. One major example of these plot holes is the return voyage of the Moonstone.

Near the end of the film, the Moonstone-now bearing multiple characters - is returning from Dunkirk, France to Weymouth, England when it survives a dangerous close encounter with an enemy fighter plane. While it is not shown exactly where or what time the encounter took place, a coastline is visible to the south of the yacht, and the film mentioned earlier that the enemy had taken Calais. Therefore, one can assume that the visible coastline in this scene was near Calais (Figure 6-1). Given that the voyage from Dunkirk to Calais is about 30 miles and the Moonstone is likely sailing an average of $13.8 \mathrm{mph}$ (15 knots), it was concluded that the Moonstone had been sailing for about 2.2 hours since leaving Dunkirk, and that it was about 7:14pm Central European Summer Time, or CEST (6:14pm British Summer Time, or BST). When we next see the Moonstone, the white chalk cliffs of England's southern coast are visible to the north, which the film identifies as the cliffs of Dorset. Above, the sun is setting directly overhead (Figure 6-2). Given the location of the cliffs and time of sunset in this region, it was concluded that the Moonstone was about 6.5 miles east of Weymouth, and that the time was about 8:38pm CEST (7:38pm BST). However, this means that the Moonstone had only 1.4 hours to sail from Calais to Dorset, a distance of 181.5 miles. As a result, the Moonstone had to have been sailing nearly $130 \mathrm{mph}$ (112.97 knots), which is an impossible feat (Nolan \& Thomas, 2017). 


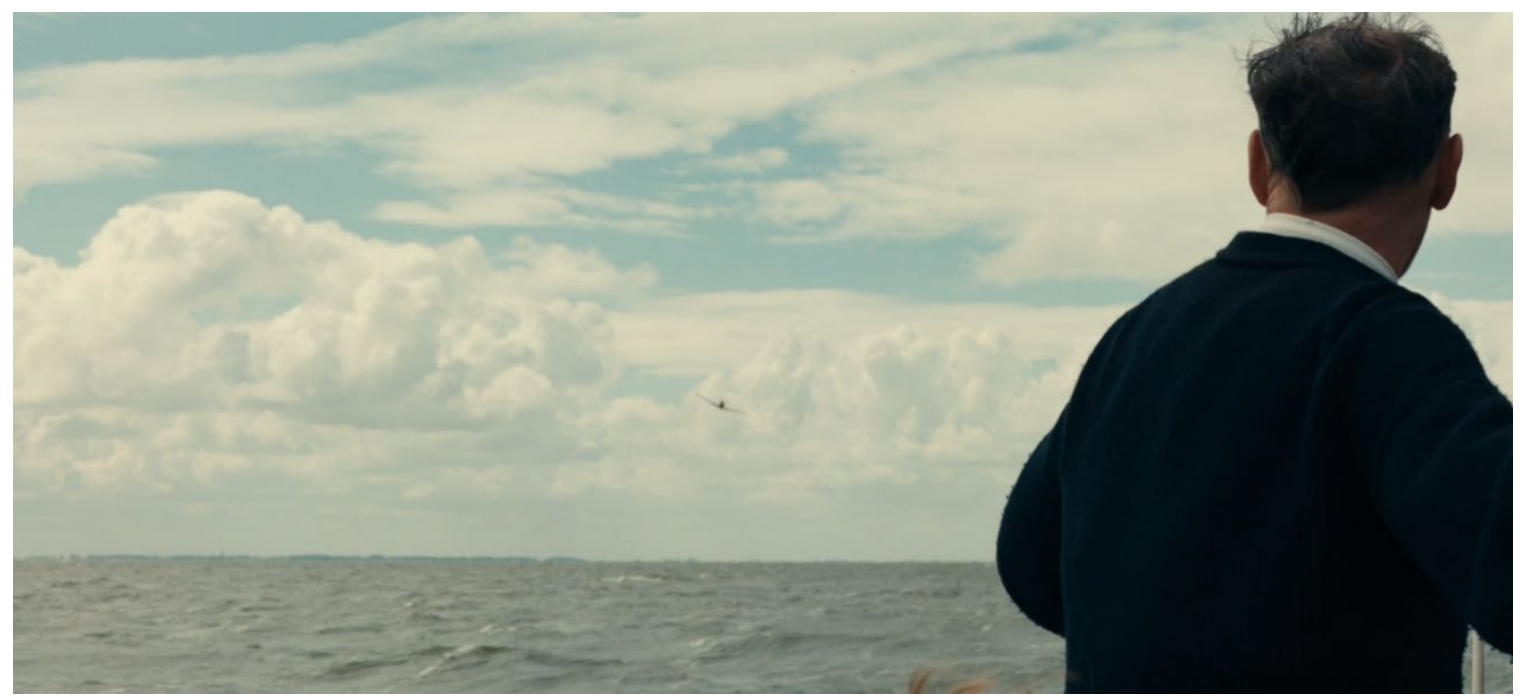

Figure 6-1: Mr. Dawson watches an enemy fighter plane approach the Moonstone. (Nolan \& Thomas, 2017). Screenshot by author.

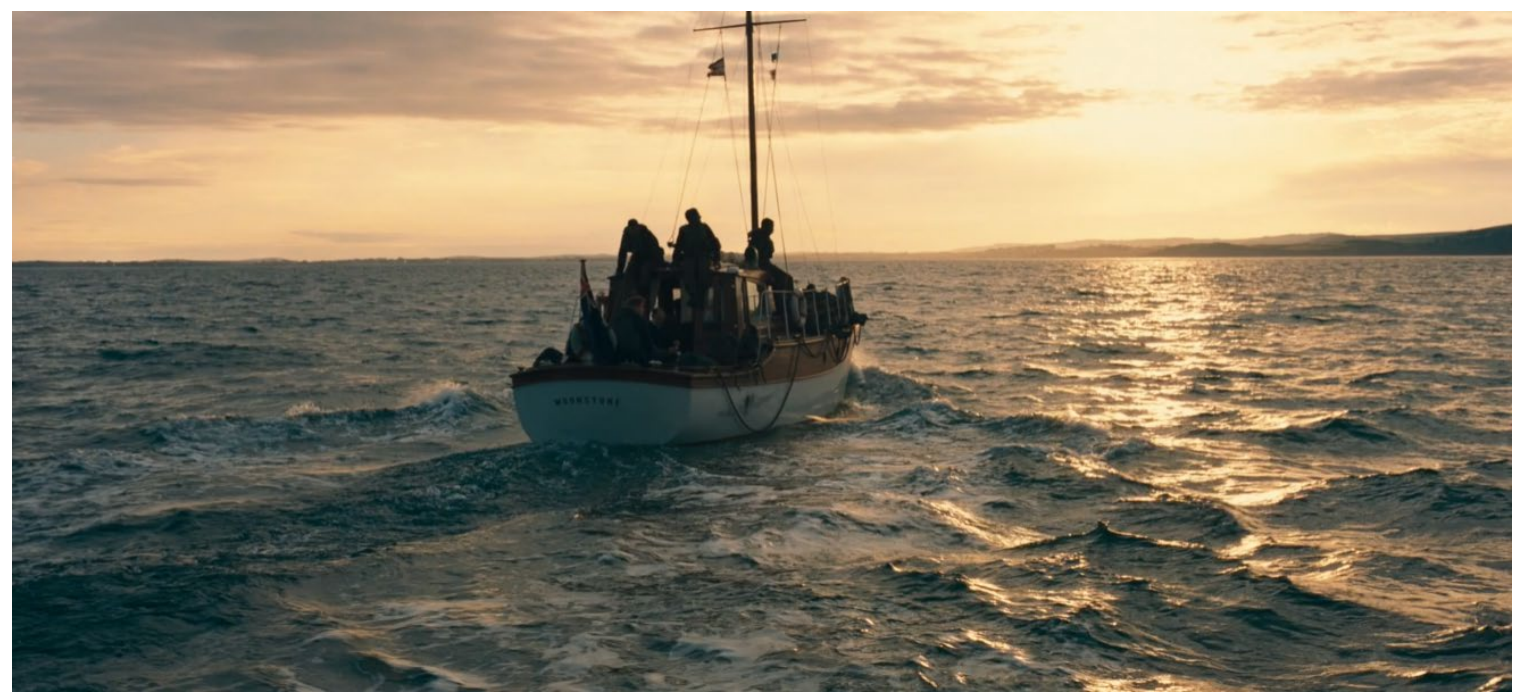

Figure 6-2: The Moonstone returning to Weymouth.

(Nolan \& Thomas, 2017). Screenshot by author.

\subsubsection{Plot Holes for Artistic Cinematography: Farrier's Landing}

A second major series of plot holes uncovered in the space-time cube regarding characters' paths was Farrier's arrival and landing at Dunkirk beach. After defending the evacuating British Expeditionary Force (BEF) over the English Channel for about 1.25 hours, Farrier arrives at Dunkirk beach in his plane out of gas (Figure 6-3). His estimated location of arrival is about 3.6 miles east of the mole, with the time being about 5:02pm CEST (4:02pm BST). Farrier then glides west along the beach, bypassing the mole below. Less than two minutes later, Farrier manages to turn his plane around and shoot down an enemy dive bomber about to bomb the mole. Farrier proceeds to glide east along Dunkirk beach until finally touching down on the sand at sunset. Given the time of sunset in this region, it was concluded that Farrier landed at about 8pm CEST (7pm BST). 
Farrier then lights his plane on fire and stays to watch it burn. Eventually, enemy soldiers close in and take him into custody as twilight falls, at about 9:58pm CEST (8:58pm BST) (Figure 6-4). This entire sequence of events presents a number of plot holes, none more glaring than the amount of time that Farrier remained in the air. From his arrival in Dunkirk to his landing, Farrier glided for nearly three hours, over twice as long as the amount of time he spent flying over the English Channel. Realistically, it is impossible that he could have stayed airborne that long. In addition, even though Farrier's landing was not filmed on location (and therefore challenging to place narratively), it is odd that he did not walk back west towards the Allied perimeter during the two-hour stretch of time between lighting his plane on fire and being captured. In fact, had Farrier done so, he likely would have been able to join the rest of the soldiers awaiting rescue, and return home to England (Nolan \& Thomas, 2017).

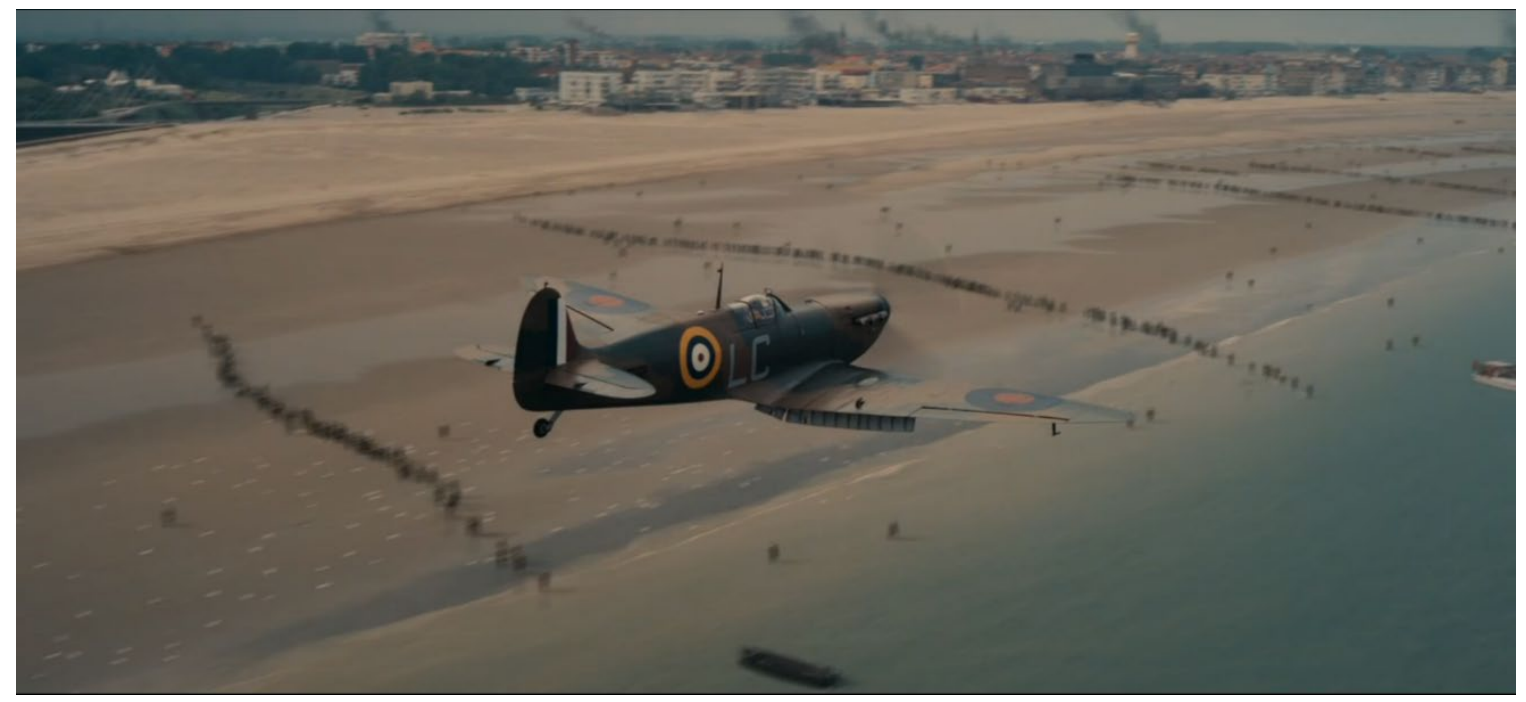

Figure 6-3: Farrier arrives at Dunkirk beach.

(Nolan \& Thomas, 2017). Screenshot by author.

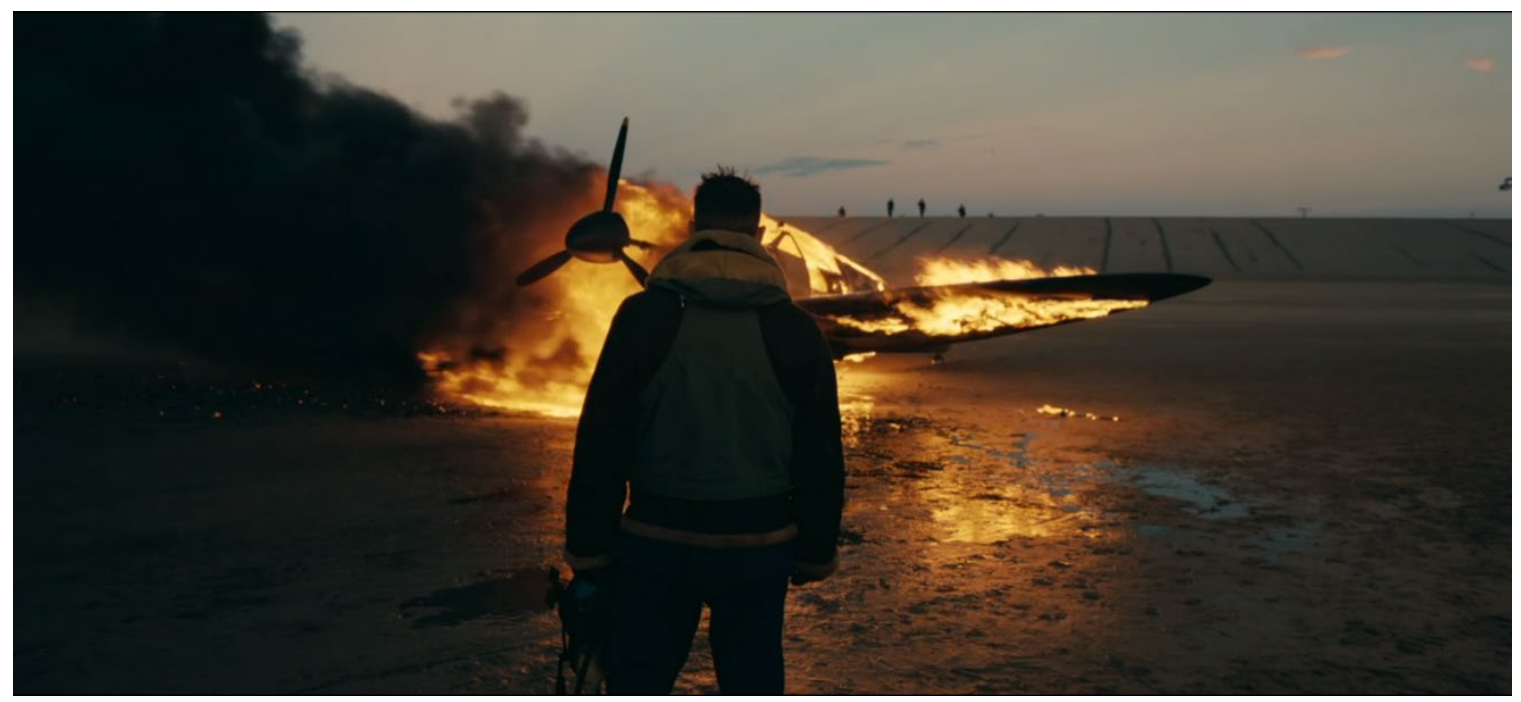

Figure 6-4: Farrier watches his Spitfire burn as enemy soldiers appear.

(Nolan \& Thomas, 2017). Screenshot by author. 
The translation of Dunkirk's fictional narrative into a space-time cube uncovered numerous spatial-temporal plot holes. However, the skillful cinematography of the film rendered these lapses in logic a non-issue in terms of the overall story. The space-time cube demonstrated that the return voyage of the Moonstone and Farrier's landing were impossible, but it was never the intent of the film to portray a literal interpretation of Operation Dynamo. Indeed, as film critic Joe Morgenstern writes, the crux of the story was the emotions experienced by its varied characters, the "terror, excruciating vulnerability and fragile hope that they will make it home" (Morgenstern, 2017). The above two sequences exemplify this idea perfectly. In the case of the Moonstone, as the enemy fighter plane bears down on the unarmed yacht carrying soldiers and civilians alike, a palpable sense of anxiety pervades the scene. In the next scene, however, soldiers gaze north towards the coast of their homeland as the sun paints them in hues of cathartic orange-gold. In the case of Farrier, running out of gas places him in a vulnerable position, one he ultimately does not escape from. As enemy soldiers surround him, the hope that Farrier will make it home quietly shatters as the last of the sun's rays vanish below the horizon. Despite their literal implausibility, these sequences proved insightful when examining Dunkirk through the lens of artistic cinematography.

\subsection{Limitations in Translation}

While the overall ability of 3D GIS to translate Dunkirk into a space-time cube was successful, there were several details from the film that were lost in translation due to multiple factors, including limitations in the GIS software and spatial-temporal uncertainty.

\subsubsection{Limits in Elevation}

The first of these lost details was elevation, which played a vital role in the paths of Royal Air Force (RAF) pilots Farrier and Collins as they take to the skies over the English Channel. Throughout the course of the film, the pilots climb and descend in elevation in order to avoid surprise enemy attacks and to initiate surprise attacks of their own. In addition, there are scenes in Dunkirk when characters occupy the same spatialtemporal location, but at different elevations. For example, early in the film, Gibson and Tommy hide themselves in the substructure of the mole at Dunkirk beach, hoping to sneak aboard the next departing ship (Figure 6-5). Directly above them on the deck of the mole, Colonel Winnant and Commander Bolton convene to discuss the evacuation of the BEF (Figure 6-6). In this scene, these four characters share the same X, Y, and Z data, but are separated by about 20 feet of elevation. 


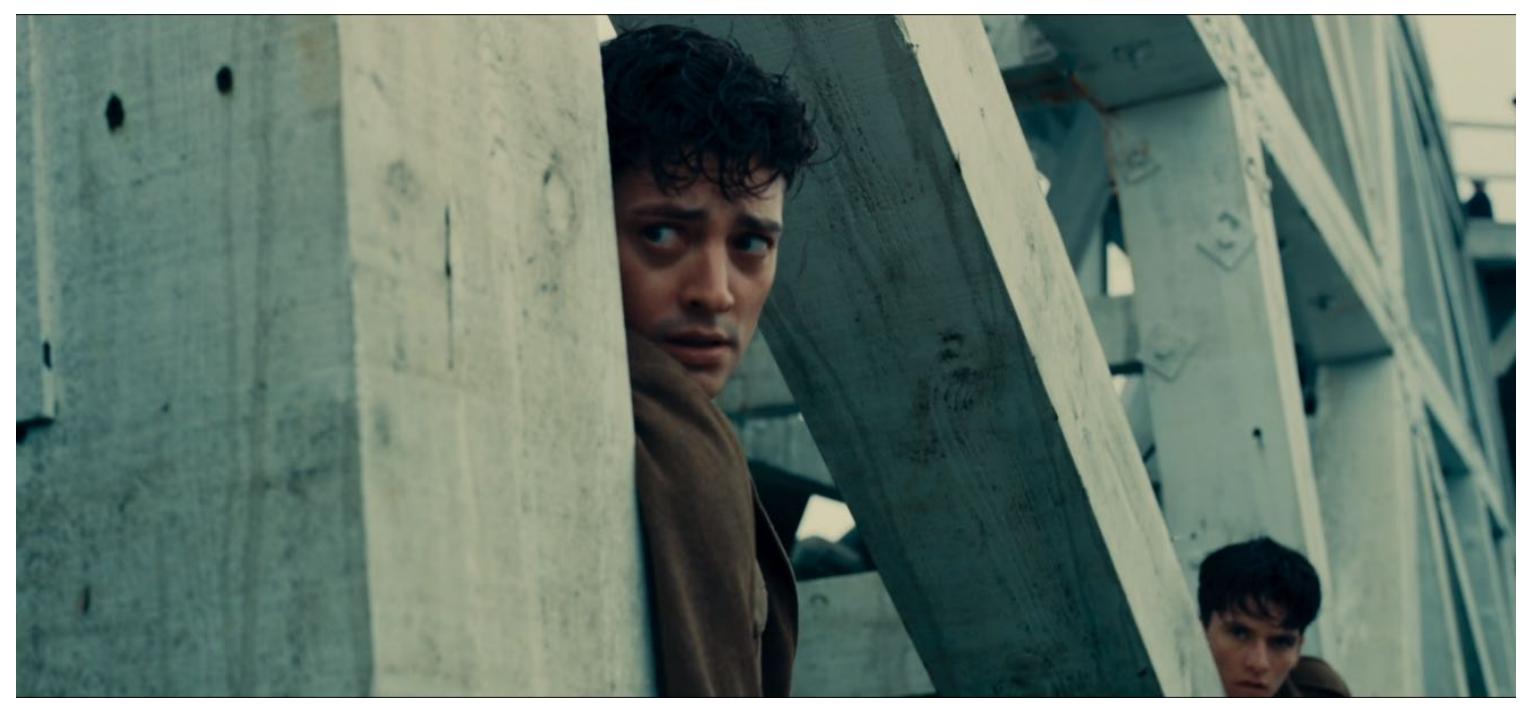

Figure 6-5: Gibson and Tommy in the substructure of the mole. (Nolan \& Thomas, 2017). Screenshot by author.

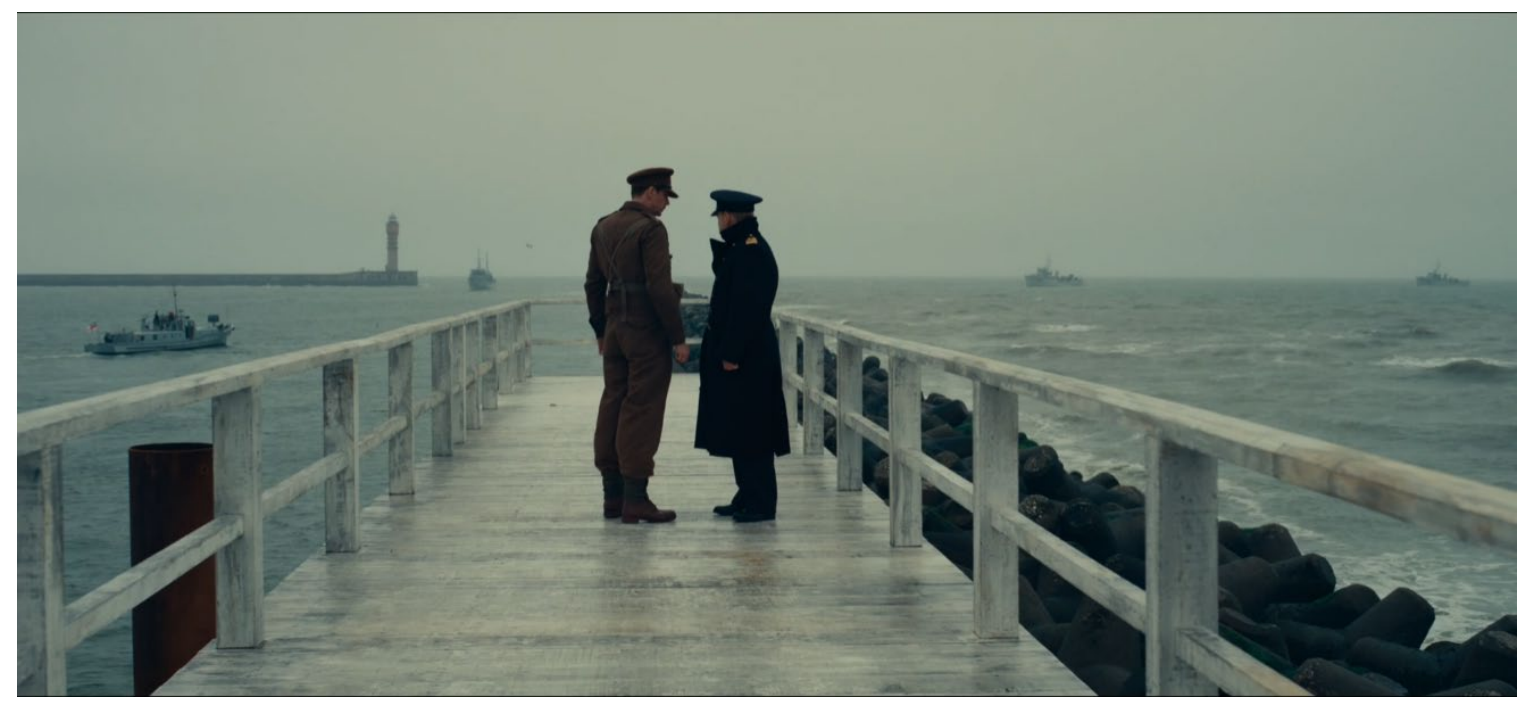

Figure 6-6: Colonel Winnant and Commander Bolton on the deck of the mole. (Nolan \& Thomas, 2017). Screenshot by author.

Because elevation was an important plot element in Dunkirk, it was added as the attribute ELEVATION FT in the project database. However, GIS software traditionally utilizes the vertical (Z) axis to map elevation data, such as for visualizing buildings or terrain. In this project, the $Z$ axis was used to map time data instead of elevation. Because the GIS was not capable of four-dimensional display, ELEVATION FT was not visually symbolized in the Dunkirk space-time cube. As a result, the differences in elevation between characters was collapsed; characters could only be distanced from each other by space and/or time. The pilots' changes in elevation could not be displayed, and characters both below- and above-deck at the mole appeared to all occupy the same location. To minimize this loss of information, ELEVATION FT was added as a detail in the pop-up windows for the eleven line feature classes representing characters' paths. However, due 
to limitations in ArcGIS Pro, visualization of characters' elevation data - and the narrative details associated therein — was sacrificed in favor of visualizing time.

\subsubsection{Limits in Granularity}

Another detail lost in translating Dunkirk into a space-time cube was the exact granularity of characters' paths, particularly in relation to the aircraft dogfights. Farrier and Collins engage numerous hostiles in the skies over the English Channel; each encounter is filled with sharp maneuvers in every vertical and horizontal direction. It was impossible to track these exact movements in the space-time cube for multiple reasons. Firstly, as previously mentioned, it is not possible to map changes in elevation simultaneously with changes time in on the $Z$ axis. Secondly, while in a dogfight, the pilots climb, descend, and change directions numerous times within the span of seconds. In order to map all these maneuvers in the space-time cube, every single turn, dive, and circle would require its own data entry in the project database. With very little time passing between each motion, individually mapping movements like these would inflate the data of the dogfight, resulting in even greater compaction of vertical space (see Chapter Five). The third reason for the loss in granularity was due to the lack of certainty in characters' spatial locations. Many scenes from Dunkirk were not shot on location (Mottram, 2017). As a result, the narrative location of these scenes, including the dogfights, were extrapolated in the space-time cube. Because it was challenging enough to estimate the spatial-temporal location of each dogfight, the additional granularity of every single tight maneuver was considered impractical to extrapolate as well, and was thus dropped from the space-time cube.

\subsubsection{Remaining Vertical Compaction}

Chapter Five provided a discussion regarding visual compaction between data points on the $\mathrm{Z}$ axis, as well as this project's method of addressing the compaction. Organizing the project database into five time sections and then resampling each section with a unique linear equation worked to expand vertical space throughout the cube, and was accepted as a solution to the issue of visual compaction. However, this method did not eliminate the occurrence of compaction completely; compacted data could still be found in certain areas of the cube.

While there are methods and tools for aggregating data in a space-time cube, these tools are meant for statistical analysis of quantitative data, making them inappropriate for this project. Because every point in the Dunkirk space-time cube represented a scene from the film, it was necessary that all scenes be present in the cube to generate a faithful translation. In addition, the remaining areas of compacted data were found to represent climactic action scenes near the end of the film. These action scenes were naturally compacted in the cube due to the artistic design of the film, which uses consecutively shorter amounts of real-world time between each scene to give audiences the illusion that time is speeding up. This in turn serves to increase emotions of peril and suspense in the story. While it was important to vertically expand these scenes as data points on the $\mathrm{Z}$ axis for the purpose of legibility, the remaining compaction reflects Dunkirk's climactic action, and serves as its own legitimate form of translation. 


\subsection{Benefits to the Client}

This project comes at an opportune time in the GIS industry. Over the past several years, Environmental Systems Research Institute (Esri) has elevated 3D requirements across platforms and has dedicated more of its teams towards expanding the capacity of 3D GIS. Nathan Shephard - the client for this project - manages one such team, whose job it is to design how users interact with time-aware data and to deliver software components that improve the strength and utility of ArcGIS Pro. According to Mr. Shephard, 3D cartography - and by extension, 3D GIS - "is an intoxicating mixture of science, art, and story-telling" with the "potential to explain any dataset in the world, to any audience in the world" (N. Shephard, personal communication, March 19, 2019).

This project contributes to all of these concepts. By providing a storyboarding tool that helps storytellers visualize their craft and avoid narrative, spatial, and temporal plot holes, the Dunkirk space-time cube expands the utility of 3D GIS beyond the field of geographic science and into digital humanities and the performing arts. The cube also grants a new level of spatial and temporal awareness to fictional narratives, and provides a new avenue for mapping qualitative data.

However, out of all of this project's information products, the one of most importance to Mr. Shephard was the project database. The database contained the complete narrative of Dunkirk translated from a non-chronological film into chronological spatial-temporal data, thus forming the genesis of the Dunkirk space-time cube in ArcGIS Pro and the web scene in ArcGIS Online. The design of the project database offers a synthesis of art and data, and seeks to benefit GIS, film, and any other products created from it. It is a key element for any future replication and/or advancement of this project, and can be readily customized into more complex workflows. 


\section{Chapter 7 - Conclusions and Future Work}

This project was an exploration into the use of 3-dimensional geographic information systems (GIS) as a storyboarding tool, specifically in the form of a space-time cube. The premise was, by providing an interactive mapping environment that inherently displays space and time, creators may be able to better visualize their stories and ultimately craft more cohesive narratives. As a proof of concept, this project created a space-time cube of Christopher Nolan's 2017 film Dunkirk to demonstrate the ability of space-time cubes to not only translate fictional narratives into a GIS, but to provide spatial-temporal clarity to complex story structures. Dunkirk was chosen due to its tripartite narrative, involving several characters scattered across different settings and time scales. Understanding the film's narrative requires tracking the characters' paths relative to one another through space-time, however this is made difficult due to the story's non-chronological composition. While there are no flashbacks or time travel in Dunkirk, precise cutting across timelines casts the illusion of concurrent narratives. In reality, each timeline starts and ends separately, usually converging at emotionally crucial moments. While the creative design of the film was not considered a "problem" in need of "correcting," this project's space-time cube was designed to interpret the Dunkirk narrative through the lens of a 3D GIS, where it could be re-visualized in chronological order for improved comprehension.

Translating Dunkirk into a space-time cube necessitated the extraction of narrative, spatial, and temporal data from the eleven main characters from each scene of the film. Where these data could not be discerned due to the fictional nature of the film, other resources, such as the officially-licensed The Making of Dunkirk book and research on World War II's Operation Dynamo were used to fill in the gaps. Data from these three sources were organized into attributes in a database, which was then imported into ArcGIS Pro to generate a geodatabase comprising of eleven 3D point and line feature classes, one for each character. These points and lines represented the plot events from Dunkirk and the path each character had to travel to reach each plot event in chronological order. Time in the space-time cube flowed upwards, such that the chronological beginning of the story was mapped at the bottom of the cube and the end of the story was mapped at the top.

Despite the imprecision inherent in mapping fictional data, all characters and scenes from the film were successfully located in space-time using a combination of contextual clues provided in-film, logical reasoning, historical research, and Equation $4.1(D=R$ * $T)$. However, to acknowledge the uncertainty in locating fictional data in real-world space-time, two certainty metrics were added to the database. The certainty metrics provided a grade for positioning each data entry in space-time, with an A grade indicating a high level of certainty and a $\mathrm{D}$ grade indicating a low level.

In the first variation of the Dunkirk space-time cube, certain areas of data demonstrated visual compaction along the vertical $(Z)$ axis. These areas usually represented fast-paced action sequences from the film, where very little real-world time was passing between data entries. As a result, there was little vertical space separating these data entries, making them difficult to differentiate and read. In order to artificially expand the vertical distance between compacted areas, the entire database was broken 
into five time sections. Each time section was bounded by a natural break in the narrative, usually a scene of falling action following a climax. A unique linear equation was then applied to each time section to resample the data into five sections of equal size, thus expanding the vertical distance between areas of data compaction.

The Dunkirk space-time cube then underwent preparations to be published to ArcGIS Online as a 3D web scene. Preparations included:

1. Reprojecting the data feature classes.

2. Changing the feature classes to display in real-world units.

3. Converting the line feature classes to multipatches.

4. Generating informational pop-up windows for the feature classes. Only the point feature classes were given pop-up windows with photo attachments.

5. Creating bookmarks in the space-time cube for conversion into slides in the web scene.

Finally, the completed Dunkirk space-time cube was published to ArcGIS Online using the Share as Web Scene function. The point feature classes were cached online to retain their photo attachments, while the multipatches were cached locally. As a web scene, the space-time cube demonstrated the potential for creative teams to share GIS storyboarding projects between teammates online without prior purchase and installation of the ArcGIS Pro desktop software.

\subsection{Conclusions}

This project met all of its functional requirements (listed in Chapter Three) to varying degrees of success. The first requirement stated that the project's space-time cube shall map the Dunkirk film narrative in chronological order, as it would have occurred in reality. To a certain extent, it was impossible to map the entirety of Dunkirk as the story would have happened in reality. As covered in Chapter Six, mapping the plot of the film revealed several plot holes in some characters' paths that could not be rectified within the bounds of reality. Despite the difficulty in translating a fictional narrative into real-world space-time, every scene was successfully attributed a real-life date, clock time, and relative seconds value that indicated exactly where the scene occurred chronologically.

The second requirement stated that the space-time cube shall account for the nonchronological narrative of Dunkirk, as this is how the plot is originally presented. The purpose of the cube was not to recreate the non-chronological narrative of the film, but to present a chronological interpretation. Therefore, to acknowledge the original order of plot events in Dunkirk, the project database included the beginning and ending runtimes of each scene in the form of the attributes FILM TIME FROM, FILM TIME TO, and FILM SECONDS. These runtimes indicated exactly where each scene is located in the DVD version of the film, and served as a contrast to attributes that indicated the chronological order of the scenes such as RELATIVE TIME FROM, RELATIVE TIME TO, and RELATIVE SECONDS. The runtimes were included in the informational popup windows in the space-time cube.

The third requirement stated that Dunkirk tells a tripartite narrative from the perspective of multiple characters. This narrative shall be translated into a space-time cube. This project successfully mapped the plot of Dunkirk from the perspectives of eleven characters scattered across space-time. Therefore, all three of the film's settings ("THE MOLE - one week," "THE SEA - one day," and "THE AIR - one hour") were 
represented in the space-time cube. Eleven point and line feature classes were generated in the project geodatabase to illustrate plot events and paths as experienced by each character. Basic 3D cartography and the GROUP CODE attribute were used to indicate additional character details, such as when people were travelling in groups and who was in those groups.

The fourth requirement stated that the space-time cube shall portray characters' methods of travel, as this plays an important part in the film's narrative. The completed space-time cube contained attributes detailing certain aspects of characters' methods of travel, such as DIRECTION, VEHICLE, ELEVATION FT and VELOCITY MPH. However, while the velocity of characters' travel paths is illustrated in the space-time cube by the slope of each line segment, the other attributes were more limited in their display. DIRECTION was illustrated using point rotation on a 0 - 359-degree scale, with 0 degrees indicating north (geographic rotation style). However, because the space-time cube used the default 3D symbols in ArcGIS Pro (spheres, diamonds, etc.) the exact rotation of each point was unclear. This would have been improved if VEHICLE had been symbolized with custom 3D models such as ships and planes, however using these models required finding and downloading them from third party websites. Due to limitations in scope, this project ultimately ran out of time to utilize custom 3D models, and therefore retained the default symbols. Lastly, as covered in Chapter Six, the spacetime cube could not symbolize elevation on the $\mathrm{Z}$ axis, as that axis was reserved for mapping time. ELEVATION FT was included as a detail in the pop-up windows to make up for this loss.

The fifth requirement stated that the space-time cube shall visually resemble the film upon which it is based. This requirement was most successfully fulfilled through the inclusion of 919 photo attachments in the pop-up windows for the point feature classes in the space-time cube. These photo attachments were generated by taking screen captures from Dunkirk, and served to relate each point to its corresponding scene in-film. However, additional features could have been added to the cube to enhance its resemblance to the film, such as 3D models of ships and planes that matched the vehicles in Dunkirk.

\subsection{Future Work}

In envisioning potential extensions to this project, possibilities fall into four main categories: non-fiction, fiction, movie-related, and movie-unrelated. Not all future work necessitates space-time cubes, however all involve some form of 3D GIS.

\subsubsection{Non-Fictional Space-Time Cubes}

Although this project focused on the capacity of space-time cubes to translate and map a fictional narrative, space-time cubes were originally proposed for mapping and analysis of both qualitative and quantitative aspects of non-fictional narratives. Based on methods employed in this project, the use of space-time cubes for non-fictional storytelling may be adapted for users beyond the GIS community, such as journalists, historians, and documentarians seeking to track stories through space-time. Likewise, space-time cubes may be utilized by scientists and conservationists to track the paths of wild animals, both individuals and populations. In addition, while studies such as Nakaya and Yano (2010) 
have demonstrated that space-time cubes may be adapted for spatial-temporal analysis of crime, this project posits using cubes for investigators to individually map specific criminal narratives, such as those of serial offenders.

Another possibility for non-fictional space-time cubes is the potential for visualization and analysis of movement strategy. Field and Shephard (2013) have demonstrated that space-time cubes can recreate historical military campaigns, however the question remains as to the aptitude of space-time cubes to analyze or predict military strategy. As exhibited by this project, a space-time cube can incorporate and display multiple attributes related to movement, such as vehicles and travel velocity. Given that: (1) space-time cubes can track narratives both finished and in-progress; (2) predictive GIS tools such as statistical trend and route analysis currently exist; (3) machine learning can be used to perform predictive analytics in GIS, how viable would it be to create a space-time cube that can analyze or anticipate military movement?

On a related note, a second option for predictive analysis in a space-time cube is sports strategy. Field (2016) has demonstrated that space-time cubes can capture the spatial-temporal pathways of a soccer match, however the next step would be to create a space-time cube that can analyze movement in sports and develop game strategy. As exemplified in Figure 7-1, organizations such as the South Africa national union rugby team are already incorporating machine learning as a tool to enhance training and player strategy (Microsoft, 2019). It would be interesting to see if this kind of analysis is possible in a space-time cube, or if space-time cubes can be adapted for use with current machine learning analytics.

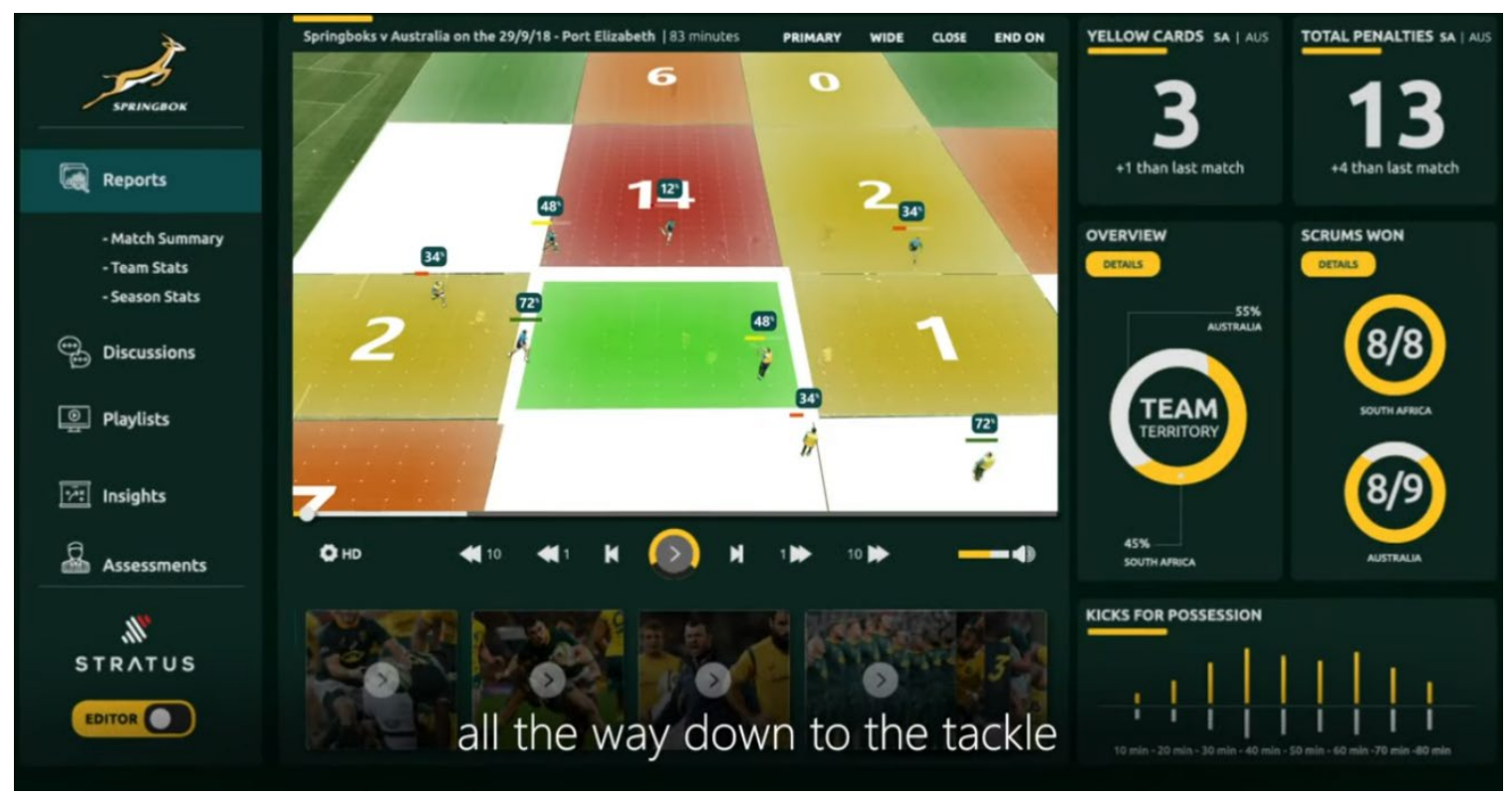

Figure 7-1: Machine learning with the South Africa national union rugby team. (Microsoft, 2019).

\subsubsection{Fictional Space-Time Cubes}

This project was merely a proof of concept for designing a fictional narrative in a spacetime cube by translating a pre-existing story. The logical evolution of this project would 
be to storyboard an entirely new narrative using space-time cubes in anticipation for final delivery in a number of media, such as film, television, and video games. While this is most feasible for stories that take place entirely on a realistic portrayal of Earth, there remains the question of whether a space-time cube is appropriate for stories unbound by Earth's geography or a standard measurement of time. Given the infinite breadth of fiction, there are certainly stories in which the exact relative distance between plot locations is either unimportant to the story or impossible to map in a GIS, both spatially and temporally. (For instance, in Star Wars, does it matter where Tatooine is relative to Coruscant? Or how long it takes to travel there at faster-than-light speed?) (Lucas \& McCallum, 1999).

Because GIS is designed to map reality, it would be an interesting challenge to see a space-time cube used to storyboard a completely fantastical narrative. The first step would likely be to create a 2D basemap of the new universe, from which a space-time cube could be built. As an example, by using the map of Tolkien's Middle Earth as a basemap, one could potentially create a space-time cube of The Lord of the Rings trilogy. Ultimately, the purpose of a space-time cube as a storyboarding tool is to help creators visualize their stories in space-time so that they can avoid narrative plot holes. The exact precision and granularity of the narrative in the cube is up to the creator.

\subsubsection{Beyond Space-Time Cubes: The Potential of 3D GIS}

Space-time cubes are only one avenue to incorporate 3D GIS in filmmaking. Currently, Esri's CityEngine software has been used to model 3D urban environments in films and video games ("Esri Releases New Version of CityEngine," 2011). Future projects could delve into the potential of CityEngine to design additional elements of filmmaking, such as finding filming locations and the ideal placement of equipment such as cameras and lights. Another option might be exploring the potential of CityEngine to previsualize film or video game action scenes in an urban environment, especially chase sequences.

In addition to CityEngine, recent developments in ArcGIS Pro 2.4 have enhanced the software's potential to engage in filmmaking processes. Some of these enhancements include determining hot spots for filming locations as well as generating calendar heat charts to help schedule filming dates. 3D enhancements include the ability to add ambient occlusion in a scene, customize building models, animate water surfaces, and perform camera viewshed analysis (Esri Events, 2019). With these new functionalities, coupled with pre-existing tools in ArcGIS Pro such as time-aware animation, future work needs only to put it all together and actually make a movie. 


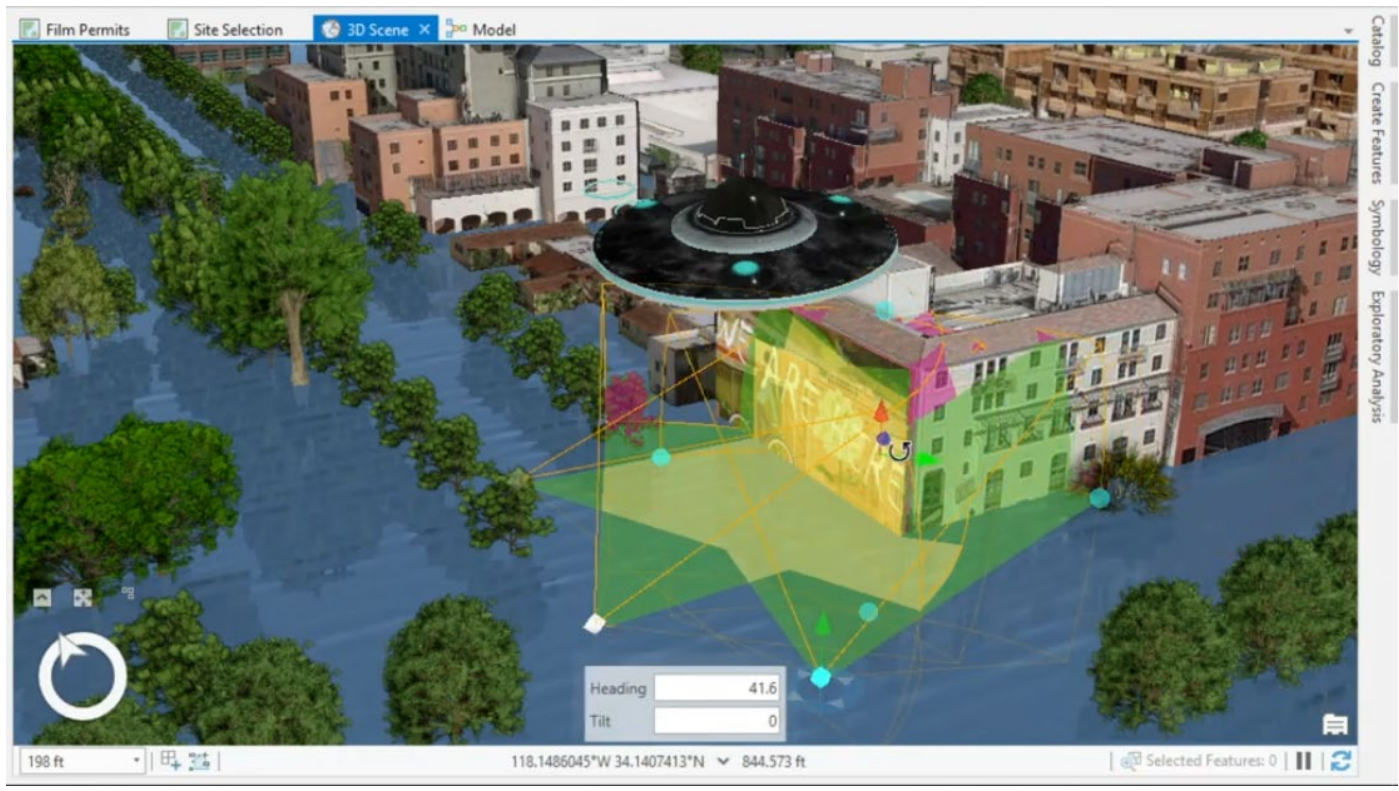

Figure 7-2: New filmmaking functionalities in ArcGIS Pro.

(Esri Events, 2019). 


\section{Works Cited}

Berman, E. (2017). Christopher Nolan's Great War. Time, 190(5), 53-55. Retrieved November 6, 2018.

DeGraff, A. (2017) Paths of Amity [Digital art]. Retrieved from http://www.andrewdegraff.com/moviemaps\#/jaws/

DeGraff, A., \& Jameson, A. D. (2017). Cinemaps: An atlas of great movies. Philadelphia: Quirk Books.

Edelstein, D. (Writer). (2017). 'Dunkirk' is harrowing war movie muddled by a convoluted timeline [Transcript, Radio series episode]. In Fresh Air. NPR. Retrieved November 16, 2018, from https://www.npr.org/2017/07/21/538528192/dunkirk-is-a-harrowing-war-movie muddled-by-a-convoluted-timeline

Esri. (n.d.). Multipatches [Software help page]. Retrieved from https://desktop.arcgis.com/en/arcmap/latest/extensions/3d-analyst/multipatches.htm

Esri. (n.d.). Units and symbol size [Software help page]. Retrieved from https://pro.arcgis.com/en/pro-app/help/mapping/layer-properties/units-and-symbolsize.htm

Esri Events. (2019, June 8). ArcGIS Pro 2.4 [Video file]. Retrieved from https:/www.youtube.com/watch?v=EbhWxBmOOxE\&list=PLaPDDLTCmy4bC2d GacC3ZH8YnCl4x7kuB\&index $=13 \& \mathrm{t}=0 \mathrm{~s}$

Esri releases new version of CityEngine; Esri CityEngine 2011 makes it easier to create 3D models from 2D GIS data. (2011). PR Newswire. Retrieved February 2, 2019 from LexisNexis.

Field, K. (2016). They think it's all over... it is now! Retrieved October 21, 2019 from http://carto.maps.arcgis.com/apps/webappviewer3d/index.html?id=2a9802b281dd4 d30a69d9fc188a5a177

Field, K., \& Shephard, N. (2013). Napoleon's march to Moscow. Retrieved from https://www.esri.com/en-us/maps-we-love/gallery/napoleons-march

Goodchild, M. F. (2013). Prospects for a space-time GIS. Annals of the Association of American Geographers, 103(5), 1072-1077. doi: 10.1080/00045608.2013.792175

Gordon, M. S. (2016). Dunkirk [Movie still]. 2016 Warner Bros. Entertainment Inc., Ratpac-Dune Entertainment, LLC, and Ratpac Entertainment, LLC. Retrieved February 4, 2019 from

https://www.imdb.com/title/tt5013056/mediaviewer/rm3482857216

Hägerstrand, T. (1970). What about people in regional science? Ninth European Congress of the Regional Science Association. 24(1), 7-21. doi: 10.1111/j.14355597.1970.tb01464.x

Kang, Y., Cho, N., \& Son, S. (2018). Spatiotemporal characteristics of elderly population's traffic accidents in Seoul using space-time cube and space-time kernel density estimation. Plos One, 13(5), 1-17.

doi:10.1371/journal.pone.0196845

Kraak, M. (2003). The space-time cube revisited from a geovisualization perspective. Proceedings of the $21^{\text {st }}$ International Cartographic Conference (ICC) (pp. 19881996). Duban, South Africa: The International Cartographic Association (ICA).

Kraak, M., \& Kveladze, I. (2017). Narrative of the annotated space-time cube - 
revisiting a historical event. Journal of Maps, 13(1), 56-61, doi:

$10.1080 / 17445647.2017 .1323034$

Kwan, M.-P. (2004). GIS methods in time-geographic research: Geocomputation and geovisualization of human activity patterns. Geografiska Annaler: Series B, Human Geography, 86(4), 267-280., doi:10.1111/j.0435-3684.2004.00167.x

Kwan, M.-P., \& Ding, G. (2008). Geo-narrative: Extending geographic information systems for narrative analysis in qualitative and mixed-method research. The Professional Geographer, 60(4), 443-465. doi:10.1080/00330120802211752

Kwan, M.-P., \& Ren, F. (2008). Analysis of human space-time behavior: Geovisualization and geocomputational approaches [PDF file]. Retrieved from https://www.researchgate.net/publication/261871322_Analysis_of_human_spacetime_behavior_Geovisualization_and_geocomputational_approaches. (Originally uploaded September 26, 2015).

Lucas, G. (Director), \& McCallum, R. (1999). Star Wars: Episode I- The Phantom Menace [Motion picture]. USA: 20th Century Fox.

Microsoft. (2019, September 18). SARU tackling the future of rugby | Microsoft In Culture [Video file]. Retrieved November 8, 2019 from https://www.youtube.com/watch? $\mathrm{v}=$ nq8YV-ao-RE

Morgenstern, J. (2017). Life \& arts - film review: 'Dunkirk': Finding humanity in calamity. Wall Street Journal. pp. A.11. Retrieved November 6, 2018, from http://ezproxy.redlands.edu/docview/1920206800?accountid=14729

Mottram, J. (2017). The Making of Dunkirk. San Rafael, CA: Insight Editions.

Nakaya, T. (2013) Analytical data transformations in space-time region: Three stories of space-time cube. Annals of the Association of American Geographers, 103(5), 1100-1106, doi:10.1080/00045608.2013.792184

Nakaya, T., \& Yano, K. (2010). Visualising crime clusters in a space-time cube: An exploratory data-analysis approach using space-time kernel density estimation and scan statistics. Transactions in GIS, 14(3), 223-239, doi: 10.1111/j.14679671.2010.01194.x

Newsom, S. (2017). Dunkirk; You've seen the film, now see where it all happened. Sean Newsom gets to the heart of Operation Dynamo. The Sunday Times, p. 13. Retrieved from Nexis Uni.

Nolan, C. (Director/Producer), \& Thomas, E. (Producer). (2016). Dunkirk [Movie poster]. 2016 Warner Bros. Entertainment Inc., Ratpac-Dune Entertainment, LLC, and Ratpac Entertainment, LLC. Retrieved February 4, 2019 from https://www.imdb.com/title/tt5013056/mediaviewer/rm1769746176

Nolan, C. (Director/Producer), \& Thomas, E. (Producer). (2017). Dunkirk [Motion picture]. United Kingdom: Warner Bros. Pictures.

Shephard, N. [Nathan]. (n.d.). Posts [LinkedIn page]. Retrieved November 8, 2018 from https://www.linkedin.com/in/nathan-shephard-0622912a 


\section{Appendix A. Location and Time Certainty}

As covered in Chapter Four, one of the main challenges of this project was appointing real-world space-time data to fictional scenes from Dunkirk, many of which were not filmed on location (Mottram, 2017). By extracting information from a combination of infilm content and outside research, each film scene was assigned a location in space (in easting and northing) as well as a location in time (including date and time of day). Infilm content used to locate scenes included character dialogue, a watch, the tides at Dunkirk, and dates in newspapers, and - to a limited extent - natural sunlight. Outside research used to locate scenes included the official-licensed The Making of Dunkirk book (Mottram, 2017), historical research regarding Operation Dynamo, and Equation 4.1 ( $D$ $=R * T)$.

For every data entry located in space and time, two metrics were included to indicate the level of certainty of translating fictional information into real-world data. The first metric was a measurement of certainty in placing characters in space, and the second metric was the same for time. Named as the attributes LOCATION CERTAINTY and TIME CERTAINTY in the project database, both metrics offered a grading scheme ranging from A to D. An " $A$ " grade indicated the highest level of certainty in locating scenes, and a "D" grade indicated the lowest. The two metrics were largely independent; a grade in one metric did not necessarily determine a grade in the other. Tables 9 through 12, together with Figures A-1 through A-4, offer a breakdown of LOCATION CERTAINTY. Tables 13 through 16, with and Figures A-5 through A-8, provide the same for TIME CERTAINTY.

Table 9. LOCATION CERTAINTY: Grade A

\begin{tabular}{|c|c|l|l|}
\hline Grade & \multicolumn{1}{|c|}{ Certainty } & \multicolumn{1}{c|}{ Description } & \multicolumn{1}{c|}{ Example } \\
\hline A & Very certain & $\begin{array}{l}\text { Scene was filmed } \\
\text { on location; } \\
\text { location was } \\
\text { identified in reality }\end{array}$ & $\begin{array}{l}\text { George's location was explicitly } \\
\text { identified as Custom House Quay } \\
\text { in Weymouth, England. The } \\
\text { intersection with South Parade is } \\
\text { visible behind him, to the } \\
\text { audience's right. }\end{array}$ \\
\hline
\end{tabular}




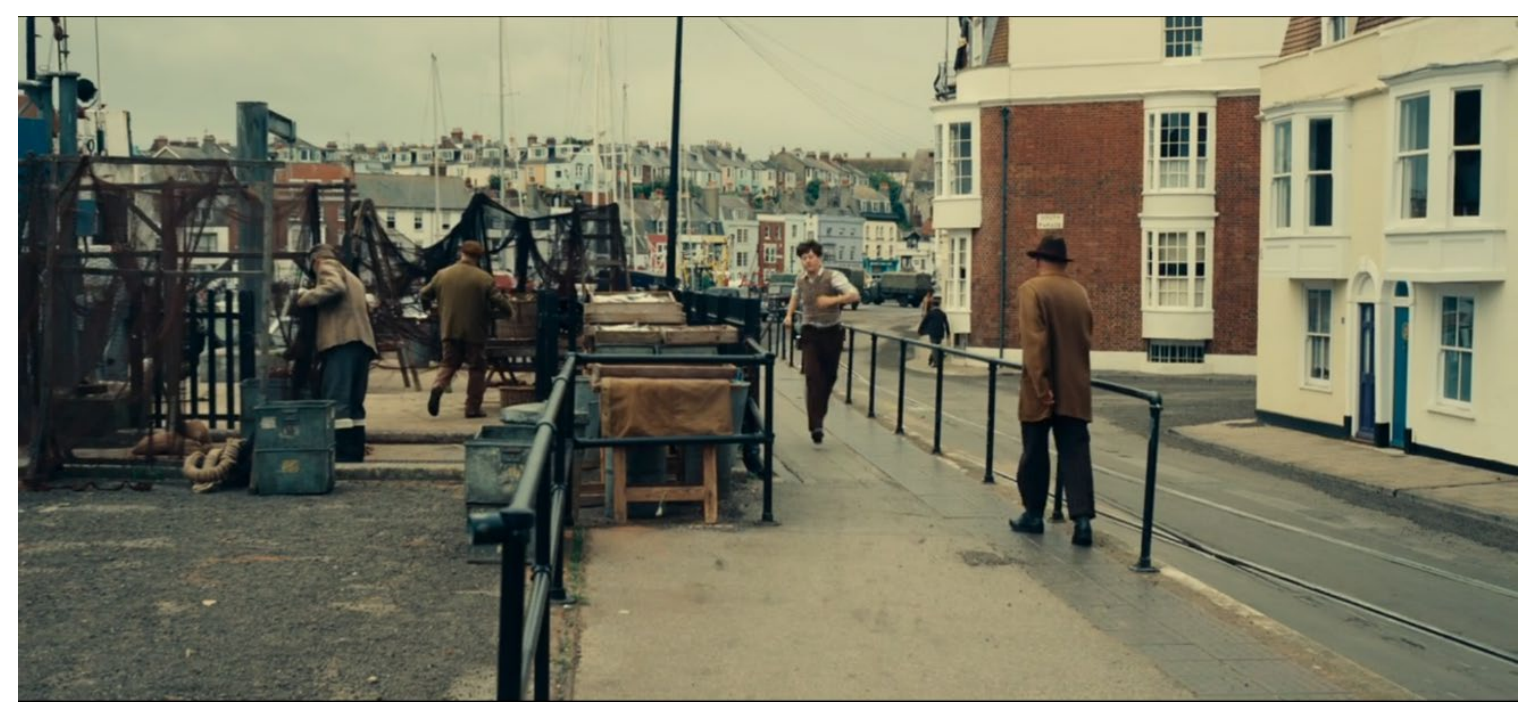

A-1: George in Weymouth, England. (Nolan \& Thomas, 2017). Screenshot by author.

Table 10. LOCATION CERTAINTY: Grade B

\begin{tabular}{|c|c|l|l|}
\hline Grade & Certainty & \multicolumn{1}{c|}{ Description } & \multicolumn{1}{c|}{ Example } \\
\hline B & Certain & $\begin{array}{l}\text { Scene was filmed } \\
\text { near location; } \\
\text { location was } \\
\text { estimated in reality }\end{array}$ & $\begin{array}{l}\text { Farrier marks a vague location on } \\
\text { his map, stating that he is about } \\
\text { five minutes from Dunkirk. The } \\
\text { scene was not filmed on location. }\end{array}$ \\
\hline
\end{tabular}

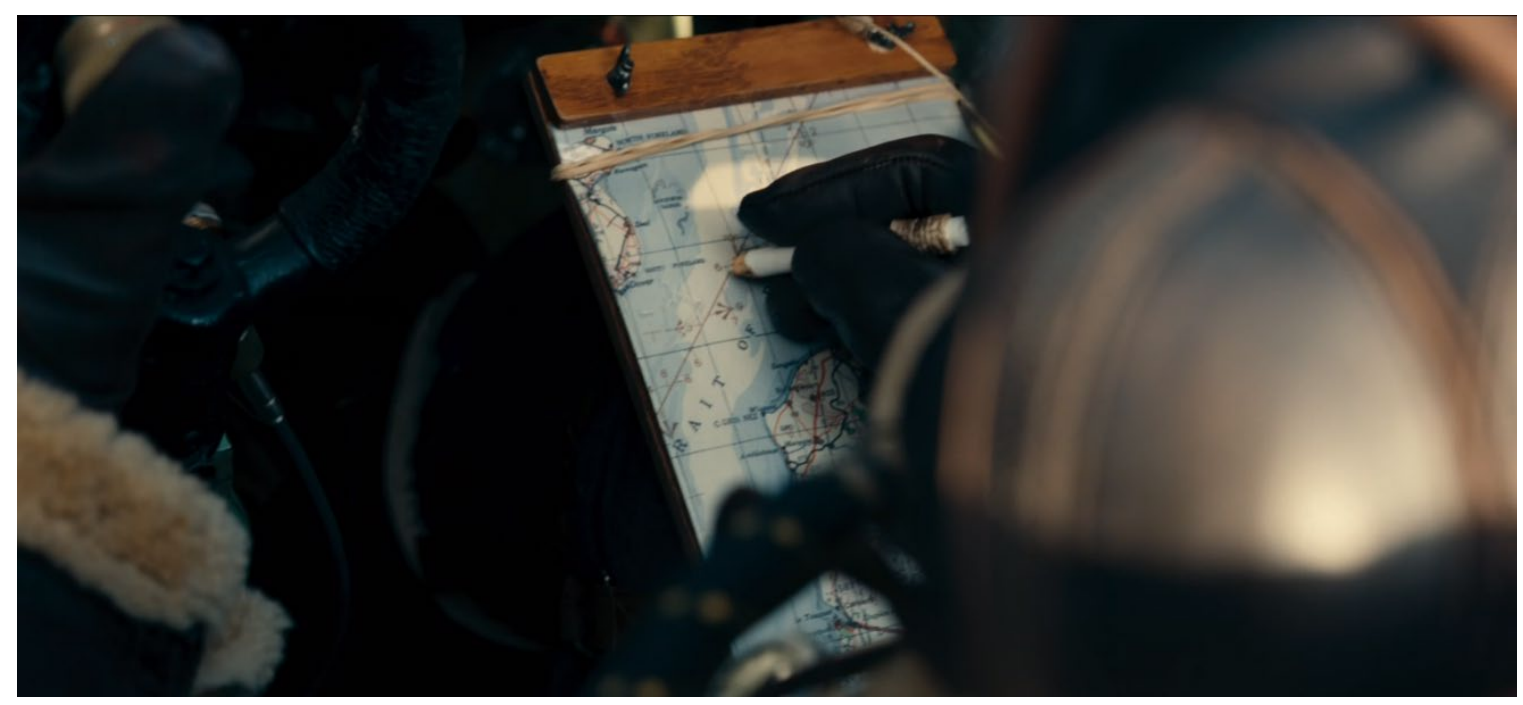

A-2: Farrier's map at five minutes to Dunkirk. (Nolan \& Thomas, 2017). Screenshot by author. 
Table 11. LOCATION CERTAINTY: Grade C

\begin{tabular}{|c|l|l|l|}
\hline Grade & Certainty & \multicolumn{1}{c|}{ Description } & \multicolumn{1}{c|}{ Example } \\
\hline C & Uncertain & $\begin{array}{l}\text { Scene may be } \\
\text { filmed near } \\
\text { location; location in }\end{array}$ & $\begin{array}{l}\text { A group of Highlanders walk } \\
\text { towards a beached trawler, the }\end{array}$ \\
& & $\begin{array}{l}\text { Fire of Saint-Pol lighthouse } \\
\text { visible in the distance. This scene } \\
\text { reality was } \\
\text { estimated with } \\
\text { concessions made }\end{array}$ & $\begin{array}{l}\text { is 3 miles east of Dunkirk beach, } \\
\text { its supposed narrative location. }\end{array}$ \\
\hline
\end{tabular}

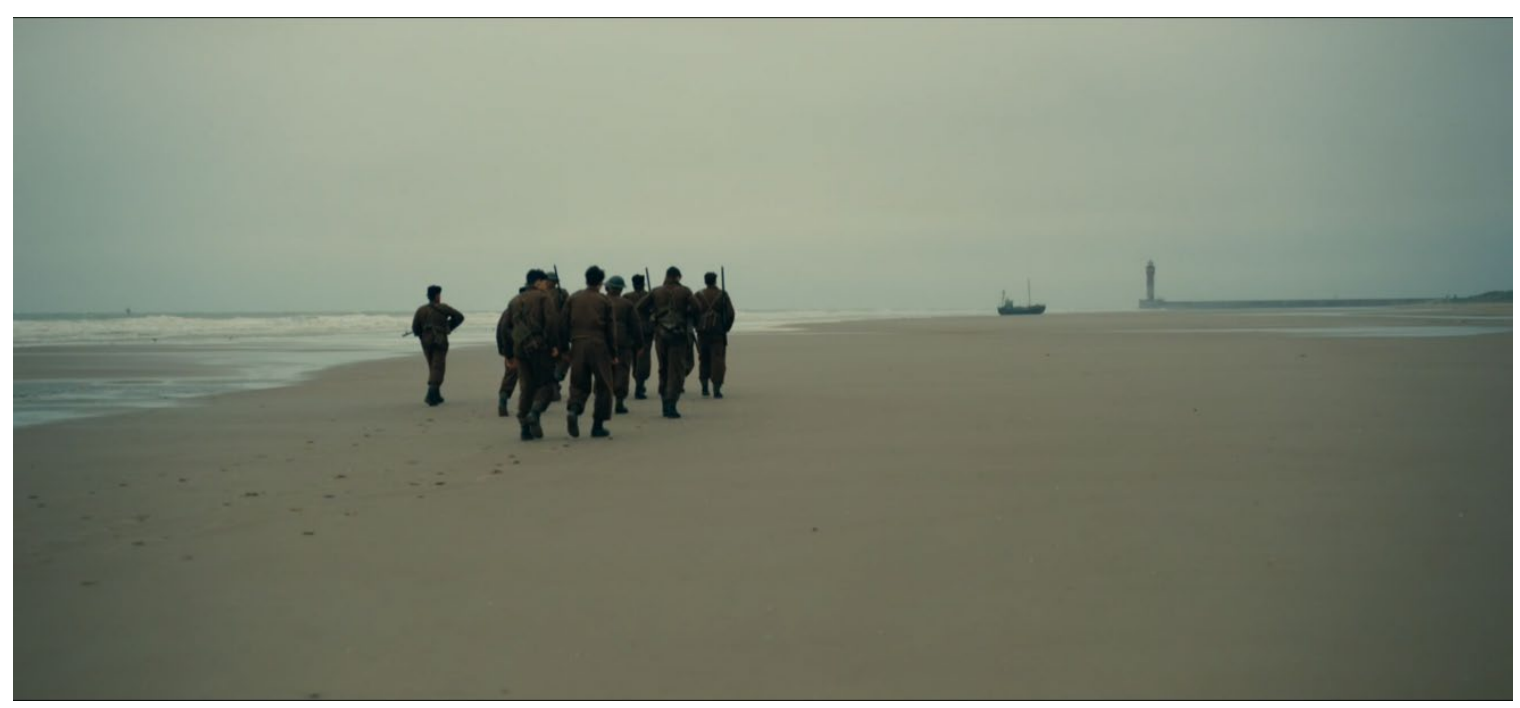

A-3: Highlanders make their way towards a beached trawler.

(Nolan \& Thomas, 2017). Screenshot by author.

Table 12. LOCATION CERTAINTY: Grade D

\begin{tabular}{|c|c|l|l|}
\hline Grade & Certainty & \multicolumn{1}{c|}{ Description } & \multicolumn{1}{c|}{ Example } \\
\hline D & $\begin{array}{c}\text { Very } \\
\text { uncertain }\end{array}$ & $\begin{array}{l}\text { Scene was not } \\
\text { filmed on location; } \\
\text { location in reality } \\
\text { was estimated with } \\
\text { concessions made }\end{array}$ & $\begin{array}{l}\text { Collins is trapped in his sinking } \\
\text { Spitfire, supposedly somewhere } \\
\text { in the English Channel. This } \\
\text { scene was actually filmed at Falls } \\
\text { Lake in Universal Studios, } \\
\text { Hollywood (Mottram, 2017). }\end{array}$ \\
\hline
\end{tabular}




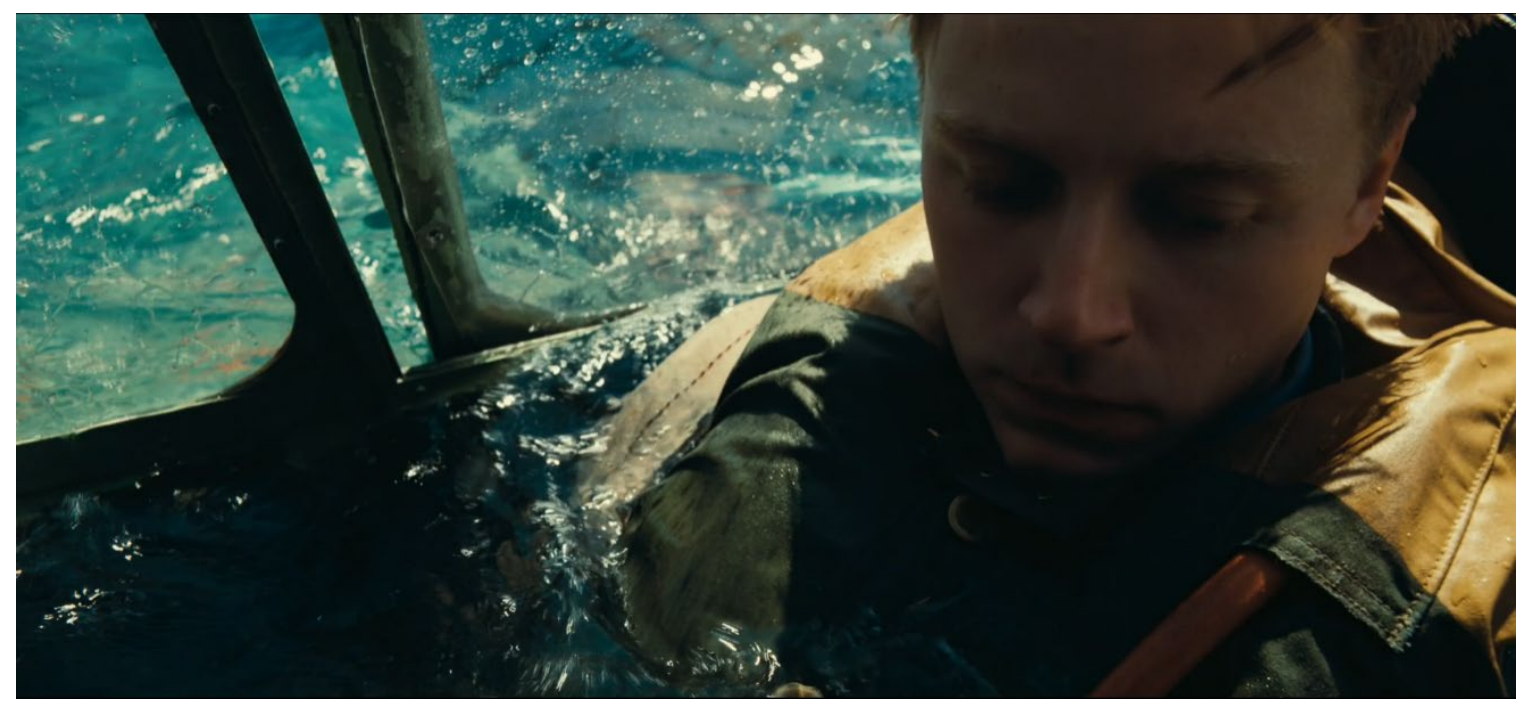

A-4: Collins trapped in his sinking Spitfire.

(Nolan \& Thomas, 2017). Screenshot by author.

Table 13. TIME CERTAINTY: Grade A

\begin{tabular}{|c|l|l|l|}
\hline Grade & Certainty & \multicolumn{1}{|c|}{ Description } & \multicolumn{1}{c|}{ Example } \\
\hline A & Very certain & Time was explicitly & Farrier consults his watch. It is \\
& & shown in-film & 2:59pm British Summer Time \\
& & & (BST), aka 3:59 Central European \\
& & & Summer Time (CEST) on June 4, \\
& & & 1940. \\
\hline
\end{tabular}

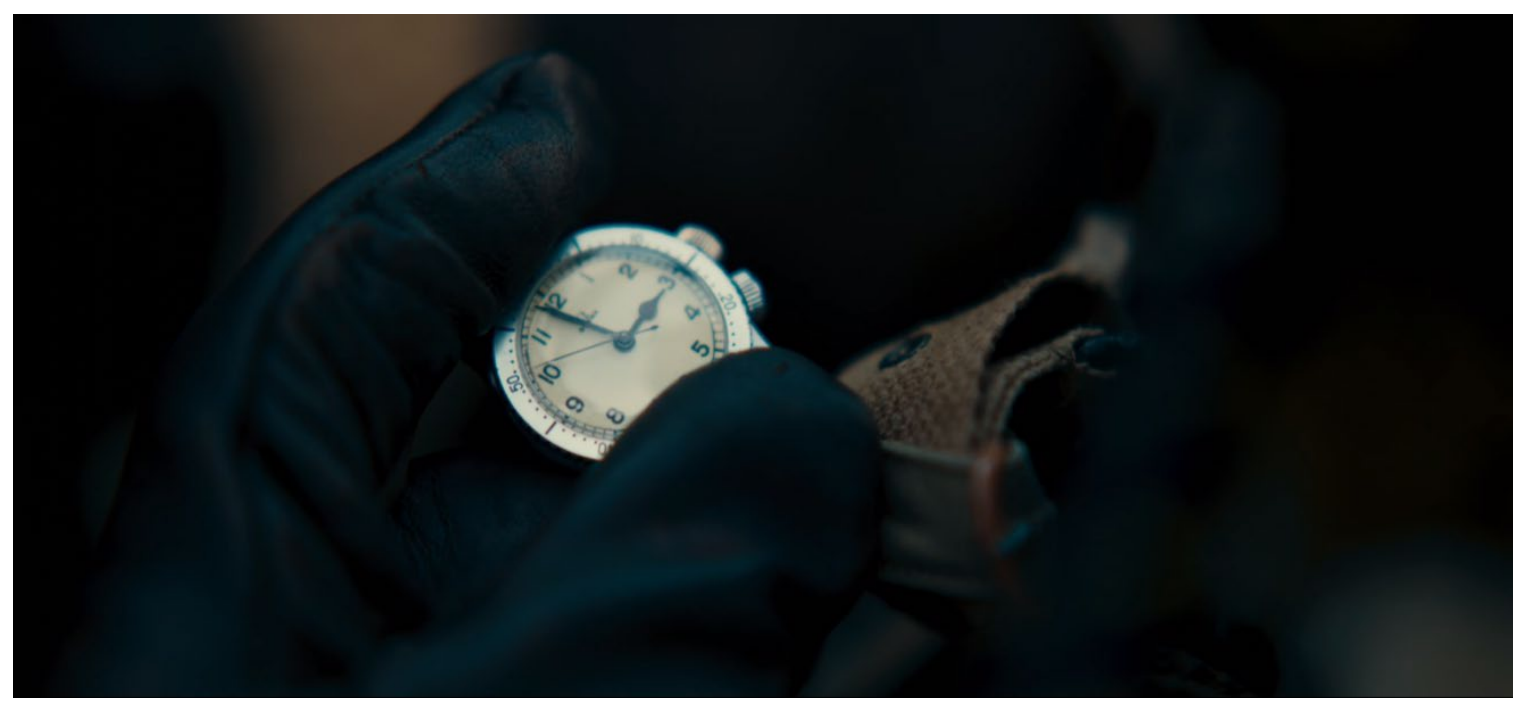

A-5: Farrier's watch at 2:59pm BST. (Nolan \& Thomas, 2017). Screenshot by author. 
Table 14. TIME CERTAINTY: Grade B

\begin{tabular}{|c|l|l|l|}
\hline Grade & Certainty & \multicolumn{1}{c|}{ Description } & \multicolumn{1}{c|}{ Example } \\
\hline B & Certain & $\begin{array}{l}\text { Scene was filmed } \\
\text { on location at } \\
\text { logically correct } \\
\text { timeframe }\end{array}$ & $\begin{array}{l}\text { A rowboat of soldiers returns to } \\
\text { Dunkirk beach at daybreak. Date/ } \\
\text { time is estimated to be June 4, } \\
\end{array}$ \\
& & $\begin{array}{l}\text { 1940 at 5:29am CEST (4:29am } \\
\text { BST). }\end{array}$ \\
\hline
\end{tabular}

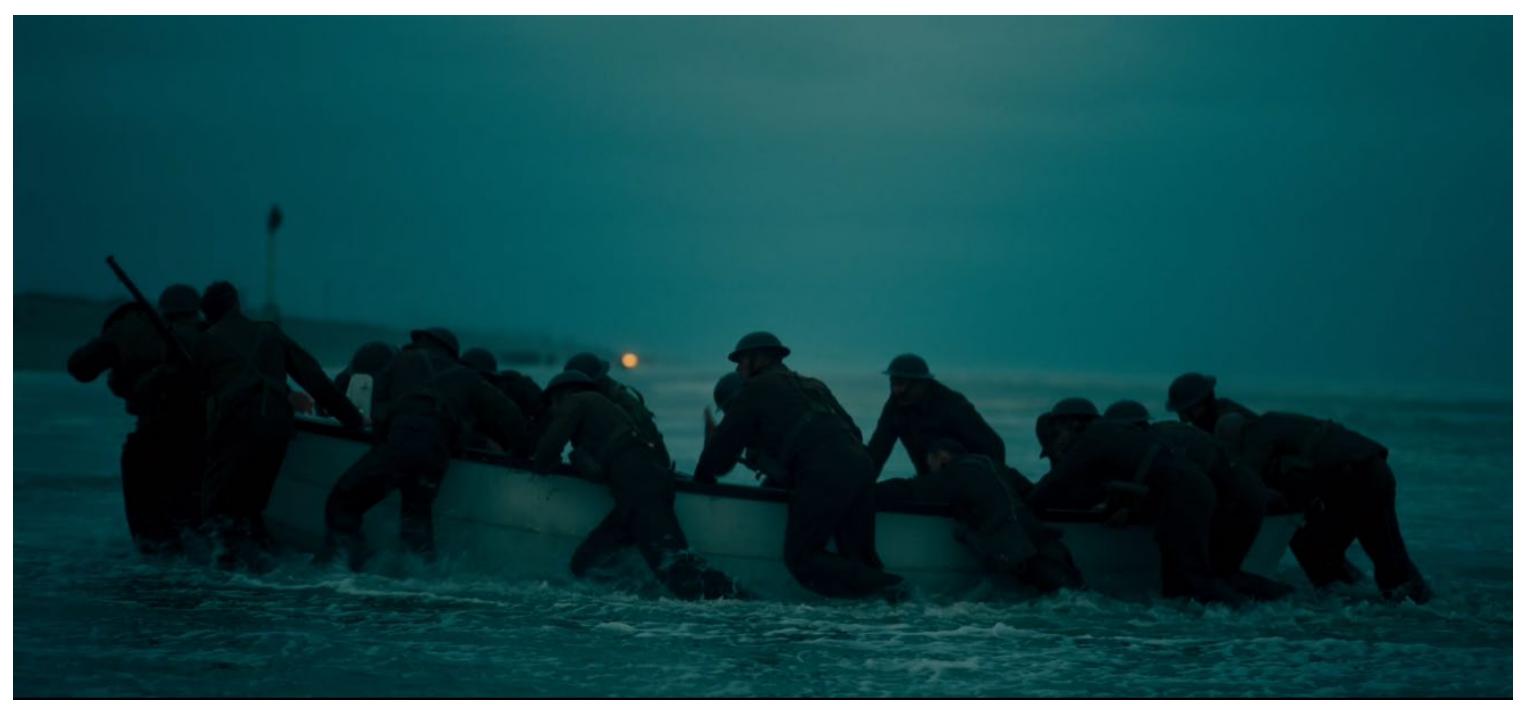

A-6: Soldiers returning to Dunkirk at daybreak.

(Nolan \& Thomas, 2017). Screenshot by author.

Table 15. TIME CERTAINTY: Grade C

\begin{tabular}{|c|c|c|c|}
\hline Grade & Certainty & Description & Example \\
\hline $\mathrm{C}$ & Uncertain & $\begin{array}{l}\text { Scene may be } \\
\text { filmed on location } \\
\text { or at logically } \\
\text { correct timeframe; } \\
\text { time estimated }\end{array}$ & $\begin{array}{l}\text { The Moonstone passes an Allied } \\
\text { destroyer likely sailing to } \\
\text { Portsmouth, England. Assuming } \\
\text { the yacht traveled } 140 \text { miles from } \\
\text { Weymouth at a velocity of } 20 \mathrm{mph} \\
\text { (17.4 knots), date/time is } \\
\text { estimated to by June } 4,1940 \text { at } \\
2: 01 \text { pm BST ( } 3: 01 \text { CEST). }\end{array}$ \\
\hline
\end{tabular}




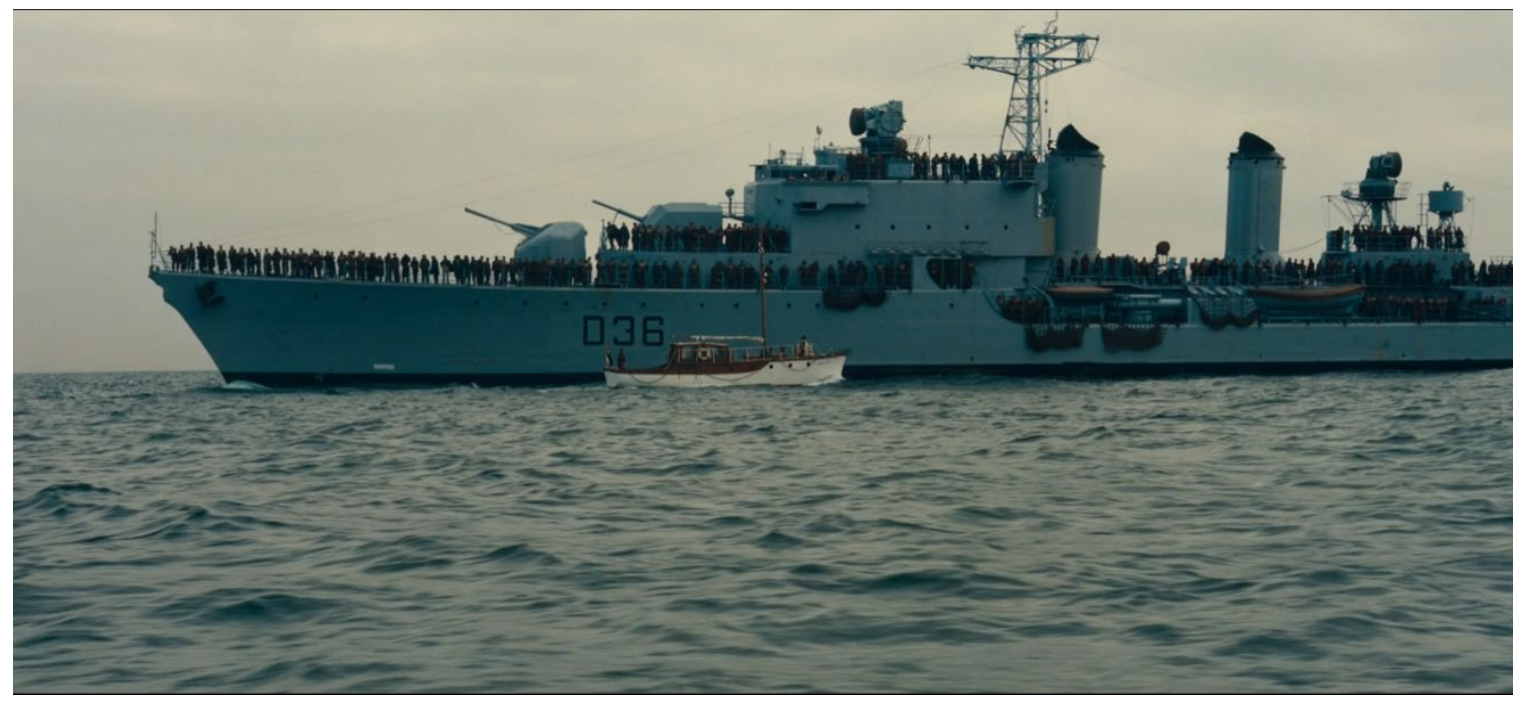

A-7: The Moonstone passes an Allied destroyer.

(Nolan \& Thomas, 2017). Screenshot by author.

Table 16. TIME CERTAINTY: Grade D

\begin{tabular}{|c|l|l|l|}
\hline Grade & Certainty & \multicolumn{1}{|c|}{ Description } & \multicolumn{1}{c|}{ Example } \\
\hline D & Very & Time in-film does & Following its improbable voyage \\
& uncertain & not make logical & back to Weymouth (see Chapter \\
& & sense in reality; & Five), the Moonstone docks back \\
& & time in reality & at Custom House Quay at \\
& & estimated with & 11:40pm BST (12:40am CEST) \\
& & concessions made & on June 4/5, 1940. \\
\hline
\end{tabular}

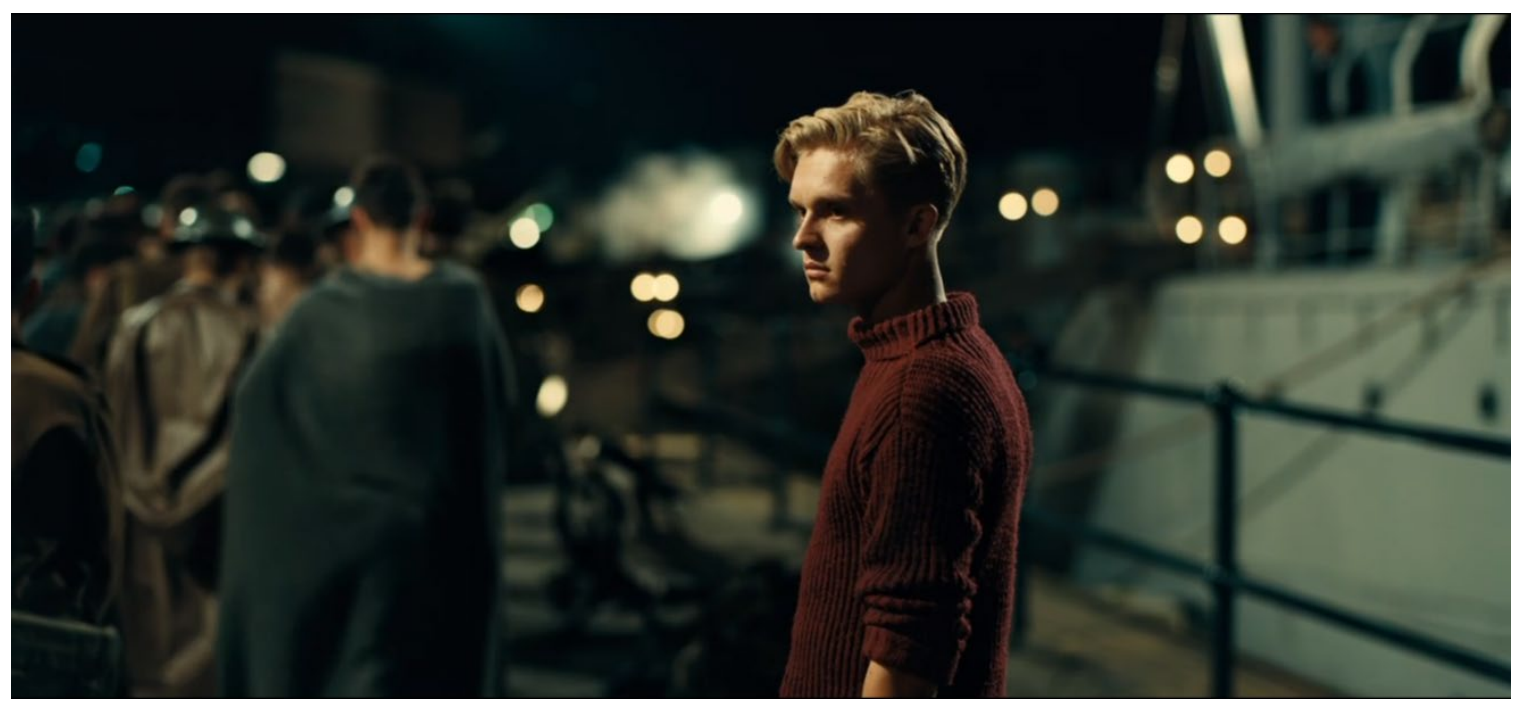

A-8: Peter back in Weymouth, England.

(Nolan \& Thomas, 2017). Screenshot by author. 


\section{Appendix B. Group Codes}

As covered in Chapter Five, the project's group codes were designed to serve as alternate character designations to recategorize groups of individuals traveling together as a single entity, instead of using multiple characters in a single data entry. As an example, the group involving Mr. Dawson, Peter, and George was recategorized from three entities into one with the code "Moon 1." Group codes were also applied to individuals traveling alone to indicate their status as a party of one. Only groups and individuals that appeared in Dunkirk were given a code. For instance, there is no code for Commander Bolton and Collins as a group because they never appear together in the film, and there is no code for Mr. Dawson as a single entity because he is never alone in the film. Using this scheme, a total of 22 group codes were developed.

Group codes were comprised of two parts. The first was a designation based off of each characters' setting of origin ("THE MOLE - one week," "THE AIR - one day," and "THE SEA - one hour"). The second part included either characters' initials, a numeric identifier, or a call sign to specify exactly which individuals were grouped together or traveling alone. The group codes were entered into the project database as the attribute GROUP CODE, which was then used as a factor to determine symbology in the Dunkirk space-time cube. While each character was assigned a unique color, the GROUP CODE attribute determined the size of each 3D point and line feature in meters. Small groups and individuals were given smaller point and line sizes than larger groups. GROUP CODE also determined the use of two-tone striped lines, mainly to indicate characters traveling in pairs. Table 17 provides a breakdown of the group codes as well as the symbology applied to the point and line features ascribed to each code. 

Table 17. Group Codes and Symbology

\begin{tabular}{|c|c|c|c|}
\hline \multicolumn{4}{|c|}{ THE MOLE - one week: D for "Dunkirk" and the soldiers trapped there } \\
\hline $\begin{array}{l}\text { Character } \\
\text { groups and } \\
\text { individuals }\end{array}$ & Code & $\begin{array}{l}\text { 3D point } \\
\text { symbology }\end{array}$ & 3D line symbology \\
\hline \multirow[t]{2}{*}{ Tommy } & DT & & \\
\hline & & $\begin{array}{c}\text { Size: } 325 \\
\text { meters }\end{array}$ & Size: 200 meters \\
\hline \multirow[t]{2}{*}{ Gibson } & DG & NA & \\
\hline & & & Size: 190 meters \\
\hline \multirow[t]{2}{*}{$\begin{array}{l}\text { Tommy \& } \\
\text { Gibson }\end{array}$} & DTG & & \\
\hline & & $\begin{array}{c}\text { Size: } 350 \\
\text { meters }\end{array}$ & Size: 215 meters \\
\hline \multirow[t]{2}{*}{$\begin{array}{l}\text { Tommy \& } \\
\text { Alex }\end{array}$} & DTA & & \\
\hline & & $\begin{array}{c}\text { Size: } 1000 \\
\text { meters }\end{array}$ & Size: 350 meters \\
\hline \multirow[t]{2}{*}{$\begin{array}{l}\text { Tommy \& } \\
\text { Gibson \& Alex }\end{array}$} & DTGA & & \\
\hline & & $\begin{array}{l}\text { Size: } 1500 \\
\text { meters }\end{array}$ & Size: 700 meters \\
\hline \multirow[t]{2}{*}{$\begin{array}{l}\text { Commander } \\
\text { Bolton }\end{array}$} & DCB & & \\
\hline & & $\begin{array}{c}\text { Size: } 1000 \\
\text { meters }\end{array}$ & Size: 350 meters \\
\hline \multirow[t]{2}{*}{$\begin{array}{l}\text { Colonel } \\
\text { Winnant }\end{array}$} & DCW & & \\
\hline & & $\begin{array}{l}\text { Size: } 1000 \\
\text { meters }\end{array}$ & Size: 350 meters \\
\hline
\end{tabular}




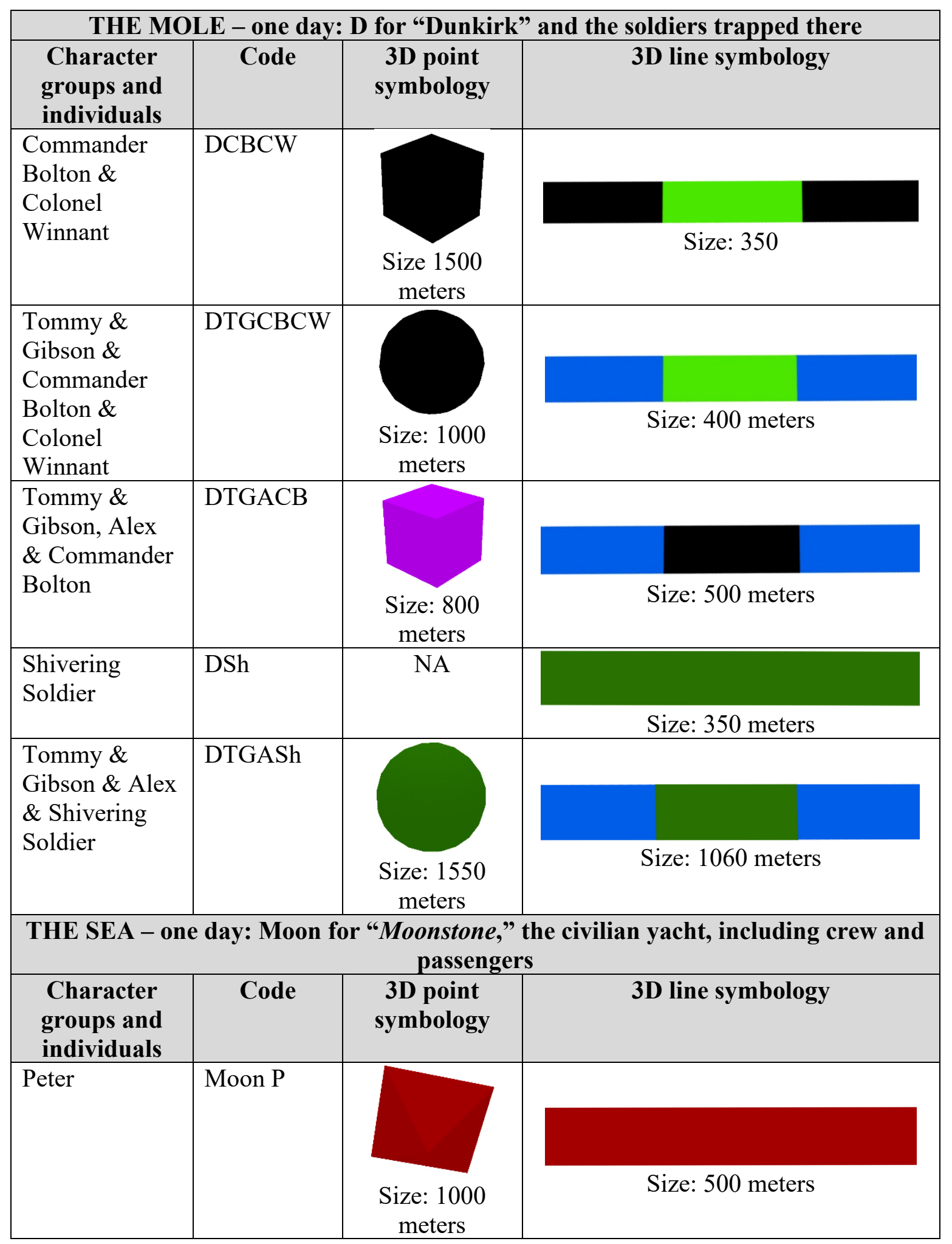




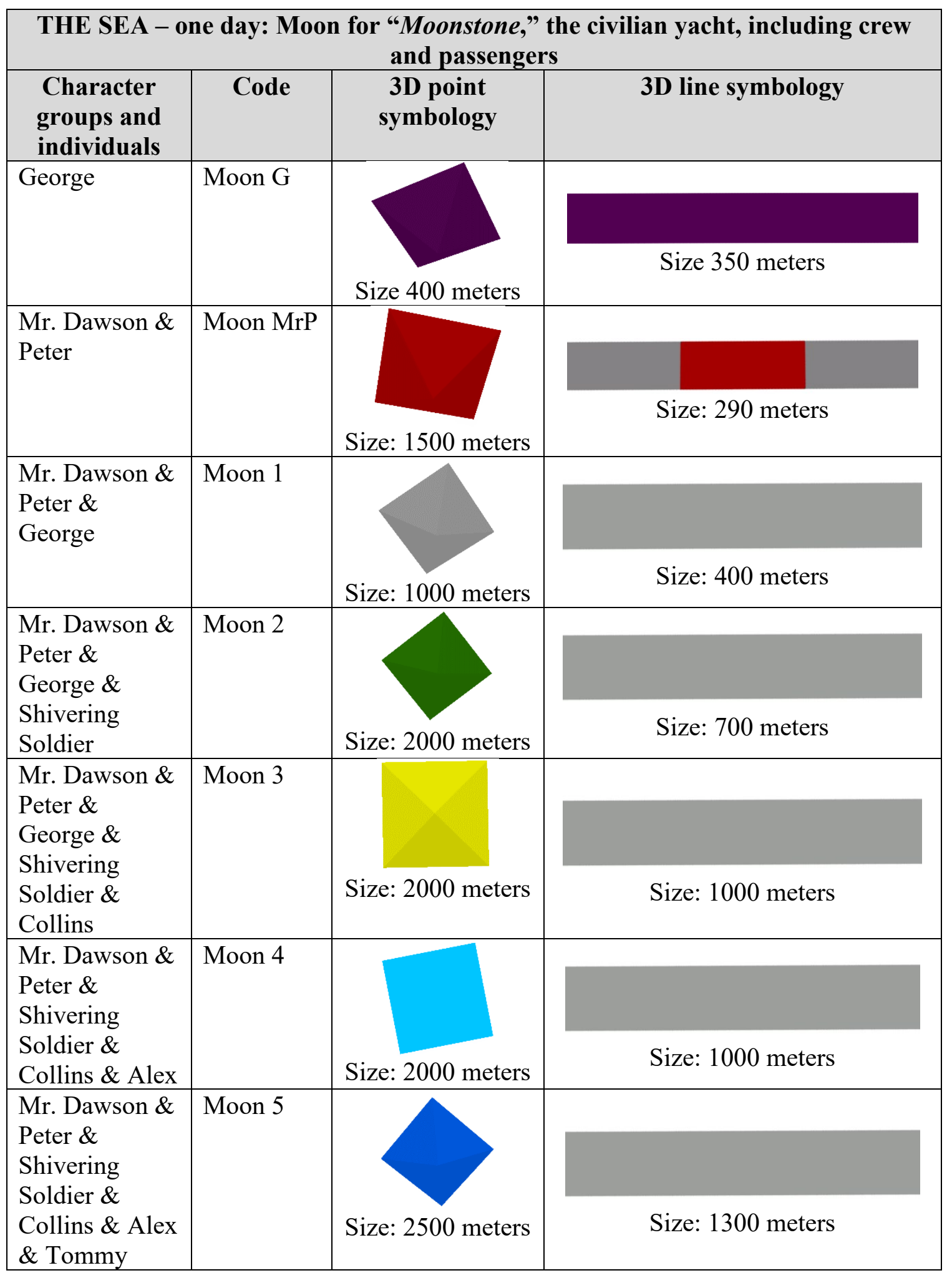




\begin{tabular}{|l|l|c|c|}
\hline \multicolumn{3}{|c|}{ THE AIR - one hour: F for "Fortis," the RAF squadron } \\
\hline $\begin{array}{c}\text { Character } \\
\text { groups and } \\
\text { individuals }\end{array}$ & \multicolumn{1}{|c|}{ Code } & $\begin{array}{c}\text { 3D point } \\
\text { symbology }\end{array}$ & 3D line symbology \\
\hline Farrier & F1 & & \\
\hline Collins & F2 & Size: 1000 meters & Size: 350 meters \\
& & Size: 1000 meters & Size: 350 meters \\
\hline $\begin{array}{l}\text { Farrier \& } \\
\text { Collins }\end{array}$ & FG & & Size: 550 meters \\
& & Size: 1500 meters & \\
\hline
\end{tabular}

